\title{
A TAXONOMIC STUDY OF THE LARVAE OF WEST AFRICAN SIMULIIDAE (DIPTERA : NEMATOCERA) WITH COMMENTS ON THE MORPHOLOGY OF
THE LARVAL BLACK-FLY HEAD
}

\author{
By R. W. CROSSKEY ${ }^{1}$
}

CONTENTS

\begin{abstract}
INTRODUCTION
Definition of West Africa and List of West African Simuliddae $\quad 3$

MAterial AND Methods . $\quad . \quad$. $\quad . \quad$. $\quad . \quad$. $\quad . \quad 5$

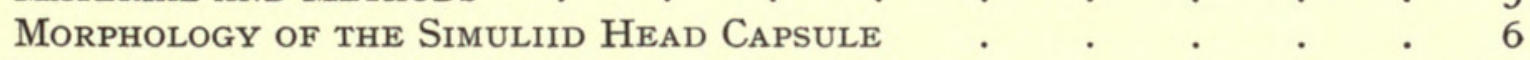

Larval Characters and Their Taxonomic Value $\quad . \quad+\quad . \quad . \quad . \quad$.

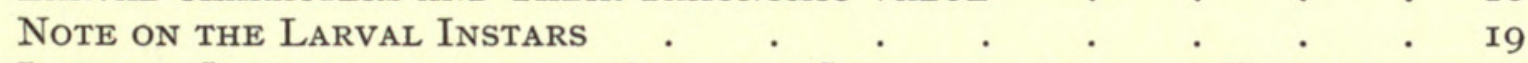

Larval Classification and Key to Species-groups of Ethiopian

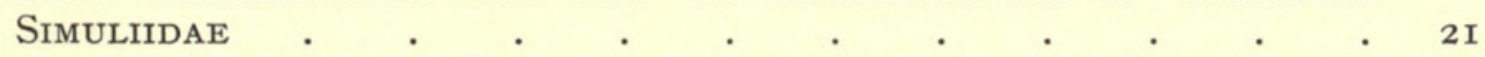

Key for the Identification of Larvae of West African Black-flies 30

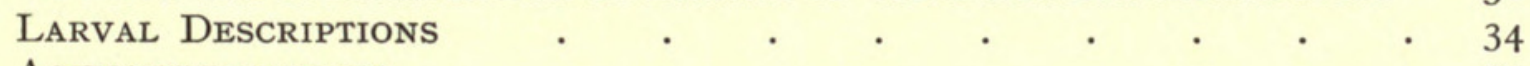

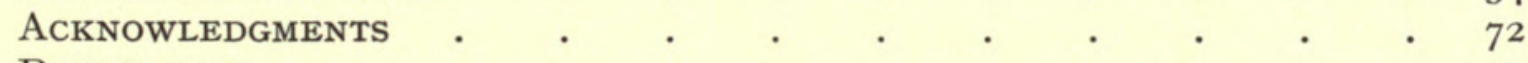

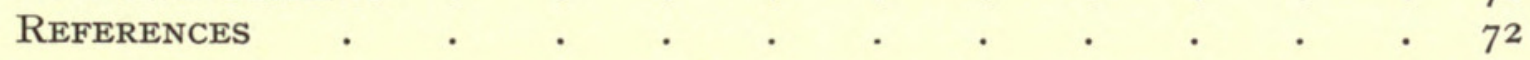

\section{INTRODUCTION}

THE present study of the larvae of West African black-flies was begun in I954 when I was engaged on a survey for Simuliidae in Northern Nigeria, mainly in connection with the distribution of Simulium damnosum Theo., the West African vector of onchocerciasis (Crosskey, I956, I957). It soon became clear that in the absence of any keys to Ethiopian black-fly larvae it was impossible reliably to identify larvae unless $(a)$ they were associated with pupae of one species only, in which case it was reasonable to assume that larvae and pupae were conspecific, or $(b)$ they showed a characteristic form of "gill-spot" in mature larvae which made their correlation with known pupae virtually certain. This difficulty fortunately did not apply to $S$. damnosum, whose characteristic larval features were already known, but larvae of other species could usually not be named at all, particularly if they were collected separately from pupae. On the other hand identification of pupae and adults was reasonably straightforward with the use of Freeman \& de Meillon's (I953) monograph of Ethiopian Simuliidae; although these authors have briefly

\footnotetext{
${ }^{1}$ Lately Entomologist, Ministry of Health, Northern Nigeria.
}

ENTOM. IO, I. 
alluded to some of the more evident larval characteristics they have not given detailed larval descriptions or keys, and the present contribution is in a sense supplementary to their work with the intention of bringing our knowledge of the larvae more into line with that of the other stages. In this paper I have described, and given a key to, the species of West Africa only (for definition of West Africa see below), and it is hoped to provide a further study of the species of the rest of the Ethiopian Region (i.e. Africa south of the Sahara) at a later date. I have however examined all larval material of Ethiopian Simuliidae in the B.M. collection, and have taken into consideration all published larval descriptions including those of species from Madagascar. In this way I have been able to draw up a key to the larvae of the species-groups for the Ethiopian Region as a whole, but it should be appreciated that the definitions of species-groups and the key may require modification as more becomes known (especially since the larvae of many central and southern African species are still unknown).

The early instars of the larvae of almost all the Ethiopian Simuliidae are unknown and most collections contain only mature larvae or larvae of medium size which are probably in the third or fourth instar (assuming that there are normally six instars in larval Simuliidae, as has recently been well demonstrated by Terterjan (I957) in Wilhelmia paraequina (Puri)). It will doubtless be some years before all the instars of all species are collected and described, and at the present time taxonomy has perforce to be based on mature or almost mature (presumably VIth stage) larvae, and this must be borne in mind in using the keys and descriptions. Younger larvae normally differ very considerably from older larvae and attention has been drawn to these differences in another section below. In this paper I use the words " mature larva" in the accepted sense of a larva which has attained its greatest length and in which the histoblast of the pupal respiratory organ is developed, although according to Hinton (I958) the so-called fully mature larva is in reality a " pharate pupa " which has undergone the larval-pupal moult and which continues to masquerade as a larva within the last larval cuticle. But since the taxonomic characters reside in the cuticular structures evidenced by this last larval skin it is legitimate taxonomically to speak of the mature larva, albeit that the living animal invested by the non-ecdysed skin is already the pupa.

The larvae of several species of Ethiopian Simuliids have already been described, but many of the descriptions are very incomplete and until the present paper no larval keys have been published. The first references to larvae of Ethiopian blackflies are those of Roubaud (I907), who commented on the rectal gills of S. damnosum, and of King (I909), who gave somewhat imperfect coloured illustrations and a few lines of description of S. damnosum and S. griseicolle Becker; the observations of these authors were repeated by Austen (I909). Further scattered, but more detailed, descriptions were given by Gibbins (I933, I934, I935, I936, I939). Gibbins' larval slides (in the B.M. collection) have been examined and there are several inaccuracies in his descriptions; as Freeman \& de Meillon (I953) have already remarked, Gibbins seems sometimes to have made his drawings from mounts of whole larvae, so that " differences" between species appear which do not in reality exist, especially in the case of the mandibles which are in fact often remarkably uniform. In some 
cases the number of rows and hooks per row in the posterior circlet seems to be exaggerated by Gibbins, and my own counts on his slide material do not agree, particularly in species with very numerous hooklets such as $S$. dentulosum Roubaud ; I have recorded these discrepancies where appropriate in the descriptions which follow. One of the most striking and easily seen differences between species, that of the postgenal cleft, was overlooked by Gibbins and he did not record this character in any of his larval descriptions. However, most of Gibbins' description is essentially sound, and difficulties of working in African conditions may be responsible for inaccuracies.

More recently the larvae of some further species have been described by Roubaud \& Grenier (I943), Grenier \& Doucet (I949a, I949b), Grenier \& Rageau (I949), Grenier \& Ovazza (I95I, I956), Grenier, Hamon \& Rickenbach (I955), and Grenier \& Mouchet (I959); a few larval features have been noted by Freeman \& de Meillon (I953), and Freeman (I955) has briefly described the larva of $S$. berneri Freeman, a remarkable species associated with mayfly nymphs and possibly belonging in the $S$. copleyi Gibbins complex. McMahon (I957) has noted some characteristics of the larvae of the $S$. neavei Roubaud complex and Lewis (I960) records certain differences in the hypostomium of species in this complex.

In other zoogeographical areas knowledge of black-fly larvae is, for some territories at least, more advanced than in the Ethiopian Region, and larval keys exist for : Alaska (Sommerman, I953) ; Australasia (Tonnoir, I925) ; Australia (Mackerras \& Mackerras, I948, I949, I950, I952) ; Britain (Edwards, I920 ; Puri, I925 ; Smart, I944) ; Central Asia (Rubtzov, I95I) ; France (Grenier, I953) ; Guatemala (Dalmat, I955); Java and Sumatra (Edwards, I934); Mexico (Vargas, Palacios \& Najera, I946) ; New York State, U.S.A. (Johannsen, I903; Stone \& Jamnback, I955) ; North-eastern States, U.S.A. (Johannsen, I934); U.S.S.R. (Rubtzov, I956).

\section{DEFINITION OF WEST AFRICA \\ AND LIST OF WEST AFRICAN SIMULIIDAE}

In this paper I use the term West Africa in a geographer's sense (e.g. Harrison Church, I957) to include that area lying to the west of the western boundary of the Cameroons Republic (former French Cameroons). Long usage has given West Africa this fairly precise meaning based upon its physical separateness from Equatorial and North Africa. The northern limit of West Africa is defined by the northern boundaries of the territories of French West Africa, but for all practical purposes by the Sahara. The western boundary of Cameroons Republic (the boundary between the former British and French Cameroons) lies along the watershed formed by the Cameroon-Adamawa Highlands (Adamawa Massif), which stretch with few breaks from the Gulf of Guinea to Lake Chad. This mountainous area is drained southeastwards to the Sanaga River and Bight of Biafra, and north-westwards principally to the Benue-Niger system; the narrow plain of the Benue River forms the only major break in the upland chain, which in places rises to 7,000 or $8,000 \mathrm{ft}$. with the southernmost outlier (Cameroons Mountain) reaching over I3,000 ft., the highest land in Africa west of the Ruwenzori range. 
To what extent the natural divide provided by the Adamawa Highlands forms a zoogeographical barrier is problematical but its significance may have been underestimated. Zoogeographically the West African Sub-region of the Ethiopian Region is usually held to include West Africa as defined above together with Equatorial Africa and the Congo Basin, and it is true that there is often a general uniformity in the fauna of this sub-region as a whole ; nevertheless there are usually also species which are characteristic either of the Congo Basin or of Upper Guinea (that area to the west of the "Dahomey gap" where the savannah penetrates to the sea). The term West African Sub-region is scarcely apt for the composite area from Senegal to the Congo, and seems as inappropriate as the term Ethiopian Region itself; similarly the term Guinea is very unsatisfactory since its meaning has always been vague, and since confusion may now arise with the Republic of Guinea. We really require a new, less ambiguous, name to denote the area at present called the West African Sub-region, and to restrict the term West Africa to that portion of the subregion lying west of the "Cameroon corner" of the Gulf of Guinea. It seems to me that West African faunal works are best delimited by the Adamawa Highlands since this is a natural topographical entity which may very likely be of zoogeographical importance. If, on the other hand, Cameroons Republic is regarded as belonging in West Africa (as for example by French entomologists) it becomes inpossible to define West Africa in a logical way, for no topographical or zoogeographical barrier exists between Cameroons Republic on the one hand and Gabon, Middle Congo, and Oubangi on the other; the faunistic associations of Cameroons seem to me to be much more definitely with Equatorial Africa and the Congo basin than with West Africa proper.

In view of the considerations given above I have omitted from this paper Simuliidae which are known from Cameroons Republic (former French Cameroons) but not from west of the Adamawa Highlands, e.g. S. hissetteum Gibbins (=S. vargasi Grenier \& Rageau) and S. ovazzae Grenier \& Mouchet. From West Africa as defined twenty-one species and twenty-eight pupal forms of Simuliidae are known, all of which are placed by Freeman \& de Meillon in Simulium Latreille; they are listed below in the species-groupings given by Freeman \& de Meillon (I953). Full synonymy is given by these authors, and all specific names given in this paper are employed in the same sense as Freeman \& de Meillon (op. cit.).

\section{Division A}

Group I. Simulium alcocki Pomeroy, I922, type form form occidentale Freeman \& de Meillon, I953 form djallonense Roubaud \& Grenier, 1943 form coalitum Pomeroy, I922 Simulium johannae Wanson, I947 Simulium schoutedeni Wanson, I947

Simulium impukane de Meillon, I936

Simulium kenyae de Meillon, I940

Simulium momahoni de Meillon, I940 
Group II. Simulium cervicornutum Pomeroy, I920, type form

Simulium unicornutum Pomeroy, I920, type form

form palmeri Pomeroy, I922

form blacklocki Edwards, in de Meillon, I930

Group III. Simulium ruficorne Macquart, I838

Simulium aureosimile Pomeroy, I920

Group IV. Simulium hirsutum Pomeroy, I922, type form

Simulium adersi Pomeroy, I922

Simulium berneri Freeman, I954

\section{Division B}

Group V. Simulium griseicolle Becker, I903, type form

form tridens Freeman \& de Meillon, I953

Group VI. Simulium dentulosum Roubaud, I9I5, type form

Simulium loutetense Grenier \& Ovazza, I95I

Group VII. Simulium medusaeforme Pomeroy, I920, type form

form hargreavesi Gibbins, I934

Simulium vorax Pomeroy, I922, type form

Simulium colas-belcouri Grenier \& Ovazza, I95I

Simulium bovis de Meillon, I930

Simulium damnosum Theobald, I903

S. berneri Freeman, described after the publication of Freeman \& de Meillon (I953), is placed here in the hirsutum-group because it appears to be most nearly allied to S. copleyi Gibbins and S. lumbwanus de Meillon, species which are also associated with mayfly nymphs and which Freeman \& de Meillon place in Group IV. Whether the copleyi and neavei complexes can legitimately be placed in the same group as hirsutum and adersi seems, however, very problematical.

\section{MATERIAL AND METHODS}

Larvae of all the twenty-one West African species are known and have been examined. Those of fifteen species were personally collected in Northern Nigeria, and larvae of the remaining species have been studied from material in the B.M. collection or belonging to Dr. D. J. Lewis. In addition to the spirit material I have also examined the slides of larvae in the B.M. collection, including those made by the late E. G. Gibbins from which his larval descriptions were drawn up.

Correlation of larvae with known species has been established by: (a) collecting larvae with pupae of known species; $(b)$ confirming identity by dissection of the pupal respiratory organ of mature larvae (many of the Ethiopian species having very characteristic pupal gills); and $(c)$ by examination of male genitalia from pupae collected with larvae, particularly for confirmation of identity in cases where the pupae themselves might be confused.

Larvae collected personally and those in the B.M. collection are preserved in $80 \%$ alcohol and it should be noted that descriptions of colouring are based on this spirit material; long preservation in spirit changes the general colour and so 
far as possible the colour descriptions have been made from my own larval material recently collected. Larvae are undoubtedly best kept in spirit; material kept in chloral gum seems most unsatisfactory since after such treatment the body shape may be distorted, the pigmentation and general colour difficult to make out, and the presence or absence of ventral papillae may become difficult to ascertain with certainty.

Certain characters are best seen in spirit material without mounting; these include body shape, pigmentation and coloration, presence or absence of ventral papillae, form of the postgenal cleft, secondary lobules in the anal gills, and sometimes the cuticular ornamentation of scales or spines. Almost all other characters require slide mounts. Mounts of whole larvae have been found of very little value, and for the present study separate balsam mounts of the following larval structures have been made for each species (after the customary treatment with $\mathrm{I0} \% \mathrm{KOH}$ and clearance in cedar-wood oil): head capsule (mounts of whole head capsule without appendages, ventral surface uppermost, in cavity slide), hypostomium, antennae, cephalic fans, mandibles, maxillae and hypopharynx and labrum, proleg, pupal respiratory histoblasts, abdominal cuticle, posterior circlet and anal sclerite. Staining is in general not required, and in this study a phase-contrast microscope was used for the examination of very small or unsclerotized structures, particularly for the fan-ray setae, the pecten of the lateral plate of the proleg, and the cuticular hairs (? microtrichia) and setae. Stained preparations (using $\mathrm{I} \%$ acid fuchsin in $20 \%$ alcohol) were however made of the rays of the cephalic fans.

In the descriptions I have, however, omitted mention of the setae on the inner surfaces of the cephalic fan-rays. These setae are generally very uniform in species which are closely similar, and only differ slightly from the usual picture in species which are otherwise very easily distinguished; consequently they seem to have little or no taxonomic value for separating closely allied species, where one needs to find reliable characters. I have recorded the number of rows in the posterior circlet to which the posterior arm of the anal sclerite extends; it will be noticed that this number is very different in different species, but it is of course a measure of the closeness of the rows in the circlet, and not of the length of the arm of the sclerite.

Segment length ratios for the antennal segments have been given in the descriptions, and for this purpose the third and fourth segments have been regarded as a single segment since the fourth (apical) segment is extremely small; only three figures therefore appear in the ratios given.

Larval descriptions are based on mature larvae; in species with more than one pupal form the larva is described from the type form, except in the case of $S$. medusaeforme form hargreavesi which is very common and abundant whereas the type form of medusaeforme is rare. As far as is known at present the larvae of different pupal forms are in any case indistinguishable from one another except on the respiratory organ, which is strictly a pupal character.

\section{MORPHOLOGY OF THE SIMULIID HEAD CAPSULE}

The need to apply in taxonomy a valid name to the strongly sclerotized anteroventral region of the cranial wall has led me to consider in this section the general 
morphology of the larval black-fly head. Although the morphology of the head capsule of other groups of larval Nematocerous Diptera has been recently studied, e.g. in the Anisopodidae by Anthon (I943), in Ceratopogonidae by Lawson (I95I), in Chironomidae by Cook (I944a) and Gouin (I959), in Culicidae by Cook (I944b) and Snodgrass (I959), and in Tipulidae by Chiswell (I955), there does not appear to be any published interpretation of this work in relation to the head of larval Simuliidae, although Grenier (I949) has made use of the term "hypostomium ". It is necessary to consider here briefly the morphology of the larval black-fly head, since in my view it is important that morphological names should be used as far as possible in taxonomic studies, and that taxonomic terms must be jettisoned if they conflict badly with the usage of morphologists.

For many years the flattened and toothed antero-ventral projection of the head capsule has been termed the mentum or submentum (most authors follow Puri (I925) in using the latter name) and sometimes even the labium. It seems odd that this structure, so evidently a part of the cranial wall without articulation of any sort, should have been regarded as of labial (i.e. head-appendage) origin. Recently however the work of the authors cited above has established that the so-called submentum is in fact formed from the head capsule proper, and the name hypostomium has been given to this area (Anthon, I943 ; Hennig, I950 ; Lawson, I95I ; Chiswell, I955; and Snodgrass, I959), and is followed in this paper. Gouin (I959) calls it the hypochilum in Chironomidae, but this seems an unnecessary departure from the accepted term hypostomium.

To appreciate the nature of the hypostomium requires some consideration of the whole ventral region of the head capsule (Text-fig. 2). The Simuliid larval head is prognathous, and the elongation of the head has required the "filling in " of the long area between the foramen magnum and the mouthparts. The foramen magnum is mainly bounded (not medio-dorsally or ventrally) by a distinct darkened band which is to be regarded as the post-occiput, delimited anteriorly by a slight groove or post-occipital sulcus (" post-occipital suture "). Ventro-laterally the post-occiput is developed into two small backwardly-directed processes which may be interpreted as occipital condyles. Anterior to each condyle is a small oval hollow which is generally surrounded by a strongly sclerotized area ; since these pits lie ventrally in the course of the post-occipital sulcus it seems legitimate to interpret them as posterior tentorial pits (occipital pits of Sommerman (I953)), although it should be noted that no tentorial endoskeleton is invaginated from them.

The sclerotized ventral surface of the head between the posterior tentorial pits and the labium is formed by the postgenae, which become greatly elongated in many insects with a prognathous head in order to form a sclerotized floor to the cranium. In some Nematocerous larvae (e.g. Chironomus and certain mosquitoes) the ventromedian union of the postgenae remains evident as a longitudinal line or median postgenal suture. In Simuliid larvae however there is no such line remaining to indicate the postgenal union, although a few species show a more weakly sclerotized longitudinal area behind the base of the hypostomium, and some (e.g. in the genus Cnephia End.) are even completely unsclerotized in the midline. The position in the Simuliid head is further complicated since the ventral cranial wall between the 

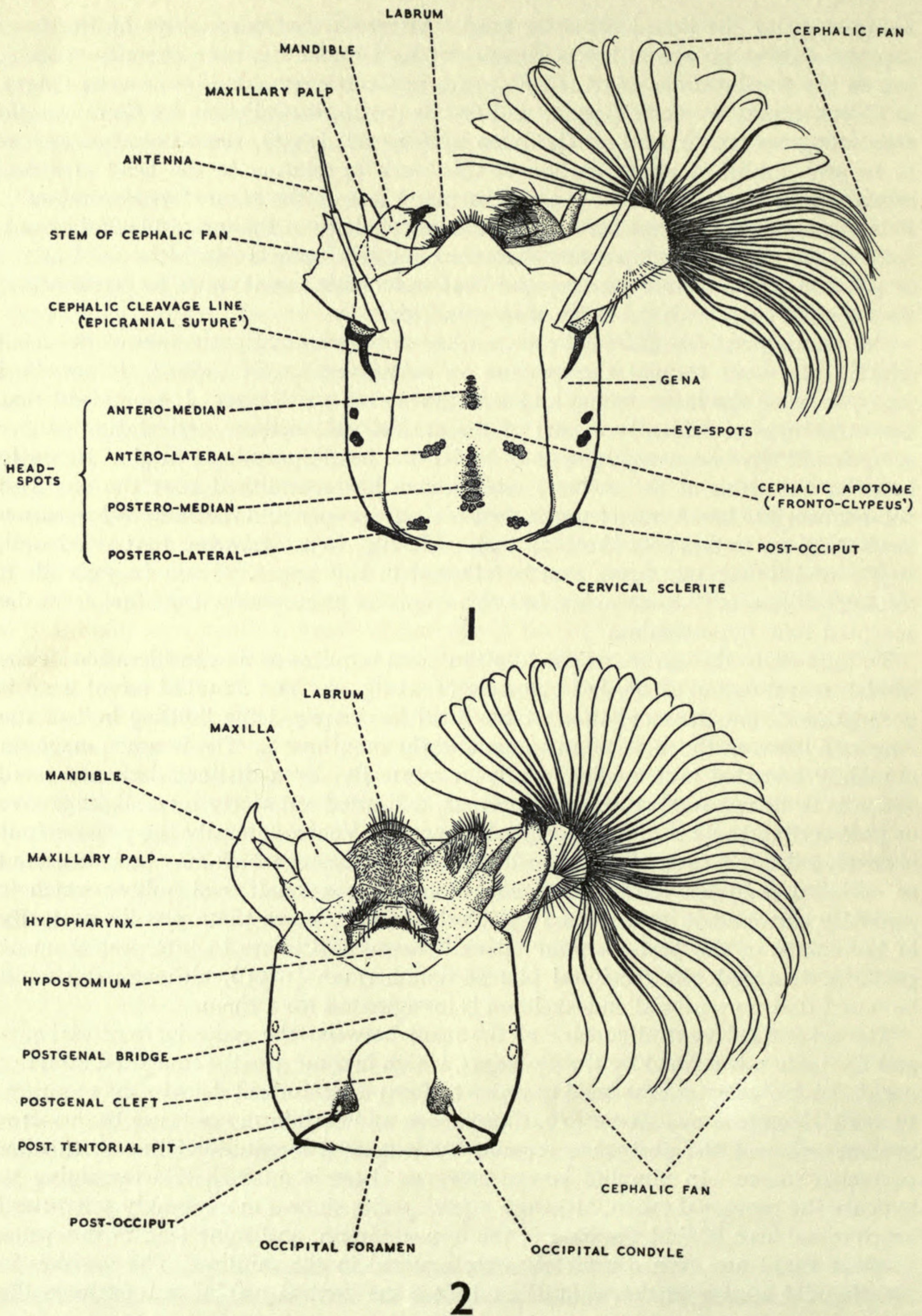

Figs, I and 2. Head capsule and head appendages of mature (VIth stage) larva of Simulium : (I) dorsal ; (2) ventral. 
foramen magnum and the hypostomium is not always completely sclerotized-in fact only very few species (e.g. S. berneri, Text-fig. 39) have a completely sclerotized ventral surface to the head capsule. The vast majority of species have the posterior part of the ventral surface unsclerotized, so that the postgenae meet only in the anterior part, leaving a membranous opening behind, the postgenal cleft (Text-fig. 2).

This cleft (occipital cleft of Sommerman (I953), epicranial cleft of Stone \& Jamnback (I955), ventral cleft of Rubtzov (I956) and French workers) occupies a position anterior to the posterior tentorial pits on the ventral surface and can hardly therefore be of occipital origin, nor can it be regarded merely as a forward ventral extension of the foramen magnum since the pits normally mark the ventro-lateral limits of the foramen. If the region of the cleft were sclerotized (as it is in fact occasionally) it would be " filled in " by the postgenae, and I have therefore described it as the postgenal cleft. The size and shape of the cleft are extremely variable (providing one of the most valuable taxonomic characters) but it does not as a rule extend forward as far as the hypostomium, leaving a sclerotic bridge between its anterior apex and the hypostomial groove which marks the base of the hypostomium. The area between cleft and hypostomium I have called for taxonomic purposes the postgenal bridge (Text-fig. 2). In some species of Cnephia however, as mentioned above, the postgenal cleft tapers forward to reach the hypostomium so that the postgenal bridge is incomplete medially; a similar condition appears very rarely in Simulium, e.g. in S. ibariense Zivkovitch \& Grenier.

The condition in these Simuliids is then not very dissimilar from that in the Tipulid larva in which the postgenae do not meet in the midline. The Tipulid hypostomium is clearly of paired origin, and according to Snodgrass (I959) is formed by the union of two processes extended forwards from the antero-median corners of the postgenae. Accepting Snodgrass' interpretation the hypostomium of Nematocerous larvae is postgenal in origin. In Chironomids the hypostomium shows no evidence of its dual origin, and there is also no line dividing it posteriorly from the postgenae proper. In Simuliid larvae however a transverse line is impressed on the cranial wall behind the hypostomium, so that the hypostomium appears to be a separate sclerotization from the postgenal bridge. This line is clearly secondary, but is valuable in taxonomy since it divides the hypostomium from the postgenal bridge and enables the relative lengths of the two areas to be compared; for this purpose it may be termed the hypostomial groove (Text-figs. 2 and 4). Morphologically the hypostomium, being postgenal, is part of the postgenal bridge, but in the taxonomy of Simuliid larvae it is useful to distinguish the areas in front of and behind the hypostomial groove as the hypostomium and postgenal bridge respectively as in Text-fig. 2.

The whole composite sclerite forming the ventral and lateral walls of the cranium is sometimes termed the epicranial plate (e.g. by Stone \& Jamnback (I955)), delimited from the fronto-clypeus which forms the dorsum of the head by the so-called frontal sutures (the arms of the Y-shaped epicranial suture). Snodgrass (I947, I959) maintains that the frontal sutures have no morphological significance, that they are simply lines of weakness at which the head capsule ruptures during ecdysis, and that they do not define any specific part of the head; he therefore calls the sutures cephalic 
cleavage lines and the sclerotic area between them the cephalic apotome, and I have followed these terms in this paper (Text-fig. I). Ordinarily, as Snodgrass points out, the clypeus extends to the bases of the mandibles, and the frons is the facial area between the antennae and the eyes ; hence the cephalic apotome is not equivalent to the fronto-clypeus, so that it is perhaps best to drop this term from taxonomic use. In the early instars of Simuliid larvae the cephalic apotome does not form part of the postero-dorsal margin of the head, since the post-occiput and the occipital region of the head are produced from either side so that they almost meet in the midline, leaving only a narrow occipital cleft rather as in mosquito larvae (the stem of the Y of the "epicranial suture"). In successive instars the gap between the parts of the post-occiput on either side widens so that the cephalic apotome comes to provide a large part of the postero-dorsal margin of the head capsule-that is to say that the occipital cleft increases so much in width that it is no longer recognizable as a cleft. The lateral area of the head in front of the eye-spots is the gena.

\section{LARVAL CHARACTERS AND THEIR TAXONOMIC VALUE}

The morphology of the Simuliid larva has been described in detail by Puri (I925), and useful brief accounts of larval characters are given by Smart (I944), Hennig (I950), Grenier (I953), Sommerman (I953), Stone \& Jamnback (I955), and Rubtzov (I956). It will be useful however to record some comments on the characters of value in the taxonomy of larvae from the Ethiopian Region.

Body shape and cuticular ornamentation. Fully mature larvae of African black-flies vary from 4-II mm. in length, but are usually fairly constant for any one species ; on average the larvae are much smaller than those of Holarctic species. There are two distinct body shapes, as has been noted in the case of Mexican and Guatemalan species by Vargas, Palacios \& Najera (I946) and Dalmat (I955) ; in some the abdomen is slightly clubbed with the posterior segments clearly set off from the anterior segments and the sides of the thorax somewhat swollen (Text-figs. 7 and II), and in others the abdomen (as seen in lateral view) expands gradually to its widest point and then contracts abruptly to the posterior circlet (Text-fig. Io) and the thorax is scarcely swollen laterally. The body form is constant within the species. Those with the clubbed abdomen normally show a pair of ventral papillae, downwardlydirected conical processes on the last abdominal segment just before the posterior circlet (Text-fig. 7), and those species with the gradually expanding form are without ventral papillae. The presence or absence of these papillae (ventral tubercles of some authors including Sommerman (I953) and Stone \& Jamnback (I955)) appears to be of some fundamental taxonomic importance, and in any faunal area there is normally a fairly clear division of Simulium s.l. species according to their presence or absence. Their correlation with a definite body form is also striking, although there are exceptions, and some African species with a clubbed abdomen are without papillae, e.g. S. griseicolle and S. bovis (Text-fig. 6). The dorsal surface of the body is normally smooth in outline, but in one Ethiopian species (S. damnosum) the anterior abdominal segments are produced dorso-laterally into paired conical processes or tubercles (Text-fig. 9), of variable size but often very strongly prominent; such protuberances seem to be very unusual, but Edwards (1934) has figured them in 
the larva of ? S. varicorne Edw. from Sumatra, and I have seen similar though smaller protuberances in the Palaearctic S. (Titanopteryx) maculatum $\mathrm{Mg}$. The function of these tubercles and of the ventral papillae is difficult to surmise, but it is notable that the latter occur principally in slow-water species and are most frequently absent in species living in swiftly-flowing water.

The cuticle of most species bears well sclerotized setae, at least dorsally on the posterior abdominal segment. In some species setae also occur on the thoracic cuticle, but are normally absent from the proleg ( $S$. damnosum is an exception to this). The large setae are socketed and presumably modified macrotrichia; in some cases they are simple spine-like setae but are frequently flattened fan-shaped or spatulate scales (Text-figs. I36-I54). The form of the setae is more or less constant for any particular species and extremely useful as a taxonomic character in Ethiopian forms, although it does not seem to have been used in the taxonomy of black-flies from other zoogeographical regions. Most species show only one type of scale or seta, but in one species (S. griseicolle) both simple setae and fan-shaped scales occur together. In a few species the cuticle is apparently bare, but careful examination always seems to show the presence of some small socketed hairs on the swollen areas of the abdomen between the anterior and posterior arms of the anal sclerite (the " expansions latero-dorsales" of Grenier (I949)). In addition to socketed setae (macrotrichia) the cuticle may show minute colourless hairs; these seem to be almost impossible to see after potash treatment but may be seen in spirit material by transmitted light with the larva lying laterally. These exceedingly minute unsclerotized hairs appear to be filamentous extensions of the cuticle, without alveoli, and are therefore microtrichia as defined by Imms (I957) ; their occurrence may be fairly general, but they are certainly present in the cervicornutum-group and in S. dentulosum which otherwise appears to have a bare cuticle. The setae in Simuliid larvae are generally scattered, haphazardly arranged and without definite chaetotaxal arrangement.

Pigmentation and colour. Although the head capsule is sometimes pale and unpigmented most species show a definite head pattern and pigmentation. The markings of the head are formed by groups of head-spots (Text-fig. I) which occur where the muscles are attached to the cranial wall. There are often more or less evident four groups of spots which may be termed antero- and postero-median, and anteroand postero-lateral head-spots. In some species the spots themselves are pale but the areas around them are darkened (e.g. Text-figs. I6-I8), and in other species the spots are dark and the surrounding areas pale (e.g. Text-fig. 23) ; Edwards (I934) and Hennig (I950) have appropriately called these " negative" and " positive " head markings respectively, and these terms are followed in this paper. Although some species show an indefinite pattern, either with an unpigmented head or with the head capsule strongly and rather evenly infuscated, it is usually possible to discern into which category they fall; negative pattern species may show very faint traces of an $\mathrm{H}$-shaped pigmentation dorsally and a 3-shaped pigmented area laterally behind the eye-spots (essentially like Text-fig. 2I), and positive pattern species may show the dark head-spots just a little more boldly than the surrounding dark pigmentation. Despite the variability in the intensity of pigmentation, the 

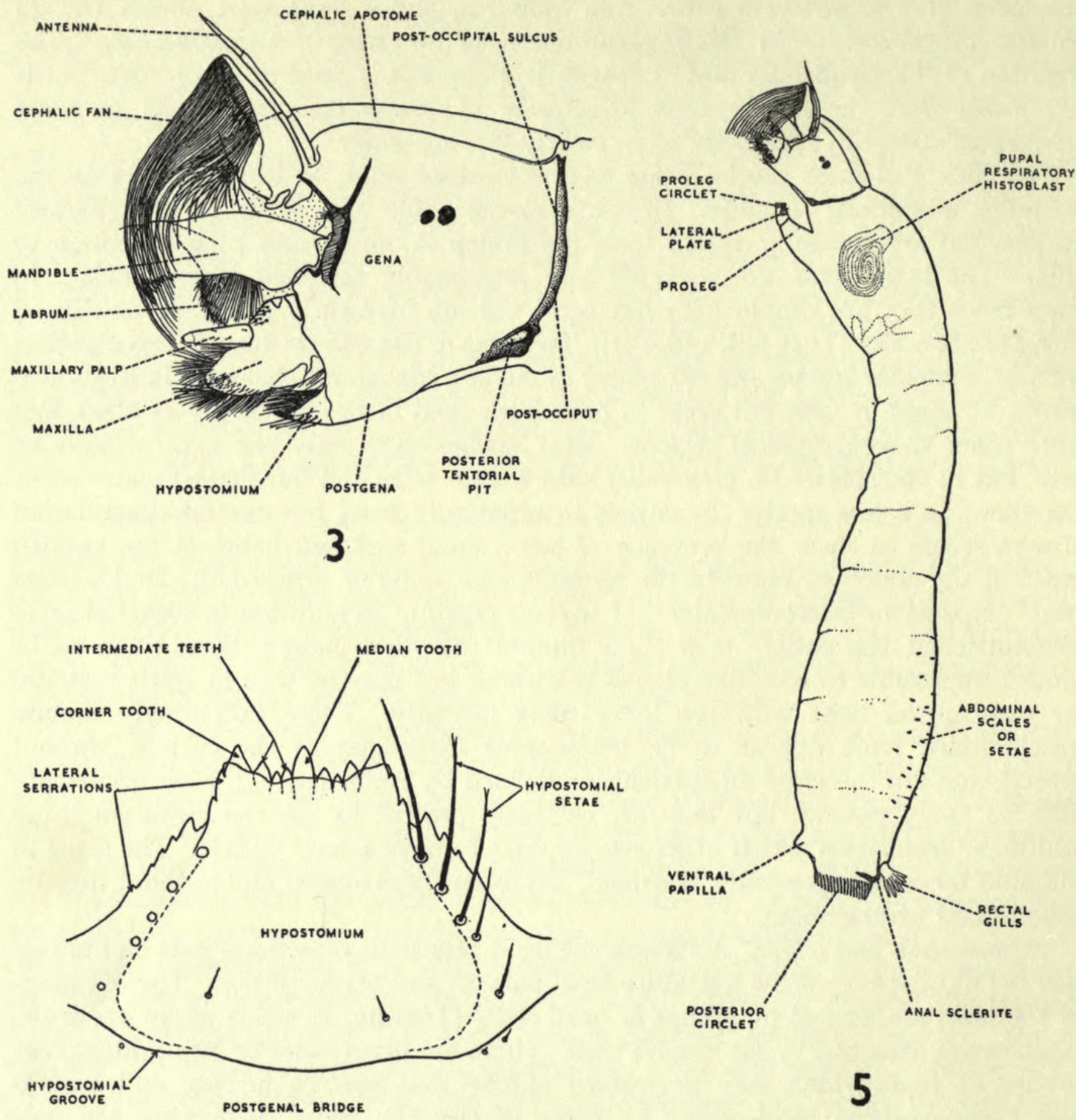

\section{4}

Figs. 3-5. Mature (VIth stage) larva of Simulium: (3) lateral view of head; (4) ventral view of hypostomium; (5) left lateral view of larva.

general head pattern is extremely valuable taxonomically, and is normally constant for a particular species-group (Freeman \& de Meillon (I953) suggested that head colour as a character is not applicable to Ethiopian species, but I have found this to be far from true). Pigmentation also varies in intensity in the antennae and in the lateral plates of the proleg, though this is not of much significance ; generally speaking these structures are pale and unpigmented in the smaller species, but darkened in the larger species, especially on the basal segment of the antenna. In 
the known Ethiopian species of Cnephia the antennae are strongly pigmented on the apical halves with a pale ring between second and third segments.

The general colour of the larval body is pale, milky-white (rather translucent in living material) but shows a variable amount of darker coloration which is determined by chromatocytes visible through the cuticle; the chromatocytes are large polygonal cells containing pigment granules which form a peripheral epithelium below the basement membrane (Hinton, I959). The chromatocytes are closely aggregated dorsally but are fewer ventrally, where instead of lying adjacent to one another they are connected by cytoplasmic threads; hence the colour of the larva is normally darker above, and pale below. On the abdomen the chromatocytes are occasionally less numerous intersegmentally, giving the larva an appearance of dark segmental mottling; they are normally absent from the abdomen ventroapically so that this region is distinctly pale. The pigment granules within the celllayer formed by the chromatocytes impart to the larva, since the cuticle and epidermis are transparent, a general colour which varies from pale yellowish or greenish or grey to dark brown or nearly black; generally speaking the colour is fairly constant in any one species, although some species do vary considerably. Chromatocytes also invest much of the nervous system and render the ventral nerve-cord very evident in certain species-e.g. the dark grey nerve-cord of S. medusaeforme. In the thoracic region the pattern of the chromatocytes varies considerably with larval development, so that whereas in younger larvae the peripheral layer covers much of the thorax in older larvae the chromatocytes withdraw from the developing histoblasts of the wings, legs and pupal respiratory organ. The histoblasts therefore form milky-white islands in the general thoracic colour which increase in size as the larva matures. The pupal respiratory histoblast becomes dark brown with maturity of the larva.

Head. The shape of the head capsule is generally very constant, but is sometimes unusually elongate as in S. neavei complex species and rarely strongly arched and contracted posteriorly as in S. copleyi. The eye-spots are of much the same size in most species, but in the $S$. neavei and $S$. copleyi complexes they are very small and also appear to be reduced in Ethiopian Cnephia. Otherwise they have no taxonomic value. The labrum has been mounted and examined in each species but seems to be very uniform and I have found no significant differences. The form of the cephalic apotome varies slightly, in some species being more or less parallel-sided and in others contracted anteriorly, but hardly provides a workable character. On the other hand the form of the postgenal cleft (Text-figs. 28-47) is very varied but provides one of the most valuable taxonomic characters since the shape is more or less constant for any species ; furthermore the shape appears to be the same in each instar. In some cases the cleft is enormous and occupies most of the ventral aspect of the head with the postgenal bridge very reduced, but in other cases the cleft is small and the postgenal bridge long (see Dorier (I945)). Rarely the cleft is absent. The form of the hypostomium is the most time-honoured larval character, but it has to be admitted that in many of the Ethiopian species it is remarkably similar and sometimes virtually indistinguishable, as in species of the alcocki-group (Text-figs. 48-52) ; nevertheless there are many species or species-groups in which 
its form is characteristic, and in order to record hypostomial characters in the descriptions I have used the names shown in Text-fig. 4. In almost all African species there is an apical row of nine teeth ( $\mathrm{I}_{3}$ in neavei-complex and $\mathrm{I}_{3}-\mathrm{I}_{5}$ in known Cnephia species) in which the teeth at the antero-lateral angles and the tooth in the centre of the row are the most prominent (i.e. the median and corner teeth) ; between the median and corner tooth of each side are three intermediate teeth which are subequal in size or in which the middle one is smaller than the others. In some groups all the apical teeth are short and blunt with the median tooth only very slightly more prominent than the others and the corner teeth very broad basally. Lying laterally behind each corner tooth are two blunt dark strongly sclerotized teeth lying in the plane of the apical teeth, and behind these in a slightly different plane the lateral margin of the hypostomium is usually produced into a series of lightly sclerotized blunt or sharp serrations ; for descriptive purposes I have referred to all this series of denticulations as "lateral serrations", although it should be appreciated that the anterior two on either side are separately sclerotized from the rest of the series and are more closely associated with the apical teeth. It appears that the two outer pairs of the thirteen apical teeth in the neavei-complex are derived from these first two serrations which have been produced forwards to lie in a row with the other teeth. The number of serrations is variable but their form, whether blunt or sharp, is fairly constant in any species. The hypostomium bears ventrally on either side a row of hypostomial setae (epicranial setae of Stone \& Jamnback (I955)) which are frequently frayed apically; the number of these setae varies slightly in each species, but some have more than others. Usually there are about $4-7$ in each row, but often more, and $S$. dentulosum may have up to I8 setae on either side ; the number each side is not always the same. The number of setae and their position relative to the lateral margin of the hypostomium are of taxonomic use ; in some species the setae lie more or less parallel to the hypostomial margin, but in others distinctly diverge from the margin posteriorly. In the latter case the hypostomium is relatively shorter and broader than in those with the setae and margin more or less parallel. The distance between the apex of the corner tooth and the base of the first hypostomial seta is variable, and this distance varies from about half of, to more or less the same as, that between the apices of the corner teeth. In addition to the rows of large setae the hypostomium also bears ventrally some small basal discal setae, often one each side (as in Text-fig. 66), but the number and arrangement is variable and they have no taxonomic value.

The antennae are 4-segmented, but the apical segment is a minute elongate cone, and for practical purposes I have regarded it as part of the third segment so that in the segment length ratios given in the descriptions the third figure represents the third and fourth segments combined. Segment length ratios vary between species, but also vary very greatly according to the age of larvae, so that different species must be compared in the same instar. The length of the first segment relative to its breadth may be useful taxonomically. The paired apical papillae on the second segment are of no value and are very uniform.

The cephalic fans (premandibles, mouthbrushes) are of limited taxonomic use. The number of rays varies somewhat in mature larvae, and also increases with 
each instar during development. The mean number of rays in mature larvae does, however, differ between species and some clearly have more than others-especially the swift-water species in which there may be as many as 60 or 70 rays. Closely allied species, in which one needs to find characters, usually have much the same number. The small secondary fan is not much help with Ethiopian species, although Sommerman (I953) has used it generically for the Alaskan fauna. The setae borne on the inner margins of the rays of the main fan have been examined with a phasecontrast microscope in each species, in case they might provide characters of use in separating closely similar species; unfortunately they appear to be of little taxonomic use. There is some variability in the pattern of the setae but they are more or less identicàl in closely allied species, and are only distinctive in species which are easily enough identified on less obscure characters-e.g. S. dentulosum and $S$. damnosum. The setae are always clearly of two types, long and strong setae which are socketed macrotrichia with shorter and finer setae between; the smaller setae appear to be without alveoli and are probably microtrichia. The macrotrichia are generally spaced at about a ray's width from each other, but the spacing varies according to the position on the ray and to the position of the ray within the fan.

The mandibles have considerable taxonomic value, especially generically, in the Simuliidae of some parts of the world, but their usefulness among Ethiopian blackflies is somewhat restricted. Certain species-groups show particular characteristics in the mandibular teeth, and occasional species have some unusual character, but in many cases the mandibles are extremely uniform, as for instance in the alcocki and cervicornutum-groups. The shape of the mandible is very constant, but in some species the outer margin is more strongly arched than usual and the basal area of the apical teeth may be very broad; the length of the apical teeth also varies slightly. The comb-like series of teeth borne on the inner side varies in different groups (cf. Text-figs. II2 and II3), and rarely they are very reduced as in S. berneri (Text-fig. II4) ; normally they either form a rather even row gradually decreasing in size, or the first three are differentiated as stout comb-teeth from the remaining more slender rather bristle-like teeth. In the latter case these first three teeth, which are referred to as comb-teeth in the descriptions, usually vary themselves in size, with the first (apical) one much larger than the others and the second shorter than the first and third; occasionally the first three comb-teeth are subequal. In addition to bearing the comb-teeth the inner edge of the mandible is produced into denticulations which I have called mandibular serrations. In almost all Ethiopian species the serrations are paired (Text-figs. II2 and II3, M.s.) with the posterior serration much smaller than the anterior. The form of the serrations has some use taxonomically; the form of the anterior serration is sometimes very elongated, and the posterior serration is absent in S. griseicolle. In one Ethiopian species of Cnephia there is a series of saw-like serrations as in the Holarctic species of Prosimulium. Unfortunately the serrations are usually identical in very closely allied species.

The maxillae are very uniform except for the single-segmented maxillary palp which varies in length; the length of the palp relative to its width at the base (when seen laterally in the flattest position of the maxilla) has been noted in the descriptions. The apical processes of the palp vary somewhat in length, and seem 
i6 TAXONOMIC STUDY OF LARVAE OF W. AFRICAN SIMULIIDAE
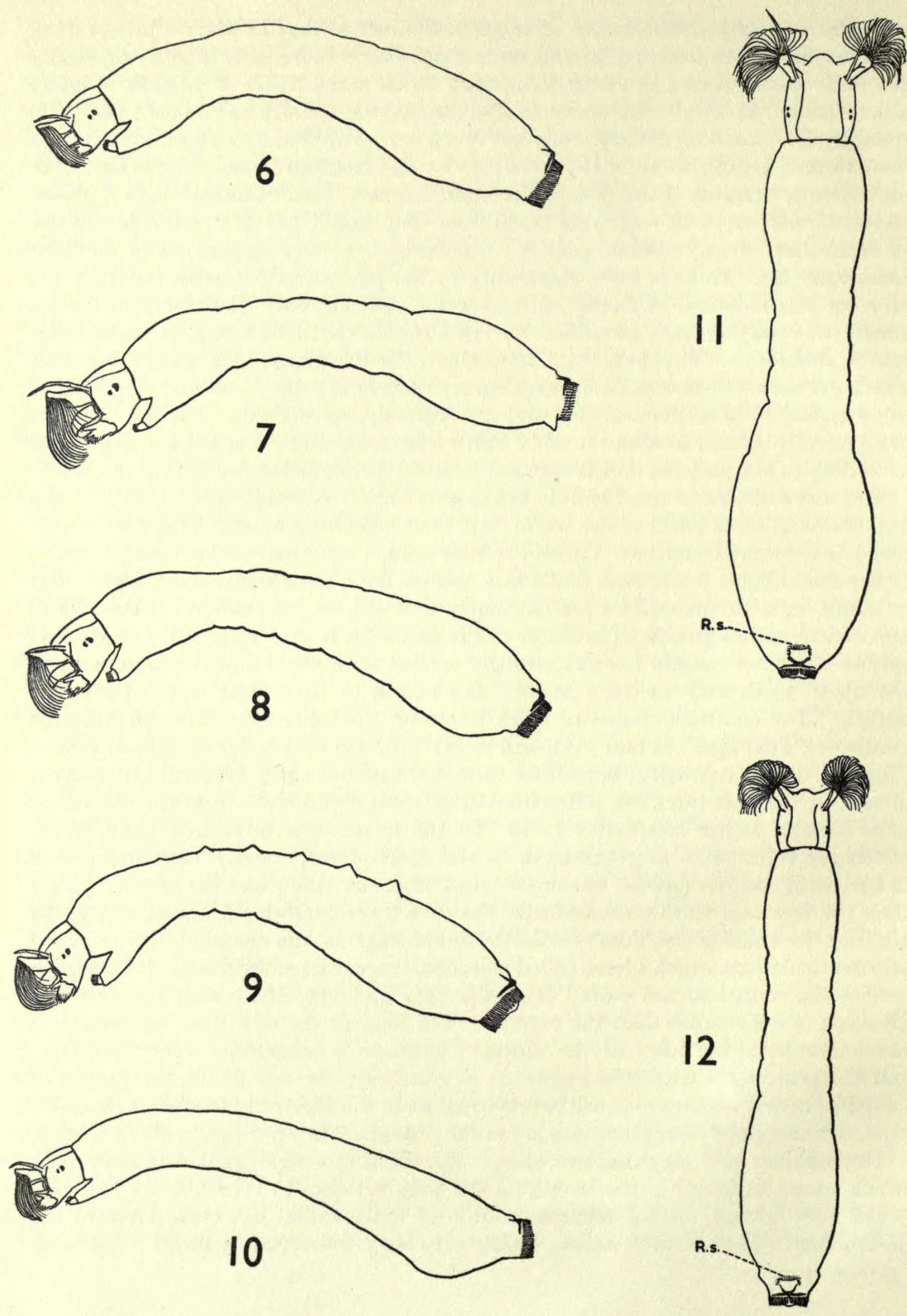
to be shortest in swift-water species. The hypopharynx and labium (very well figured by Grenier (I949 : 2I9)) have been examined in each species studied but seem to be very uniform and without taxonomic characters, although it is possible that very detailed study of these structures might show differences in the sensillae of the prementum.

Thorax. Grenier (I949: I9I) has figured the structure of the ventral proleg. The proleg bears a pair of dorso-lateral lightly sclerotized plates on the apical segment, each of which carries distally a pecten of lightly sclerotized strongly tapering processes ; the approximate number of the processes has been given in the descriptions, but they are difficult to count and are of very limited usefulness as a character. They are most numerous in species with many hooks in the circlets, especially in Cnephia species; sometimes the processes are simple and subequal in size, but often they are more or less subdivided at the base so that each strong process is associated with one or two very small secondary processes. The apical crown of hooks, the proleg circlet, shows a variable number of radial rows of hooks, and the number of hooks per row is also variable. The proleg hooks are difficult to count and not of much use for identification; Sommerman (I953) however has found that the shape of the lateral plate is helpful in the case of Alaskan Prosimulium.

The pupal respiratory organ, on each side of the prothorax in mature larvae, can be dissected out for examination and is often extremely useful in identifying Ethiopian species, many of which have very characteristic pupal gills easily recognizable in the gill-spot of the larvae; larvae belonging to different pupal forms of the same species may in some cases be recognized simply by external examination. The respiratory histoblast is not, however, very helpful in the case of species having pupal gills of the simple filamentous type-in dissecting out the gill-spot the filaments very easily break and in their tightly coiled condition are very difficult to count. The general outline of the gill-spot and the direction assumed by the branches or filaments are more or less constant in each species (Text-figs. I73-I94).

Abdomen. Apart from the presence or absence of ventral papillae (Text-fig. 5), and the setae of the cuticle, the abdomen shows few very useful taxonomic characters. In a few Ethiopian species there is a characteristic pair of small lateral sclerites on the last segment just before the circlet (Text-fig. I55, A.c.) ; sometimes these accessory sclerites are represented by two or three very small slightly separated sclerotizations, or as a series of very small pale plaques lying in a dorso-ventral line. Similar sclerites occur in certain Australian species such as S. torresianum Mackerras \& Mackerras and S. aureonigrum Mackerras \& Mackerras but in none of the known Ethiopian species is there a complete sclerotized band running ventrally round the last abdominal segment and connecting the lateral accessory sclerites as occurs in some Austrosimulium species, particularly A. mirabile Mackerras \& Mackerras and to a lesser extent in A. fulvicorne Mackerras \& Mackerras, although traces of ring-like sclerotization occur in S. buckleyi de Meillon.

Figs. 6-I2. Larval body-shape in : (6) S. bovis ; (7 and II) species of Division A with ventral papilla present ; (8 and I2) S. medusaeforme ; (9) S. damnosum ; (Io) S. vorax. R.s. = rectal scales. 
The presence or absence of rectal scales (peri-anal scales) on the dorsal wall of the rectum just before the anal opening is not very helpful with Ethiopian species, although this character has been used as the first segregate in Dalmat's (I955) key to Simulium s. str. of Guatemala ; these scales are present and very numerous in all Ethiopian species I have examined except $S$. damnosum and the neavei-group, in which they appear to be either totally wanting or reduced to the minutest vestiges. The function of these scales is presumably to clean the rectal gills which are retractile projections from the ventral floor of the rectum (Headlee, I906), protrusible through the anal opening ; it seems curious that they should be absent in a species with very numerous secondary lobules in the gills. The scales are well figured in Puri (I925) and Grenier (I949).

The form of the rectal gills is also of little value as a taxonomic character in Ethiopian species, except in so far as the gills have three simple lobes in Cnephia but are normally subdivided into numerous accessory thumb-like or finger-like lobules in Simulium. Most Simulium species have numerous secondary lobules (as in Text-fig. I7I), but rarely each of the three lobes is simple (Text-fig. I72) or has only one or two small accessory lobules (Text-fig. I70); the number of lobules increases in successive instars, but even in the mature larva the number normally varies considerably although some (mainly fast-water) species clearly have more than others. In the most variable species (e.g. S. ruficorne) some mature larvae may have the gills simple, others may have one or two extra lobes, and yet other larvae may show several digitate lobules.

The anal sclerite (anal armature of Puri (I925), Hora (I927), and Gibbins in various papers) is always strongly sclerotized and in all Ethiopian species is the usual X shape. Some authors (e.g. Stone \& Jamnback (I955)) refer to it as the $\mathrm{X}$-shaped sclerite, which is descriptive in a sense, but as Grenier (I949) says is inexact since the anterior arms lie in a horizontal plane but the posterior arms lie more or less at right-angles to them in a vertical plane. The anal sclerite is very uniform in the Ethiopian species except for those forms living in phoretic association with mayfly nymphs or crabs ; in this group, perhaps as an adaptation to attachment on other Arthropods, the anal sclerite occupies a distinctly dorso-apical position instead of the usual dorsal position and the posterior circlet is more or less shifted downwards and forwards into a ventro-apical instead of a purely apical position ; furthermore the arms of the sclerite are very attenuate. In other species there is sometimes a slight median posterior projection (e.g. Text-fig. I68), but no African species have the small backwardly-directed spur from each anterior arm as in the Austrosimulium species. The shape of the sclerite is apparently useful taxonomically in the Australian species and has been figured by Mackerras \& Mackerras (I948-52) in their larval descriptions, but in general it is not of much value with the Ethiopian fauna.

The posterior circlet, or posterior crochet ring of Sommerman (I953), normally occupies a distinctly apical position on the abdomen, but in species of the neavei and copleyi-complexes it tends to lie more obliquely than usual in a ventro-apical position. The number of rows of hooklets and the number of hooks per row differs between species. Some species clearly have very numerous hooks and rows, while in 
others there are obviously fewer (cf. Text-figs. I55-I57 and I58-I60) ; these differences provide useful characters, but the individual variability has to be borne in mind, and it may be noted that the rows and the hooks per row increase with the age of the larva from instar to instar. The number of hooks in a row is usually fairly easy to count, but the number of rows is more difficult ; the rows can most easily be counted by cutting through the circlet ventrally and flattening out either side. It is worth noting that Grenier (I949) has established that the posterior circlet is morphologically a pseudopod comparable to the anterior pseudopod (proleg); the term "posterior sucker", used for instance by Gibbins in his descriptions, is of course quite inappropriate.

\section{NOTE ON THE LARVAL INSTARS}

Simuliidae are usually said to have six larval instars, and Terterjan (I957) has confirmed this in Wilhelmia paraequina (Puri), principally by measurements of the head capsule during larval growth; Terterjan's findings probably hold generally for the family. Most larval structures undergo considerable modification during larval life, so that descriptions and keys based on last stage larvae are not of much help as a rule in identifying the younger stages ; furthermore it is usually difficult if not impossible to be certain in which instar a larva may be, though Terterjan's work, if generally applicable, helps considerably with this point. The first instar is always easily recognizable by the presence of the egg-burster on the dorsum of the head and by the simple shaft-like, apparently single-segmented antenna (the antenna is in fact 2-segmented but the apical segment is minute). The second instar has a 3-segmented antenna, and the normal 4-segmented condition is reached in the third instar. Subsequently the proportions of the antennal segments undergo alteration so that the segment length ratios are very different in the fourth to sixth instars. The number of rays in the cephalic fan, the number of hypostomial setae, and the number of hooks in the proleg and posterior circlets also increase greatly as the larva grows; the rectal gills have a simple trilobed form in the very young larva but increase in complexity in successive instars so that mature larvae of Simulium species (not always in other genera) usually have many secondary digitations. Other characters also become modified with increasing age, including the form of the hypostomium and mandibles; in fact very few characters remain similar throughout larval life. It does seem however that the shape of the postgenal cleft remains fairly constant, although its size naturally increases with the growth of the larval head capsule. The form of the capsule itself also undergoes minor modification, particularly in the shape of the cephalic apotome which comes to occupy more of the posterodorsal margin of the head because the ends of the post-occipital collar converge less closely in successive instars. The pair of small cervical sclerites (Text-fig. I) becomes more or less differentiated in the fourth instar, but remains closely associated with the ends of the post-occiput until the last stage. In the thorax the pale imaginal discs of the legs, wings, halteres and of the pupal respiratory organ become evident in the fourth stage larva as six small round spots on either side; the size of these buds increases gradually until pupation, but only the histoblast of the pupal respiratory organ becomes darkened. The areas of the imaginal buds are not covered by 

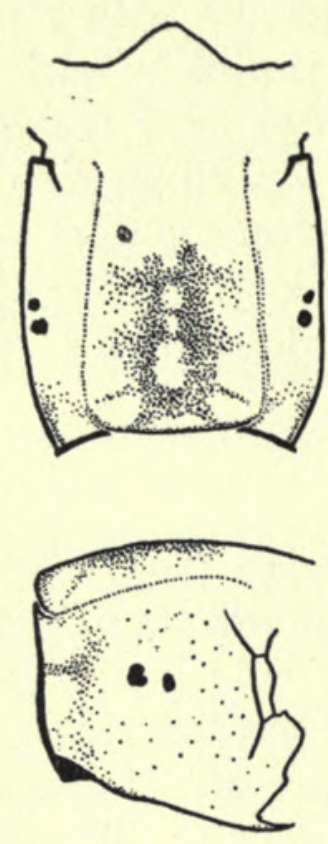

13
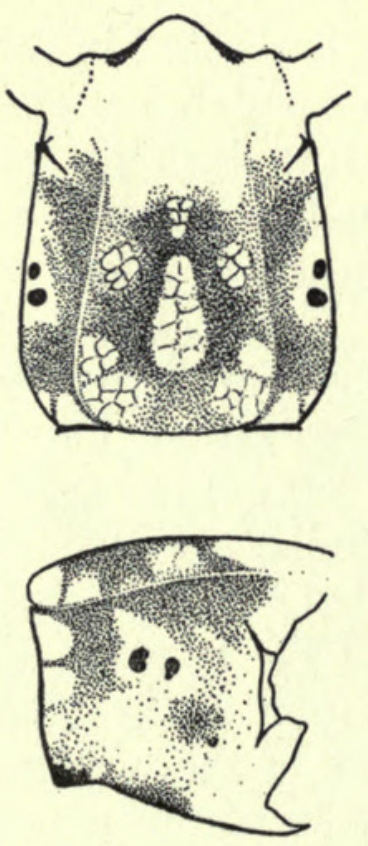

17
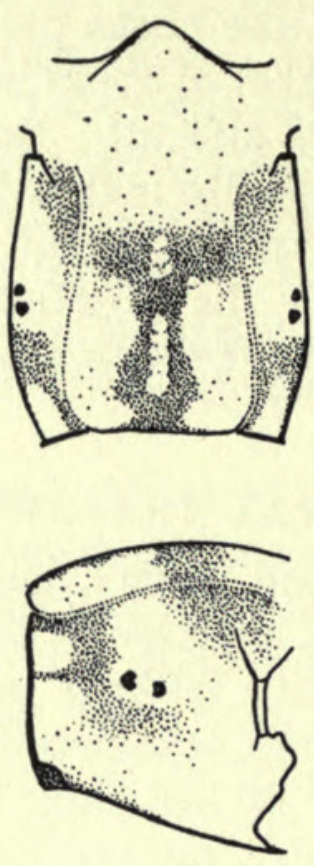

14
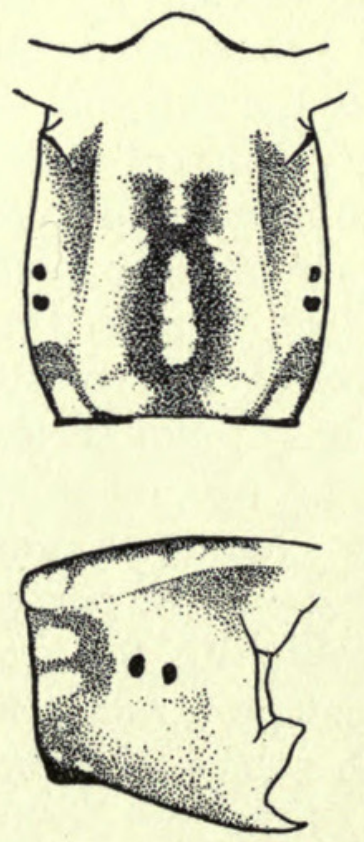

18
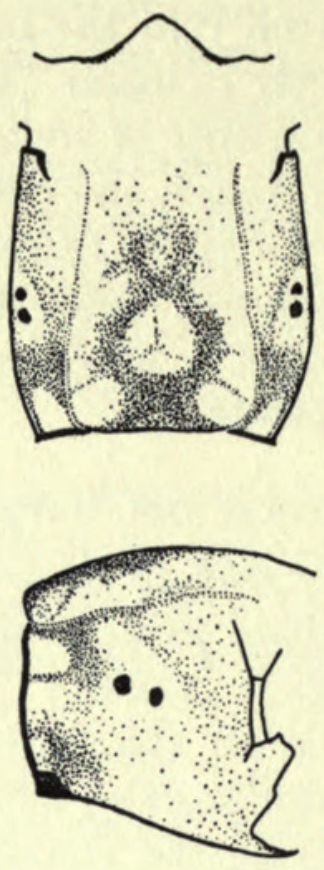

15
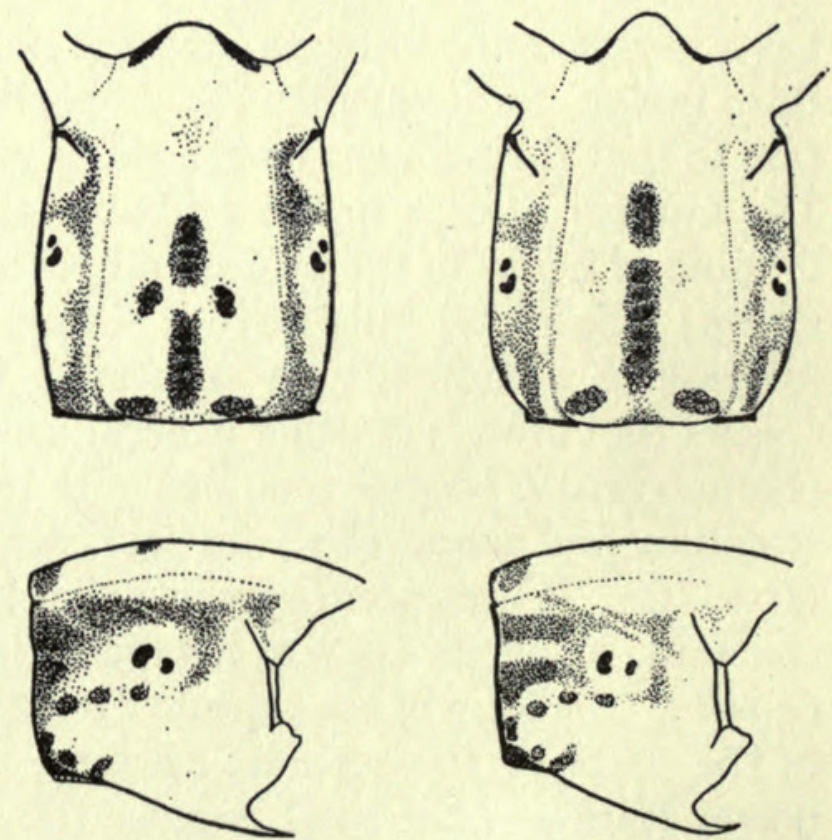

19
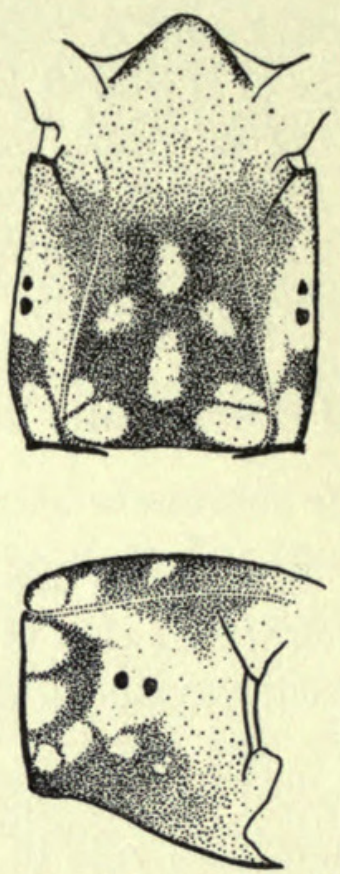

16

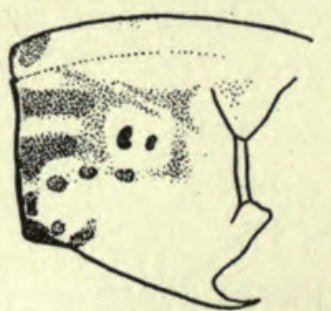

20

FIGS. I3-20. Head pattern and pigmentation of (13) S. johannae; (14) S. impukane ;

(I5) S. momahoni; (I6) S. kenyae; (I7) S. cervicornutum; (I8) S. unicornutum; (I9)

S. aureosimile; (20) S. ruficorne. 
chromatocytes, and larvae showing no traces of the buds are probably younger than the fourth instar.

\section{LARVAL CLASSIFICATION AND KEY TO SPECIES-GROUPS \\ OF ETHIOPIAN SIMULIIDAE}

Freeman \& de Meillon (I953) have provided a sound classification of the Ethiopian Simuliidae based on adult and pupal characters. They accept only two genera in the Ethiopian fauna, Simulium Latreille and Cnephia Enderlein; the latter genus is represented only by half a dozen species confined to South-West and South Africa, and the vast majority of species belong in Simulium in the broad sense. The Ethiopian Simulium fall into two more or less distinct categories, referred to by Freeman \& de Meillon as Divisions A and B, each division with a number of species-groups based on male genital characters or on the structure of the pupal respiratory organ. Some of these groups are clearly equivalent to the genera accepted by workers elsewhere, e.g. Rubtzov (I956) ; the medusaeforme and ruficorne groups for example correspond to the genera Wilhelmia Enderlein and Eusimulium Roubaud respectively.

In general the present study of the larvae strongly supports Freeman \& de Meillon's classification, and most of their groups are reasonably distinctive in the larval stage. It is not however easy to find an unexceptional larval character which distinguishes Ethiopian Cnephia from Simulium; the character of body-shape mentioned by Freeman \& de Meillon (op. cit., p. 32) does not hold, since S. vorax Pomeroy and many other Division B species have a similar shape. The best character seems to be the hypostomium, which in Ethiopian Cnephia is closely similar to that in the Holarctic Prosimulium Roubaud and quite different from that in the Palaearctic species of Cnephia such as are figured by Rubtzov (I956). In Cnephia the rectal gills are simply trilobed and the cuticle without scales or setae, but in Simulium the gills (although normally with many secondary lobules) are also very occasionally without secondary lobules and the cuticle of many species is also bare. The mandibles may be more dependable ; in Cnephia there are at least traces of three mandibular serrations and in C. muspratti Freeman \& de Meillon there is a whole series as in Prosimulium. In Simulium, on the other hand, there are almost always two serrations (rarely only one), but the larva of Simulium gyas de Meillon (described by Grenier \& Doucet $\left(\mathrm{I}_{949}\right.$ ) $)$ as Simulium sp. $\mathbf{M}_{6}$ ) from Madagascar shows three mandibular serrations; the larva of another species from Madagascar, probably belonging in the ruficorne-group and described by Grenier \& Doucet (I949a) as Simulium sp. $\mathrm{M}_{3}$, also shows three serrations. The postgenal cleft of the southern African Cnephia is very small, rather as in Prosimulium, without the long cleft which extends to the hypostomium in some of the Palaearctic Cnephia (but by no means all of them). In the material seen of Cnephia larvae from southern Africa the number of processes carried apically on the lateral plates of the proleg is very high, and far more than in any Ethiopian Simulium known to me ; the apical half of the antenna is also very strongly pigmented (except for a very distinct intersegmental ring between second and third segments). With limited material it is difficult to be sure how valuable these differences might be.

Freeman \& de Meillon (I953) regard several Ethiopian species of Simulium as 
being represented by two or more distinct pupal forms. It is possible that these pupal forms are in reality complexes of very closely allied species, but in the main the characters of the larvae (so far as they are known) belonging to different pupal forms are identical-except of course in the respiratory organ of the pupa as represented in the last stage larva. The larvae provide no evidence that the pupal forms are anything more than this. The only possible exception to this known is $S$. pauliani Grenier \& Doucet, which Freeman \& de Meillon regard as a form of S. unicornutum Pomeroy, but the larva of pauliani as described by Grenier \& Doucet (I949b) has branched fan-like scales instead of the large obvious spatulate scales on the abdomen of unicornutum; as the form of cuticular ornamentation is normally very constant in any species it seems possible that pauliani is a distinct, though very closely related, species.

Very large flattened scales on the abdomen also occur in S. schoutedeni Wanson and $S$. momahoni de Meillon, and this feature combined with other larval characters such as the large postgenal cleft and sometimes the presence of lateral abdominal accessory sclerites, suggests that these two species are closely allied to $S$. unicornutum and $S$. cervicornutum and belong in the cervicornutum-group, although Freeman \& de Meillon (I953) have - on the basis of their filamentous pupal respiratory organplaced them in Group I, the alcocki-group. When the male genitalia are considered another resemblance is evident ; the ventral plate in schoutedeni, mcmahoni, cervicornutum, unicornutum and aureliani Fain, is distinctly indented each side, as though "pinched in " laterally.

In the larva of $S$. alcocki Pom. and in closely related species in the alcocki-group, S. johannae Wanson, S.tentaculum Gibbins, and S. impukane de Meillon, the abdominal cuticle bears small branched rather fan-like setae, and the ventral plate in the male genitalia (although varying in shape) has little or no trace of a lateral hollowing-out or notch. Unfortunately the different types of setae in the larvae combined with the different ventral plates in the male genitalia does not provide a hard and fast difference between the alcocki-group and the cervicornutum-group ; the inevitable intermediates exist. In Simulium kenyae de Meillon there is a very distinctly "pinched in" ventral plate but the larval abdominal scales are much-branched, and in S. hissetteum Gibbins the opposite is the case-the ventral plate is almost identical with alcocki but the cuticular scales are simple (larvae of hissetteum have not been seen but Grenier \& Rageau (I949) have described the larva, and figured the scales, under the name $S$. vargasi Grenier \& Rageau which is synonymized with hissetteum by Freeman $\&$ de Meillon (I953)). The scales of hissetteum however are much smaller than those of cervicornutum, but the postgenal cleft is small as in alcocki.

The larvae of those species which live in so-called phoretic association with other Arthropods, i.e. the neavei-complex on crabs and the copleyi-complex on mayfly nymphs, do not completely fit in with the characters shown by free-living larvae, and on a purely larval classification extraordinary species like $S$. berneri Freeman might very reasonably be placed in a separate genus from Simulium. On the whole the mode of life of these species and their larval characters (some of which are no doubt adaptive to their unique environment) make them very different from other species of Simulium, and it is questionable whether it is legitimate to place them in 
the same group with S. hirsutum Pomeroy, as in Freeman \& de Meillon's (I953) classification, although the male genitalia and pupal respiratory filaments are admittedly similar. Until their status can be more definitely ascertained it seems desirable, certainly useful in practice, to regard these unusual species as a group on their own, the neavei-group, which is in turn divided into two sub-groups, the neaveicomplex on crabs and the copleyi-complex on mayflies (although it is not certain that the two complexes are monophyletic) ; it is then easier, as far as larval characters are concerned at any rate, to define Divisions A and B and the hirsutum-group.

An outline of the principal characteristics of the species-groups is given below, as they appear at present :

(I) S. alcocki-group. Ventral papillae present; abdominal cuticle with branched somewhat fan-shaped scales; head capsule with negative pattern; postgenal cleft small and rounded; hypostomium with usual nine apical teeth.

[Note. In material seen of S. impukane de Meillon from Nigeria and Nyasaland the pattern of the head is negative - traces of dark pigmentation around pale headspots-as in other alcocki-group species. In Grenier \& Doucet's (I949b) figure however the head-spots are clearly dark, which is unusual in Division A species except for the ruficorne-group, and furthermore the size they give-length $7 \mathrm{~mm}$.-is much larger than that in impukane larvae as known from elsewhere. It is possible that Grenier \& Doucet's material from Madagascar is not true impukane. In S. kenyae the postgenal cleft is of medium-size, transverse-oval in shape, and larger than in other species of this group.]

(2) S. cervicornutum-group. Ventral papillae present; abdominal cuticle with very large scales, serrate apically ; head capsule with negative pattern ; postgenal cleft large ; hypostomium with usual nine apical teeth; last abdominal segment usually with lateral accessory sclerites.

[Note. I include S. schoutedeni and S. momahoni in this group, and the larva of $S$. bequaerti Gibbins, not at present known, may come in here. The larva of S. pauliani Grenier \& Doucet has cuticular setae of the alcocki-group type but the postgenal cleft resembles that of unicornutum; its characters are therefore intermediate between those of most species in the alcocki and cervicornutum-groups.]

(3) S. ruficorne-group. Ventral papillae present; cuticle bare; head capsule with positive pattern; postgenal cleft small or very small, usually subquadrate; hypostomium with usual nine apical teeth ; last abdominal segment sometimes with traces of accessory sclerotizations.

[Note. This is perhaps the most distinctive group with the unusual combination of dark head-spots and ventral papillae; the absence of scales or setae is also a difference from other Division A species, and the maxillary palp is unusually long and narrow. The larvae described as Simulium sp. $\mathrm{M}_{3}$ and $\mathrm{M}_{4}$ from Madagascar by Grenier \& Doucet (I949a) evidently belong in this group, and in the figures they give of $\mathrm{M}_{4}$ there seems to be no distinction from ruficorne (the remarkable mandibular serrations with the enlarged posterior serration, the absence of antero-lateral headspots, the postgenal cleft and the hypostomial teeth appear identical).] 

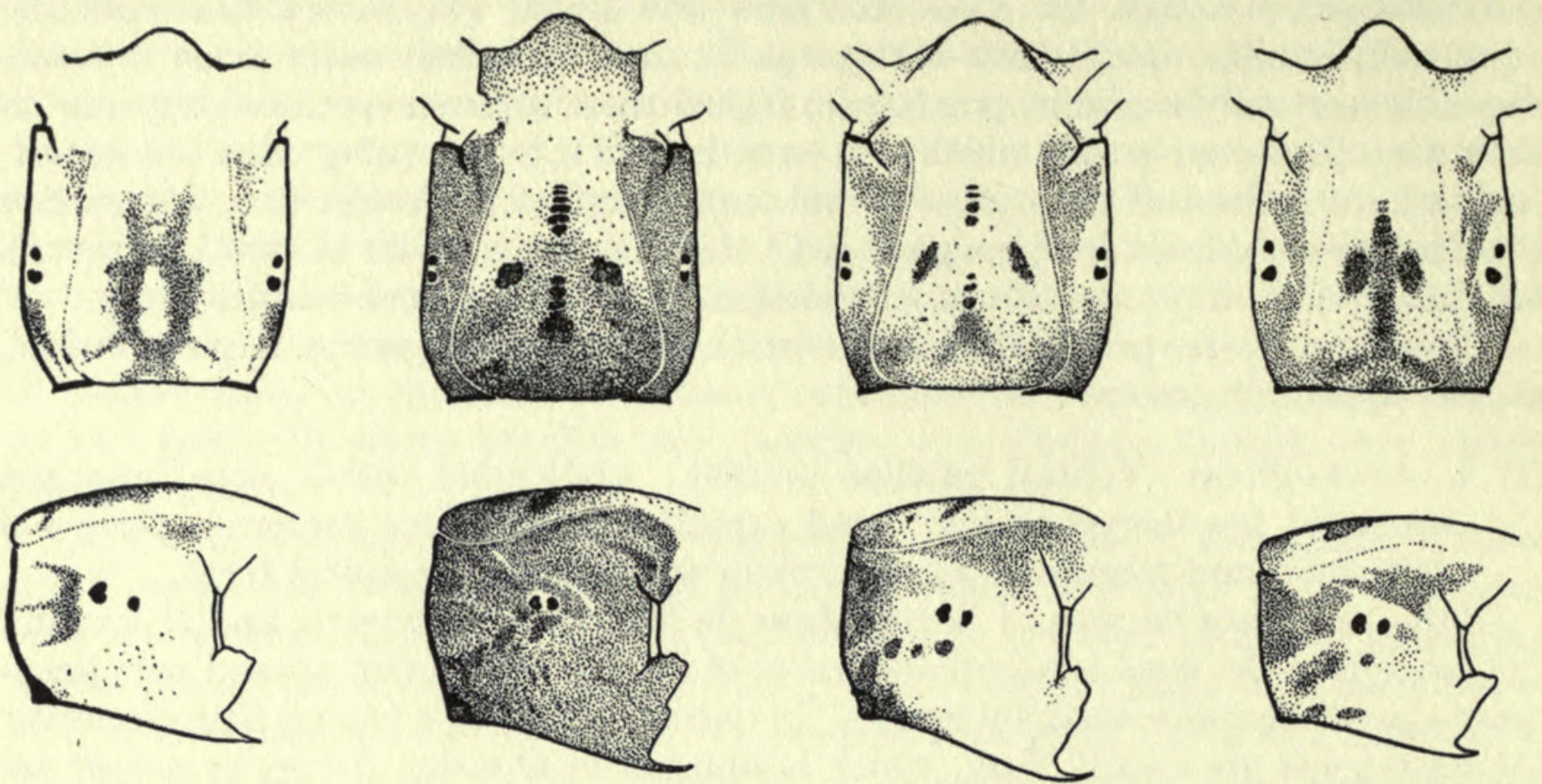

21

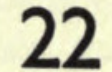

23

24
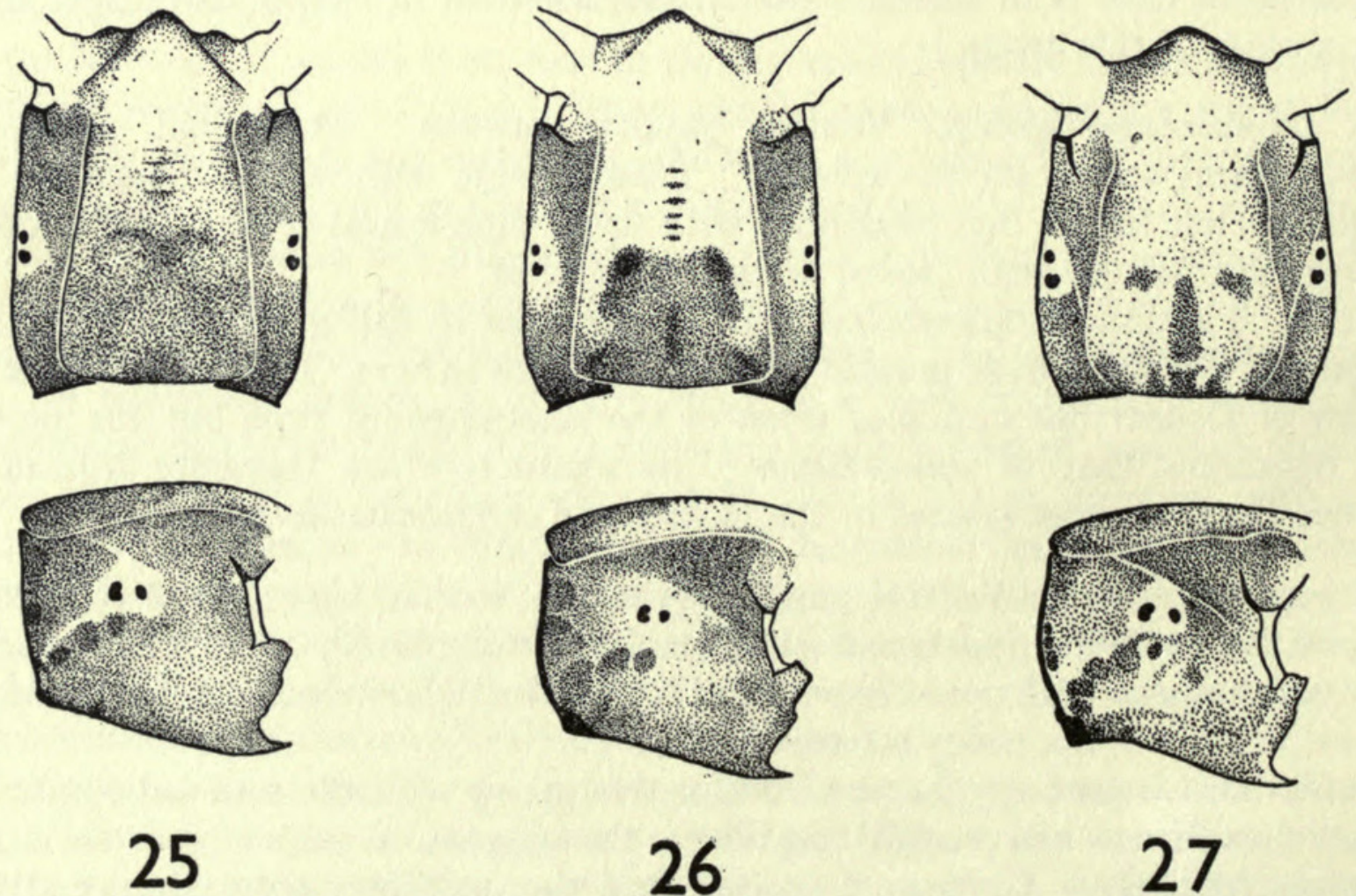

FIGS. 2I-27. Head pattern and pigmentation of (2I) S. adersi ; (22) S. dentulosum ; (23)

S. loutetense; (24) S. medusaeforme hargreavesi; (25) S. vorax; (26) S. colas-belcouri;

(27) S. damnosum. 
TAXONOMIC STUDY OF LARVAE OF W. AFRICAN SIMULIIDAE 25

(4) S. hirsutum-group (excluding neavei-copleyi-complexes). Ventral papillae present, usually small; abdominal cuticle with scattered simple spine-like setae; head capsule with negative pattern or unpigmented ; postgenal cleft of medium size, subcircular; hypostomium with usual nine apical teeth.

[Note. In the material of $S$. adersi Pomeroy described by Gibbins (I934) from Nsadzi Island, Lake Victoria, ventral papillae are absent and larvae are much larger than those of adersi as known from elsewhere. It is possible that so-called adersi is a complex of sibling species. There are no larvae available from the type locality, Zanzibar, to ascertain the characters of true adersi.]

(5) S. neavei-group. Head capsule rather elongate or strongly arched and contracted behind; eye-spots very small; hypostomium unusual, with a more or less regular row of $\mathrm{I} 3$ apical teeth in neavei-complex but of varied form in copleyicomplex ; head capsule without distinct pigmentation or with faint pigmentation around areas of pale head-spots; postgenal cleft small, subquadrate or absent; abdominal segmentation unusually distinctly marked; ventral papillae absent ; rectal scales absent or represented only by minute vestiges ; arms of anal sclerite long and narrow, anterior arms rather less strongly divergent than usual ; anal sclerite tending to lie in an apical position instead of a strictly dorsal position, and posterior circlet usually rather oblique in a ventro-apical position instead of the usual strictly apical position.

[Note. The cuticular ornamentation is variable; in some cases the cuticle is bare, e.g. S. ovazzae Grenier \& Mouchet, and perhaps all neavei-complex species, but in $S$. berneri the whole cuticle is densely covered with pale clubbed hairs. The tendency shown in these species for the posterior circlet to come to lie rather obliquely in a slightly ventro-apical position instead of directly across the apex of the abdomen is presumably an adaptation to life on the mobile host.]

(6) S. griseicolle-group. Ventral papillae absent; cuticle of thorax and abdomen densely covered with setae of two types, simple spine-like setae and branched fan-like scales; head capsule without pattern, pale; postgenal cleft very large, subcircular; hypostomium with usual row of nine apical teeth ; mandible with one serration only.

[Note. This group includes only S. griseicolle Becker and S. gariepensis de Meillon which are the only Ethiopian species in which the adult is without setae on the basal section of the radius. The larva of gariepensis however is not known and therefore may not fully conform with the characters given above.]

(7) S. dentulosum-group. Ventral papillae absent ; cuticle bare; head capsule with positive pattern; postgenal cleft small; hypostomium with usual nine apical teeth, the teeth rather blunt; often large larvae up to II $\mathrm{mm}$. usually grey in colour with abdomen of gradually expanding form.

[Note. The dark head-spots of this group are usually very distinct, but are sometimes obscured by general dark pigmentation. The hypostomial setae are very numerous in some species and the hindmost setae may lie in two or three irregular rows. Most species live in swift water and consequently the number of rows of hooks 
and the number of hooks in each row of the circlets are often very high. Simulium gyas de Meillon, described as Simulium sp. $\mathrm{M}_{6}$ from Madagascar by Grenier \& Doucet (I949b), apparently has simple setae on the cuticle of the posterior abdominal segments, and a medium-sized cordate postgenal cleft, providing an exception to the characters of the group as given above. Its larval characters are therefore very close to those of $S$. medusaeforme, and the pupal respiratory organ is also of medusaeform type; the adult is unknown, and, as Freeman \& de Meillon point out, the affinities of $S$. gyas are uncertain. On larval characters I would place it in the medusaeformegroup. Gibbins (I939) also describes the larva of S. kauntzeum Gibbins, a species closely related to $S$. dentulosum Roubaud, as having " minute spines " on the abdomen, but the cuticle appears to be quite bare in Gibbins' slide of kauntzeum (in B.M. collection) and as far as can be seen from the imperfect specimen is very like dentulosum. The larvae of $S$. ambositrae Grenier \& Grjébine (I958) (described under the name $S$. neireti Roubaud by Grenier \& Doucet (I949a)) and of S. imerinae Roubaud from Madagascar are unusual as the rectal gills are formed of three simple lobes which are brownish in colour; these species and S. milloti Grenier \& Doucet are also unusual in that the second antennal segment shows more or less distinct secondary annulation, which is not known in the larvae of other Ethiopian species. In $S$. dentulosum and $S$. debegene de Meillon the outer margin of the mandible is unusually strongly arched.]

(8) S. medusaeforme-group. Ventral papillae absent; abdominal cuticle with at least a few setae, either simple and spine-like or flattened and scale-like, never fan-shaped; head capsule with positive pattern, sometimes unpigmented; postgenal cleft medium-sized to very large, shape varied; hypostomium with usual nine apical teeth, the teeth short and blunt.

[Note. In this group the body form and size are very varied ; in the small species (e.g. S. bovis de Meillon and S. albivirgulatum Wanson \& Henrard) the body is usually pale, the abdomen of clubbed form (i.e. with the posterior segments set-off abruptly from the others) and the head unpigmented. These species have flattened abdominal scales, but larger species have sparse simple setae, often very few so that the cuticle is apparently bare in some cases. According to Gibbins (I939) the abdomen of $S$. taylori is without scales or spines, and the larva of $S$. cavum Gibbins according to Gibbins (I937)-under his earlier name obscurum -is "similar to taylori". The B.M. collection has one slide of the larva of each species, made by Gibbins, but these show fragments only and it is impossible to confirm that the abdominal cuticle is bare. I think it probable that these species have a few sparse setae as in colas-belcouri, where the cuticle also is sometimes apparently bare but in which one or two scattered setae may always be found. Most species in this group show a median sclerotized projection from the anal sclerite which extends backwards towards the "seam" in the mid-dorsal line of the posterior circlet. A similar lightly sclerotized rod-like extension occurs in some of the dentulosum-group, but not in Division A species. It should be noted here that the medusaeforme-group is clearly equivalent to the genus Wilhelmia Enderlein and the larval characters agree extremely closely with those of the Palaearctic Wilhelmia as recorded by 
Rubtzov (I956). In Wilhelmia larvae there is a positive pattern of dark head-spots, the postgenal cleft is mitre-shaped or subcordate in form, the hypostomial teeth are rather broad and blunt and only the median tooth is rather more prominent than the others, the hypostomial setae diverge posteriorly from the lateral hypostomial margin, the mandibular comb-teeth form an evenly decreasing row, the anterior mandibular serration is sometimes elongate (e.g. W. angustifurca Rubtzov), and the combined length of third and fourth antennal segments is distinctly shorter than the second segment. Following Rubtzov's classification the medusaeforme-group would have to be placed in Wilhelmia, not only on larval characters but on those of the other stages as well.]

It is difficult to distinguish Division A from Division B completely reliably on larval characters, but omitting the neavei-group they may be more or less defined as below :

Division A. Ventral papillae present; head capsule usually with negative pattern; hypostomium usually with median and corner teeth considerably more prominent than the others ; hypostomial setae lying subparallel to lateral margin of hypostomium ; first three comb-teeth of mandible of different form from succeeding teeth ; third and fourth antennal segments combined usually as long as or longer than second segment ; number of hooks and rows in circlets usually comparatively few; abdomen of clubbed form, i.e. with posterior segments more or less distinctly set-off from the anterior segments (as in Textfig. 7).

Division B. Ventral papillae absent; head capsule with positive pattern, occasionally unpigmented; hypostomium normally with apical teeth rather broad and blunt, median and corner teeth not very prominent; hypostomial setae diverging posteriorly from lateral margin of hypostomium (not noticeably in griseicolle); comb-teeth of mandible usually large and forming an evenly decreasing row; third and fourth antennal segments combined shorter than second segment; number of hooks and rows in circlets usually very high; abdomen rarely clubbed, usually more gradually expanding apically and then contracting abruptly to posterior circlet.

\section{Key to Species-groups of Larvae of Ethiopian Simuliddae}

I give below a preliminary key to the species-groups, but this is by no means perfect and some intermediate species may be difficult to place; these exceptions have been alluded to in the discussion above.

Separation of genera Cnephia and Simulium (no entirely reliable character has been found) :

Hypostomium of the Prosimulium type ; mandible with at least traces of three serrations or with a series of serrations; rectal gills with three simple lobes; cuticle bare ; apical half of antenna strongly pigmented with a very distinct intersegmental unpigmented ring between second and third segments

Cnephia

Hypostomium not of this type; mandible with two serrations or only one (traces of third serration known in two Madagascan species) ; rectal gills normally with numerous secondary lobules, very rarely simply trilobed; cuticle frequently with setae ; antennal pigmentation weak with indistinct unpigmented ring

Simulium 
28 TAXONOMIC STUDY OF LARVAE OF W. AFRICAN SIMULIIDAE

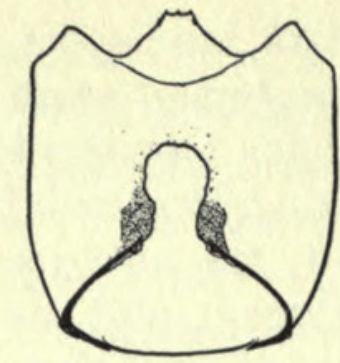

28

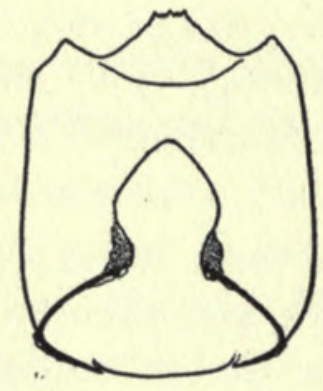

32

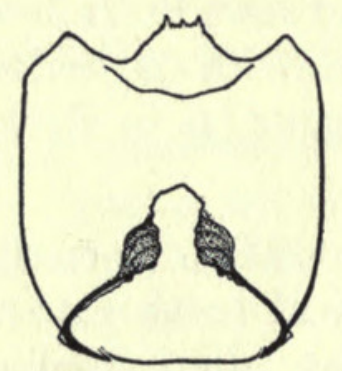

36

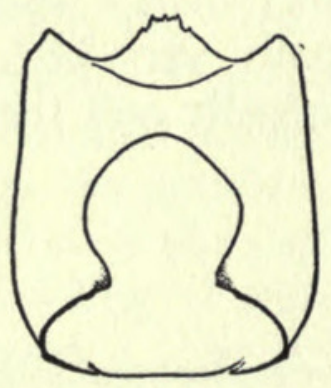

40

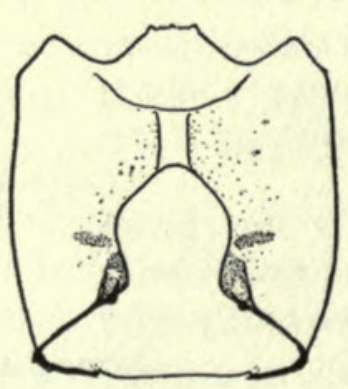

44
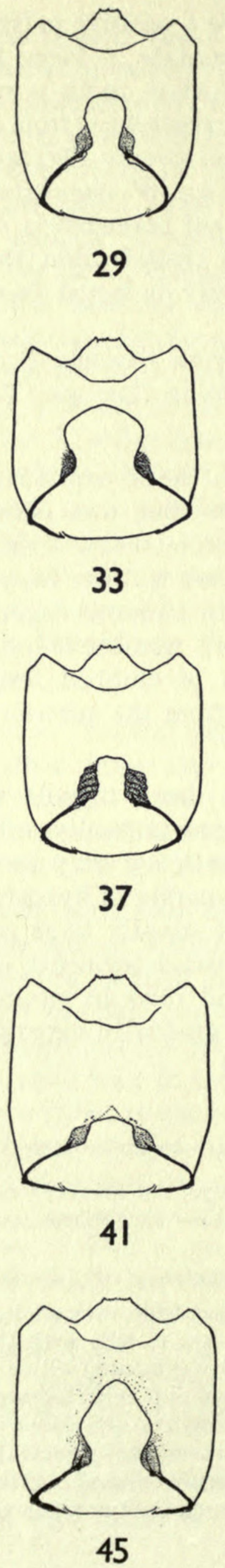

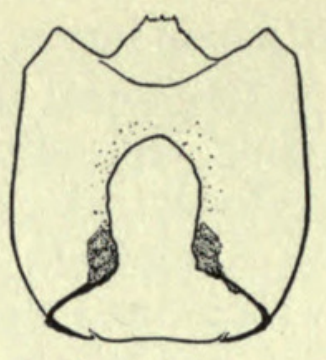

30
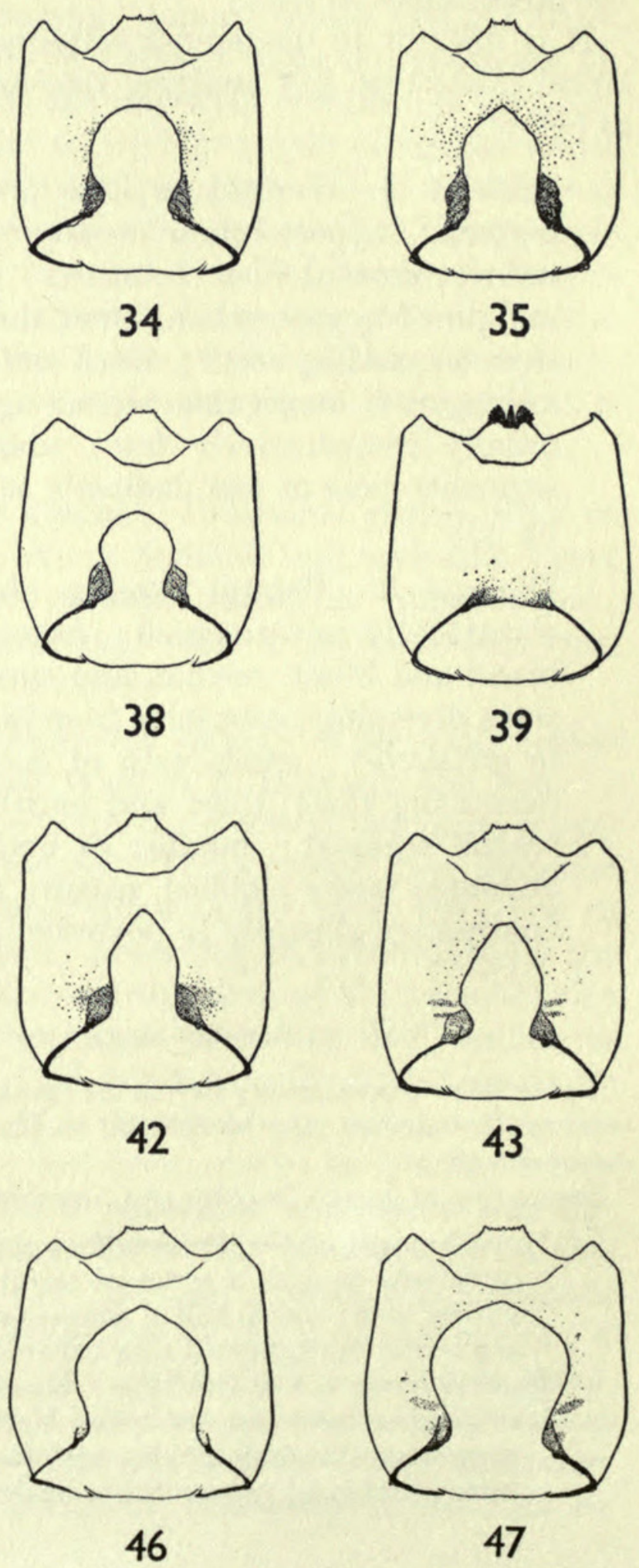


\section{Species-groups of Simulium}

I. Larvae living on crabs or mayfly nymphs ; rectal scales absent ; eye-spots usually very reduced; posterior circlet usually more ventral in position, and anal sclerite more apical in position than usual . . . . . neavei-group 2

-. Larvae living normally, not attached to other Arthropods ; rectal scales present (except damnosum) (Text-figs. I I and I2) ; eye-spots normal, rarely very reduced ; posterior circlet in usual distinctly apical position, and anal sclerite in normal dorsal position

2. Larvae attached to crabs; hypostomium with a more or less even row of $\mathrm{I} 3$ apical teeth

-. Larvae attached to mayfly nymphs; hypostomium of varied form but not as above

copleyi-complex

3. Abdominal cuticle with two distinct types of setae, both simple spines and some fan-shaped scales; thoracic cuticle with setae; mandible with one serration only ; postgenal cleft very large and circular ; head capsule pale and unpigmented

griseicolle-group

-. Abdominal cuticle bare or with one type of seta or scale only, but size of setae may vary ; thoracic cuticle bare (except damnosum) ; mandible with two serrations ; postgenal cleft rarely very large and circular; head capsule usually with some pigmentation or pattern

4. Ventral papillae present; hypostomial setae lying parallel to lateral margin of hypostomium; apical teeth of hypostomium usually pointed and median and corner teeth distinctly prominent; combined length of third and fourth antennal segments usually longer than second segment or at least as long ; head usually with negative pattern

-. Ventral papillae absent; hypostomial setae diverging posteriorly from lateral margin of hypostomium; apical teeth of hypostomium rather broad and blunt and median and corner teeth usually not strongly prominent; combined length of third and fourth antennal segments shorter than second segment ; head with positive pattern, rarely unpigmented .

5. Head with positive pattern of distinct dark spots; cuticle bare ; postgenal cleft small so that postgenal bridge is as long as or longer than hypostomium; pupal respiratory histoblast with four filaments

Head with negative pattern of pale spots with darker surrounding pigmentation or entirely pale ; abdominal cuticle with setae ; postgenal cleft of varied form ; pupal respiratory histoblast not with four filaments

6. Abdominal cuticle dorsally with large erect scales ; last abdominal segment usually with small lateral accessory sclerites; postgenal cleft large and postgenal bridge shorter than hypostomium; pupal respiratory histoblast with two or more stout lobes or with eight filaments on a long common cylindrical trunk

cervicornutum-group

-. Abdominal cuticle dorsally with branched fan-like scales or simple setae; last abdominal segment without accessory sclerites; postgenal cleft of small to medium size; pupal respiratory histoblast with numerous simple tightly coiled filaments branching near the base, not carried on a long stalk

FIGS. 28-47. Ventral view of head capsule showing postgenal cleft of (28) S. alcocki; (29) S. johannae; (30) S. schoutedeni; (31) S. impukane; (32) S. momahoni ; (33) S. kenyae ; (34) S. cervicornutum; (35) S. unicornutum; (36) S. ruficorne ; (37) S. aureosimile; (38) S. adersi; (39) S. berneri; (40) S. griseicolle; (4I) S. dentulosum ; (42) S. loutetense; (43) S. medusaeforme hargreavesi; (44) S. vorax; (45) S. colas-belcouri; (46) S. bovis; (47) S. damnosum. 
7. Abdominal cuticle with branched fan-like scales; postgenal cleft small and postgenal bridge a little longer than or about equal in length to hypostomium; ventral papillae large and distinct . alcocki-group

-. Abdominal cuticle with simple spine-like setae; postgenal cleft of medium size, rather regularly circular, and postgenal bridge a little shorter than hypostomium ; ventral papillae small, sometimes indistinct .

hirsutum-group

8. Cuticle bare; postgenal cleft normally small, subtriangular, pentagonal or subquadrate in shape, and postgenal bridge usually longer than hypostomium; dark head-spots very distinct dentulosum-group

-. Cuticle with at least some simple setae or with dense scales; postgenal cleft of medium or large size, mitre-shaped, cordate or very large and subcircular in shape, and postgenal bridge distinctly shorter than hypostomium; dark head-spots often obscured by general dark infuscation of head capsule . medusaeforme-group

\section{KEY FOR THE IDENTIFICATION OF LARVAE OF WEST AFRICAN BLACK-FLIES}

The larvae of certain West African species of Simulium are difficult to key out satisfactorily, especially pairs of closely related species such as schoutedeni and mcmahoni, adersi and hirsutum, and alcocki and johannae. The characters given are the best which I have been able to find with the limited material available, and this should be borne in mind especially in the case of couplets $\mathrm{I}_{2}, \mathrm{I}_{5}$, and 20 . When the general body cuticle bears no socketed scales or setae the cuticle is described as " bare "; it should be noted however that even in these species there are normally some minute hairs located on the swollen areas between the lateral arms of the anal sclerite (e.g. as in ruficorne, Text-fig. I44).

I. Hypostomium of unusual form with a very large deeply-sunk median tooth and 5 subequal outwardly-directed teeth on either side (Text-fig. 68) ; postgenal cleft absent (Text-fig. 39) body densely covered with long pale club-shaped setae (Textfig. I49) ; eye-spots very small; larvae attached to mayfly nymphs

\section{S. berneri Freeman (p. 55)}

-. Hypostomium of usual form with an apical row of 9 teeth ; postgenal cleft present sometimes small; setae if present not of this form; eye-spots normal; larvae living normally, not attached to mayfly nymphs

2. Cuticle of proleg with setae; rectal scales absent; anterior abdominal segments usually distinctly produced into paired dorso-lateral conical protuberances (Text-fig. 9) ; cuticle of thorax and abdomen densely covered with flattened scale-like setae (Text-fig. I54), the setae densely clustered on the abdominal tubercles. . . . . . . S. damnosum Theobald

-. Cuticle of proleg bare ; rectal scales present (Text-figs. II and I2) ; anterior abdominal segments at most only very slightly swollen dorsally; cuticle with setae confined to the dorsum of the abdomen (except in griseicolle) . . . .

3. Cuticle of thorax and abdomen with abundant simple setae and at least some branched fan-like scales postero-dorsally on the abdomen (Text-fig. 147) ; mandible with one serration only (Text-fig. II0) . . . S. griseicolle Becker (p. 58)

-. Cuticle of thorax bare; cuticle of abdomen bare or with one type of seta or scale only ; mandible with the usual two serrations

4. Ventral papillae present; hypostomial setae lying more or less parallel to lateral margin of hypostomium (as in Text-fig. 59) ; first three comb-teeth of mandible distinctly differentiated from succeeding bristle-like teeth (Text-fig. II2) ; posterior circlet with comparatively few rows of hooks (Text-figs. I55-I57) ; head capsule usually with negative pattern (not ruficorne-group); abdominal cuticle sometimes with branched fan-like setae 
-. Ventral papillae absent ; hypostomial setae more or less distinctly diverging posteriorly from lateral margin of hypostomium (as in Text-fig. 6I) ; first three combteeth not distinctly differentiated from succeeding teeth (Text-fig. I I3); posterior circlet usually with very numerous rows of hooks (Text-figs. I58-I6o); head capsule with positive pattern of dark head-spots (unpigmented in bovis) ; abdominal cuticle never with branched setae . $\quad . \quad$. $\quad . \quad . \quad . \quad . \quad$.

5. Head capsule with positive pattern of dark head-spots; abdominal cuticle bare

Head capsule with negative pattern of pale head-spots with surrounding dark pigmentation or entirely unpigmented; abdominal cuticle with setae or scales .

6. Antero-lateral head-spots present (Text-fig. I9); hypostomial setae 6-7 in each row ; median and corner teeth of hypostomium not strongly prominent (Text-fig. 59) ; mandibular serrations normal, posterior serration small (Text-fig. 98)

S. aureosimile Pomeroy (p. 49)

-. Antero-lateral head-spots absent (Text-fig. 20); hypostomial setae 4-5 in each row ; median and corner teeth of hypostomium very strongly prominent (Textfig. 56) ; posterior serration of mandible enlarged and almost as large as anterior serration (Text-fig. 95) $\quad$. $\quad . \quad$. $\quad . \quad$. $\quad$ S. ruficorne Macquart

7. Abdominal cuticle dorsally with very large erect black scales; abdomen with very
dark segmental mottling, sometimes appearing blackish; last abdominal

7. Abdominal cuticle dorsally with very large erect black scales; abdomen with very
dark segmental mottling, sometimes appearing blackish; last abdominal segment usually with small lateral accessory sclerites (Text-fig. I55) ; postgenal cleft very large and postgenal bridge shorter than hypostomium . . .

-. Abdominal cuticle with small branched fan-like setae, usually recumbent, or with simple spine-like setae ; abdomen with pale yellowish-brown segmental mottling and usually appearing rather pale; last abdominal segment without accessory sclerites; postgenal cleft small, of medium size or shaped as in Text-fig. 33, postgenal bridge usually as long as or longer than hypostomium . .

8. Abdominal scales deeply incised apically into several long thin processes (Text-figs. I4O and I4I) ; combined length of third and fourth antennal segments considerably longer than second segment (Text-figs. $7 \mathrm{I}$ and 73 ); head pigmentation usually absent or only weakly marked as in Text-fig. I5; pupal respiratory histoblast with eight tightly coiled filaments carried on a long curved cylindrical stem (Text-figs. I76 and I77)

-. Abdominal scales only slightly serrate apically (Text-figs. I 42 and I 43 ) ; combined
length of third and fourth antennal segments subequal to or even slightly shorter
than second segment (Text-figs. 74 and 76 ); head pigmentation usually very
strongly marked (Text-figs. I 7 and I8); pupal respiratory histoblast not of this

-. Abdominal scales only slightly serrate apically (Text-figs. I42 and I43); combined
length of third and fourth antennal segments subequal to or even slightly shorter
than second segment (Text-figs. 74 and 76 ); head pigmentation usually very
strongly marked (Text-figs. I 7 and I8); pupal respiratory histoblast not of this

-. Abdominal scales only slightly serrate apically (Text-figs. I42 and I43); combined
length of third and fourth antennal segments subequal to or even slightly shorter
than second segment (Text-figs. 74 and 76 ); head pigmentation usually very
strongly marked (Text-figs. I7 and I8); pupal respiratory histoblast not of this

-. Abdominal scales only slightly serrate apically (Text-figs. I42 and I43); combined
length of third and fourth antennal segments subequal to or even slightly shorter
than second segment (Text-figs. 74 and 76 ); head pigmentation usually very
strongly marked (Text-figs. I7 and I8); pupal respiratory histoblast not of this form

9. Postgenal cleft mitre-shaped (Text-fig. 30) ; last abdominal segment with small

lateral accessory sclerites; abdominal scales with most of the processes arising
near the apex (Text-fig. I40) . . . S. schoutedeni Wanson

lateral accessory sclerites ; abdominal scales with most of the processes arising
near the apex (Text-fig. I40) . . . . S schoutedeni Wanson

-. Postgenal cleft cordate in shape (Text-fig. 32); last abdominal segment without accessory sclerites; abdominal scales with the processes more divergent and arising more basally (Text-fig. I4I) . . . . S. momahoni de Meillon (p. 43)

Io. Postgenal cleft mitre-shaped, pointed apically (Text-fig. 35) ; dark pigmentation on cephalic apotome usually forming an $\mathrm{H}$-shaped mark not extending laterally to the cleavage lines (Text-fig. I8); median and corner teeth of hypostomium more distinctly prominent (Text-fig. 55); pupal respiratory histoblast formed of two broad lobes (Text-fig. I8o) $\cdot \cdot \cdot \cdot \cdot \cdot \cdot \cdot \quad$ S. unicornutum Pomeroy

-. Postgenal cleft rounded, curved apically (Text-fig. 34); dark pigmentation on cephalic apotome usually forming a lyre-shaped mark which extends in places to reach the cleavage lines (Text-fig. I7); median and corner teeth of hypostomium less prominent (Text-fig. 54); pupal respiratory histoblast formed of nine branches with five visible externally (Text-fig. I79) S. cervicornutum Pomeroy 

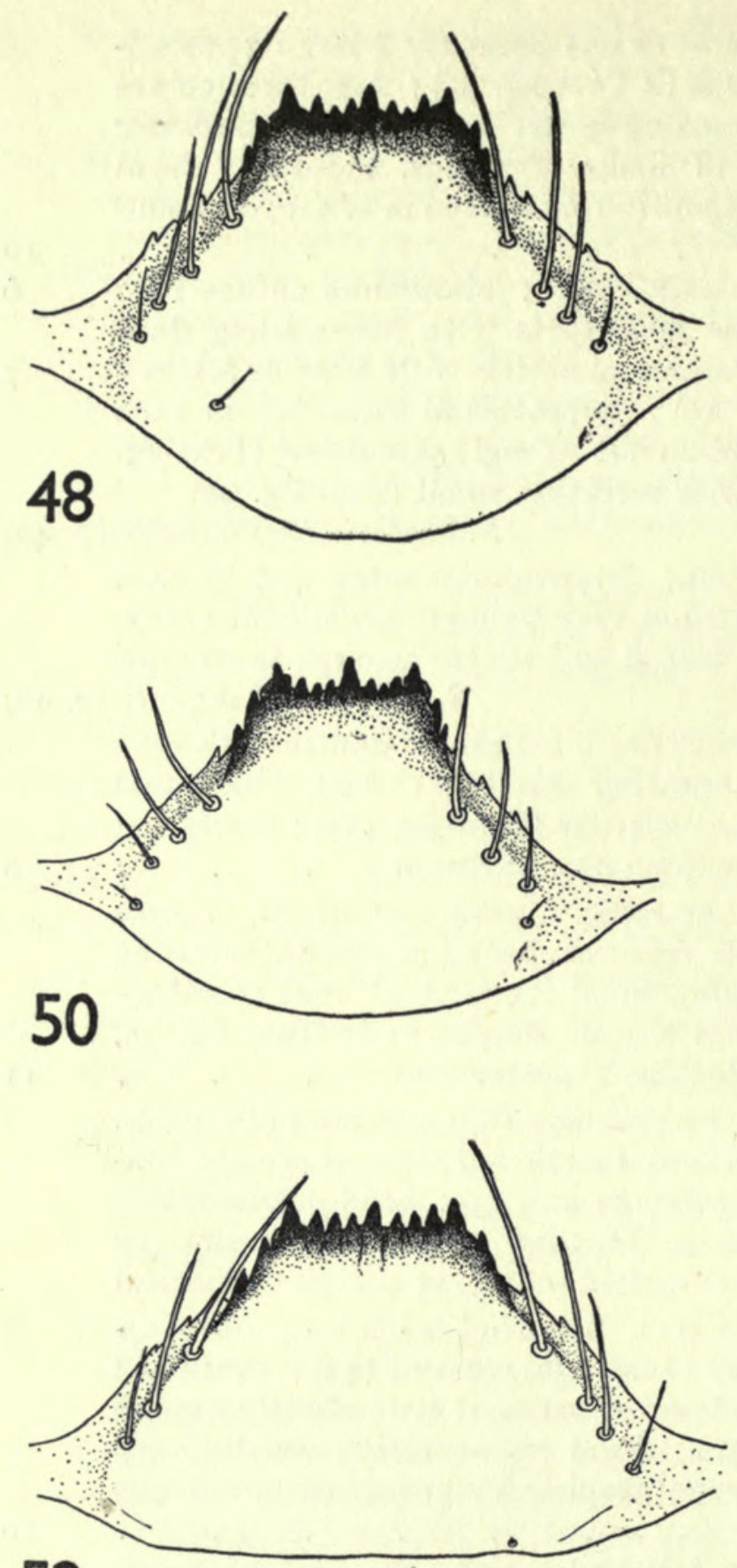

52
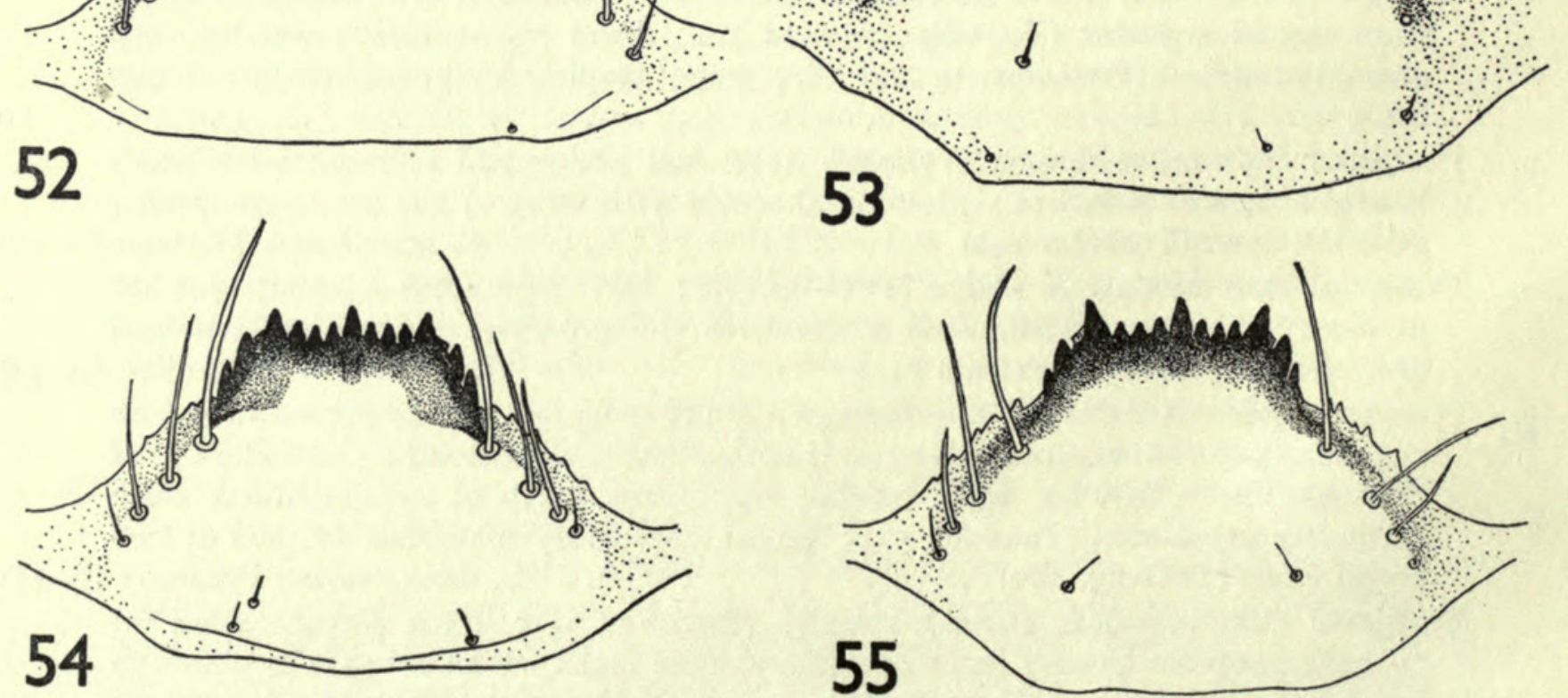

Figs. 48-55. Hypostomium of (48) S. alcocki; (49) S. johannae; (50) S. schoutedeni; (5I) S. impukane; (52) S. momahoni ; (53) S. kenyae ; (54) S. cervicornutum ; (55) S. unicornutum.

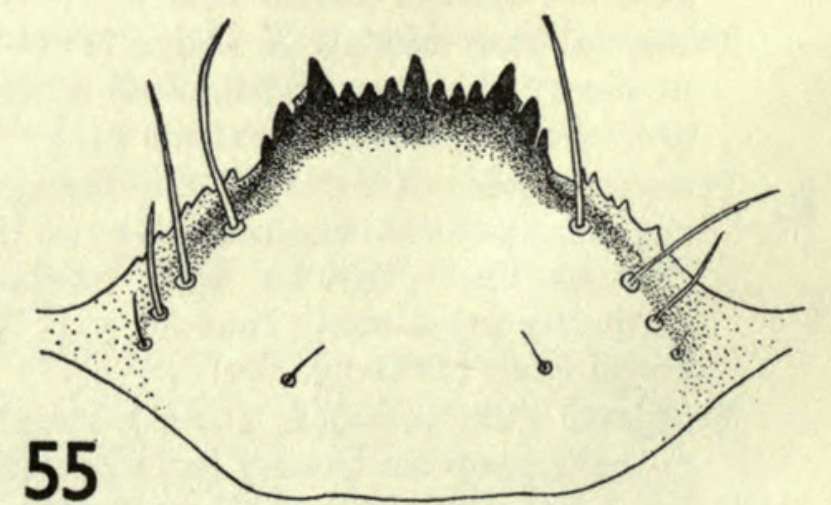


II. Abdominal cuticle with simple spine-like setae (Text-figs. I45 and I46) ; postgenal cleft of medium size and more or less circular (Text-fig. $\left.3^{8}\right)$. . . .

-. Abdominal cuticle with branched fan-like setae or scales (Text-figs. I36-r39) ; postgenal cleft usually small

12. Median and corner teeth of hypostomium very prominent (Text-fig. 57 ) $\dot{\text {; first }}$ antennal segment about 6 times as long as broad; maxillary palp about 3.I times as long as breadth at base ; pupal respiratory histoblast more or less regularly oval in outline (Text-fig. 184) with eleven filaments

S. adersi Pomeroy (p. 53)

-. Median and corner teeth of hypostomium not strongly prominent (Text-fig. $5^{8}$ ) ; first antennal segment about $7 \cdot 5$ times as long as broad ; maxillary palp about $2 \cdot 8$ times as long as breadth at base ; pupal respiratory histoblast more compressed postero-dorsally in outline (Text-fig. I83) with eight filaments

S. hirsutum Pomeroy (p. 52)

13. Postgenal cleft transverse oval in shape and broadly open behind (Text-fig. 33); abdominal setae irregularly branched with the main branches usually having secondary forks (Text-fig. I39) ; head capsule sometimes very strongly pigmented (Text-fig. I6) ; apical teeth of hypostomium short and blunt, the median and corner teeth hardly at all prominent (Text-fig. 53) ; posterior circlet with about 85 rows of 13-16 hooks . . . . . . . . S. kenyae de Meillon

- Postgenal cleft small and postgenal bridge at least as long as hypostomium; abdominal setae (Text-figs. 136-138) not secondarily branched; head capsule usually weakly pigmented (as in Text-fig. I3); median and corner teeth of hypostomium distinctly more prominent than intermediate teeth; posterior circlet with about $60-70$ rows of usually about 8-12 hooks . . . .

4. Postgenal bridge distinctly longer than hypostomium, postgenal cleft more or less parallel-sided and truncate apically (Text-fig. 3I) ; rectal gills simple or with only one or two thumb-like secondary lobules; maxillary palp long, about 3.2 times as long as breadth at base . . . . . . S. impukane de Meillon ostgenal bridge about equal in length to or only slightly longer than hypostomium, postgenal cleft more rounded anteriorly and slightly contracted behind (Text-figs. 28 and 29) ; rectal gills with 6-8 secondary finger-like lobules in each lobe ; maxillary palp about $2 \cdot 6-3$ times as long as breadth at base . . . . . .

15. Second antennal segment almost as long as first (Text-fig. 69) ; maxillary palp about 3 times as long as breadth at base . . . . S. alcocki Pomeroy (p. 34)

-. Second antennal segment only about two-thirds as long as first (Text-fig. 70) ; maxillary palp about 2.6 times as long as breadth at base

S. johannae Wanson (p. 37)

I6. Head capsule entirely pale creamy-yellow, unpigmented; abdominal cuticle dorsally with numerous small flattened scales (Text-fig. I53); postgenal cleft extremely large and rounded, widely open behind (Text-fig. 46) ; mature larva very small, about $4.5 \mathrm{~mm}$. in length . . . . S Sovis de Meillon (p.

- Head capsule with dark head-spots and usually strongly infuscated with brown pigmentation; abdominal cuticle bare or with scattered simple spine-like setae ; postgenal cleft not enormously enlarged ; mature larva often very large, at least, $5.5 \mathrm{~mm}$. in length .

I7. Abdominal cuticle bare, without setae ; groups of head-spots very distinct (Text-

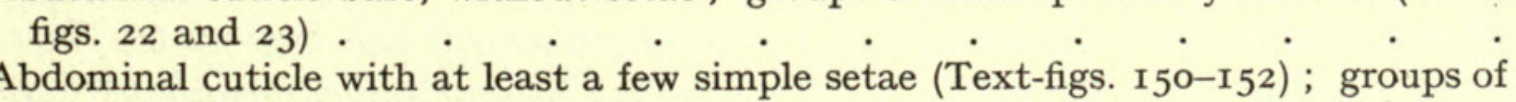
head-spots sometimes indistinct and obscured by general dark pigmentation .

I8. Length of mature larva 9-10.5 mm.; postgenal cleft very small, sometimes triangular but usually subquadrate (Text-fig. 4I), postgenal bridge very long; hypostomial setae $12-18$ in each row ; cephalic fan with 54-70 rays; outer margin of mandible strongly arched (Text-fig. 9oc) ; posterior circlet with about 220 rows of 24-39 hooks

S. dentulosum Roubaud (p. 59) 
- Length of mature larva about $5.5 \mathrm{~mm}$.; postgenal cleft large and mitre-shaped (Text-fig. 42), postgenal bridge shorter than hypostomium; hypostomial setae 6-7 in each row ; cephalic fan with about 40 rays; outer margin of mandible normal (as in Text-fig. 90a); posterior circlet with about 70-80 rows of $13-16$ hooks

S. loutetense Grenier \& Ovazza (p. 62)

19. Head capsule with dark head-spots more or less distinct at least on cephalic apotome but normally pale and unpigmented antero-laterally below the eye-spots (Textfig. 24) ; mandible with anterior serration normal, not strongly elongate (Textfig. 99) ; posterior circlet with about I40 rows of I8-30 hooks (Text-fig. I58) ; hypostomial setae $4-6$ (usually 4 ) in each row ; mature larva $5 \cdot 75^{-7}$ (usually about 6) $\mathrm{mm}$. in length; cephalic fan with with 38-45 rays

S. medusaeforme Pomeroy (p. 63)

- Head capsule with head-spots indistinct and head more or less strongly and evenly infuscated except anteriorly on cephalic apotome (Text-figs. 25 and 26) ; mandible with anterior serration very long and narrow (Text-figs. I02 and I05); posterior circlet with about I90-220 rows of 28-49 hooks (Text-fig. I 59) ; hypostomial setae 7-10 in each row ; cephalic fan with 50-60 rays ; mature larva large, $7 \cdot 75-9.25 \mathrm{~mm}$. in length

20. Head capsule usually more evenly pigmented and less distinctly pale anteriorly on cephalic apotome (Text-fig. 25) ; postgenal cleft cordate in shape (Text-fig. 44), postgenal bridge with a distinct longitudinal very lightly pigmented area sometimes almost unsclerotized; median tooth of hypostomium distinctly prominent and corner teeth very blunt (Text-fig. 64 ) ; maxillary palp about 2.75 times as long as breadth at base ; pupal respiratory histoblast with narrow branches (Text-fig. I92)

S. vorax Pomeroy (p. 64)

- Head capsule usually less evenly pigmented and distinctly pale anteriorly on cephalic apotome, the pale areas extending laterally on cephalic apotome towards the hind margin (Text-fig. 26) ; postgenal cleft elongate-cordate in shape (Text-fig. $45)$, more strongly tapering anteriorly, postgenal bridge with only faint traces of a longitudinal weakly sclerotized or weakly pigmented area; median tooth of hypostomium very blunt, scarcely if at all longer than intermediate teeth, corner teeth more pointed (Text-fig. 65) ; maxillary palp about 3 times as long as breadth at base ; pupal respiratory histoblast with broad branches (Text-fig. I93)

S. colas-belcouri Grenier \& Ovazza (p. 67)

\section{LARVAL DESCRIPTIONS}

Note. Descriptions based on last stage larvae.

Type form.

\section{Simulium alcocki Pomeroy}

Length. Mature larva, $5 \mathrm{~mm}$.

Head. Head capsule creamy-yellow, usually almost without pattern ; pattern when present of negative type, lightly pigmented yellowish-brown as in johannae (Text-fig. I3) but sometimes with slight suffusions round the eye-spots. Postgenal cleft small and rounded (Text-fig. 28), postgenal bridge about equal in length to hypostomium. Hypostomium (Text-fig. 48) with usual row of 9 apical teeth, median and corner teeth moderately prominent ; usually 4-6 strongly acute lateral serrations with the hindmost serration lying posterior to the first hypostomial seta ; hypostomial setae 4-5 in each row, lying parallel to lateral margin of hypostomium; distance 
between apex of corner tooth and first hypostomial seta subequal to that between corner teeth. Antenna (Text-fig. 69) long, very lightly pigmented, first segment about 6-7 times as long as broad, segment length ratios $5: 4 \cdot 6: 6$. Mandible of typical form, posterior serration present, small (Text-fig. 9I), second comb tooth much smaller than first and shorter than third. Maxillary palp about 3 times as long as breadth at base (Text-fig. II5). Cephalic fan with 42-44 rays (Roubaud \& Grenier (I943) give 20-25).

Thorax. Milky-white with variable dark banding; cuticle bare. Proleg circlet with about I9 rows of 5-6 hooks ; lateral plate very weakly pigmented, with about 9 processes. Pupal respiratory histoblast with 7 thin tightly coiled filaments, first division near the base (Text-fig. I73).

Abdomen. Shaped as in Text-fig. 7; milky or yellowish-white with brown segmental mottling, clear white ventro-apically. Ventral papillae present, large and pointed. Cuticle of dorsum with small scattered, strongly sclerotized, fanshaped scales (Text-fig. I36). Rectal scales present. Rectal gills with 7-9 finger-like secondary lobules on each lobe. Anal sclerite of usual form, strongly sclerotized, posterior arm extending to about Ioth row of hooks. Posterior circlet with about $6 \mathrm{I}-70$ rows of $8-\mathrm{I} 5$ hooks.

MATERIAL EXAmined. From Northern Nigeria, Southern Cameroons, Sierra Leone.

LARVAL HABITAT AND RANGE. Larvae are found mostly on dead leaves or on trailing grass in slowly-flowing, often heavily shaded streams ; they are rarely very numerous in any one place, and commonly exist among the larvae of johannae, alcocki occidentale, unicornutum and cervicornutum. Widely distributed over Tropical Africa south to Natal.

\section{Simulium alcocki form occidentale Freeman \& de Meillon}

Larvae examined are not distinguishable from alcocki type form except on the pupal respiratory histoblast of mature larvae which is ro-filamented and closely similar to that of johannae (from which no reliable differences have been found).

Material EXAMined. From Northern Nigeria.

LARVAL HABITAT AND RANGE. Habitat as in the type form; locally distributed in West Africa but probably commoner than the few records suggest.

\section{[Simulium alcocki form djallonense Roubaud \& Grenier and form coalitum} Pomeroy

Larvae of these forms are not known and may prove to be indistinguishable from the type form except in the pupal respiratory histoblast; the respiratory organ in the pupae of both forms is comprised of ro filaments. In coalitum the filaments are borne on a long common stalk which will be evident in semi-mature and mature larvae, but in djallonense the branching occurs near the base and the pupal respiratory histoblast must closely resemble that in alcocki occidentale and johannae. Both forms appear to be very localized: djallonense-Guinea and Nigeria, coalitum Nigeria and Ghana.] 

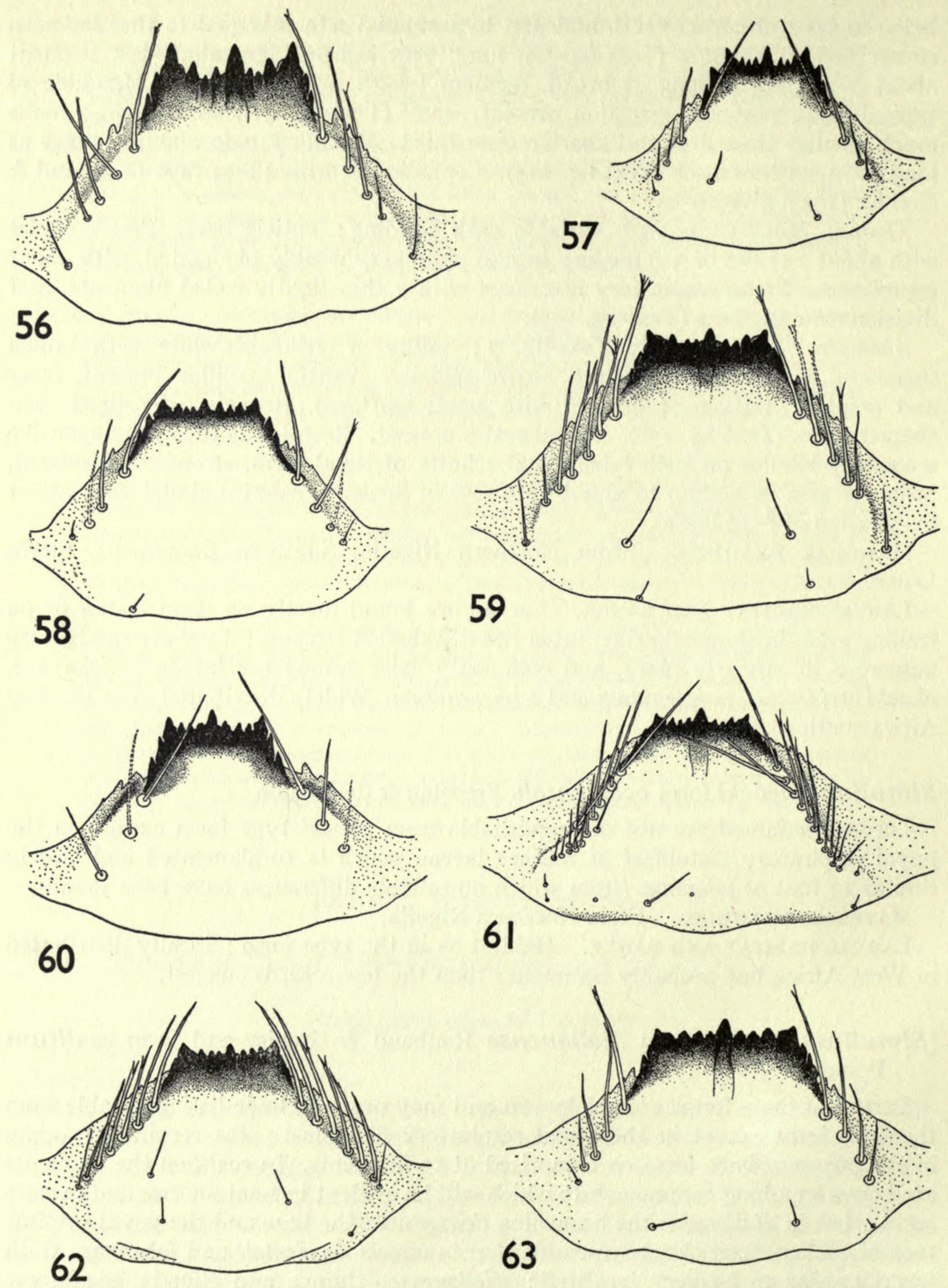

Figs. 56-63. Hypostomium of (56) S. ruficorne ; (57) S. adersi ; (58) S. hirsutum ; (59)

S. aureosimile; (60) S. griseicolle; (6I) S. dentulosum; (62) S. loutetense; (63)

S. medusaeforme hargreavesi. 


\section{Simulium johannae Wanson}

Closely similar to alcocki but mature larvae smaller.

Length. Mature larva, 4-4.5 $\mathrm{mm}$.

Head. Head capsule creamy-yellow without pattern or with a faintly marked negative pattern on the cephalic apotome (Text-fig. I3) ; sides of head with only faint traces of dark pigmentation in material seen. Postgenal cleft small and rounded (Text-fig. 29), as a rule a little more parallel-sided than in alcocki, postgenal bridge about equal in length to, or a little longer than, hypostomium. Hypostomium (Text-fig. 49) with usual row of 9 apical teeth, median and corner teeth moderately prominent ; 4-6 lateral serrations with the hindmost serration lying posterior to or level with the first hypostomial seta ; hypostomial setae 3-4 in each row, lying parallel to lateral margin of hypostomium; distance between apex of corner tooth and first hypostomial seta subequal to or a little less than that between corner teeth. Antenna (Text-fig. 70) long, almost unpigmented, first segment about 7-7.5 times as long as broad, segment length ratios I4 : $8: \mathrm{I} 6$. Mandible of typical form, posterior serration present, very small (Text-fig. 94), second comb tooth much smaller than first and shorter than third. Maxillary palp about 2.6 times as long as breadth at base (Text-fig. II6). Cephalic fan with 34-40 rays (Grenier \& Rageau (I949) give " about 20 " in their description of roubaudi = johannae).

Thorax. Yellowish-white with usual darker banding; cuticle bare. Proleg circlet with about 20 rows of 5-6 hooks ; lateral plate unpigmented, apparently with about 6-9 processes. Pupal respiratory histoblast with Io thin tightly coiled filaments, first division near the base (Text-fig. I74).

Abdomen. Shaped as in Text-fig. 7 ; yellowish-white with well-developed brownish segmental mottling, clear white ventro-apically. Ventral papillae present, large and rather pointed. Cuticle of dorsum with numerous small strongly sclerotized fan-shaped scales (Text-fig. I37) similar to those in alcocki (without scales according to Grenier \& Rageau (I949)). Rectal scales present. Rectal gills with 6-8 finger-like secondary lobules on each lobe. Anal sclerite of usual form, strongly sclerotized, posterior arm extending to about Ioth or IIth row of hooks. Posterior circlet with about 60 rows of 8 -ro hooks.

MATERIAL EXAmined. From Northern Nigeria, Southern Cameroons, Sierra Leone.

LARVAL HABITAT AND RANGE. Larvae occur on dead leaves and grasses in small streams, usually well shaded, most commonly in slowly-flowing water but sometimes in swifter streams and often in association with other small-stream species such as alcocki, unicornutum, and schoutedeni. Principally West and Equatorial Africa south to Northern Rhodesia.

\section{Simulium schoutedeni Wanson}

Closely similar to unicornutum but head capsule almost devoid of pigmentation in material seen.

Length. Mature larva, 3.75-4 mm.

Head. Head capsule pale creamy-yellow without pigmentation or with only 
faintest traces of negative pattern on the cephalic apotome (only a few larvae seen). Postgenal cleft large, almost twice as long as its basal width and similar to that of unicornutum but less pointed apically (cf. Text-figs. 30 and 35), postgenal bridge a little shorter than hypostomium. Hypostomium (Text-fig. 50) with usual row of 9 apical teeth, median and corner teeth strongly developed as in the cervicornutum group ; about 5 lateral serrations with the hindmost serration usually lying posterior to the first hypostomial seta ; hypostomial setae 4 in each row, lying parallel to lateral margin of hypostomium; distance between apex of corner tooth and first hypostomial seta subequal to or a little greater than that between corner teeth. Antenna (Text-fig. 7I) long, unpigmented, first segment about 7 times as long as broad, segment length ratios $5: 3 \cdot 6: 6$. Mandible of typical form, posterior serration present, small (Text-fig. 97), second comb tooth much smaller than first and shorter than third. Maxillary palp 2.5 times as long as breadth at base (Text-fig. II7). Cephalic fan with about 35 rays.

Thorax. Whitish with extensive dark mottling; cuticle dorsally with numerous very minute colourless hairs. Proleg circlet with about 20 rows of $5^{-6}$ hooks ; lateral plate unpigmented, with about (?) 6-8 processes. Pupal respiratory histoblast with 8 thin tightly coiled filaments carried on a long stalk which does not divide before the postero-ventral curve of the "gill-spot" (Text-fig. I76).

Abdomen. Shaped as in Text-fig. 7, but sometimes with small dorso-lateral swellings on the intermediate abdominal segments; pale grey or yellowish-grey with extensive very dark segmental mottling, pale yellowish ventro-apically. Ventral papillae present, large and pointed. Cuticle dorsally and laterally on posterior segments with numerous erect black scales, the scales deeply incised apically into about I0-I2 parallel-sided finger-like processes (Text-fig. I40); cuticle of anterior segments dorsally with minute colourless hairs as on the thorax, but without scales. Last abdominal segment just anterior to posterior circlet with a small black sclerite as in unicornutum (Text-fig. I55). Rectal scales present. Rectal gills with secondary lobules (not sufficiently extended in material seen for counting but probably few). Anal sclerite of usual form, strongly sclerotized, posterior arm extending to about I2th row of hooks. Posterior circlet with about 65 rows of 8 -Io hooks.

MATERIAL EXAMINED. From Northern Nigeria (5 larvae only).

LARVAL HABITAT AND RANGE. The larvae collected by me were in very small slowly-flowing streams attached to blades of grass dipping into the water. Wanson (I947) records the species from swift current, but it seems to be most often found in slow streams, sometimes associated with alcocki, johannae and unicornutum. The larvae are extremely similar to those of unicornutum, with the same dark coloration, presence of the pair of small sclerites on the last abdominal segment, similar large black abdominal scales, and similar postgenal cleft. Mature specimens can very easily be distinguished by the respiratory histoblast (cf. Text-figs. I76 and I8o), but younger larvae may be confused. The species is known from Sierra Leone to Belgian Congo, but records are few, perhaps because it seldom occurs in large numbers and is easily overlooked. 


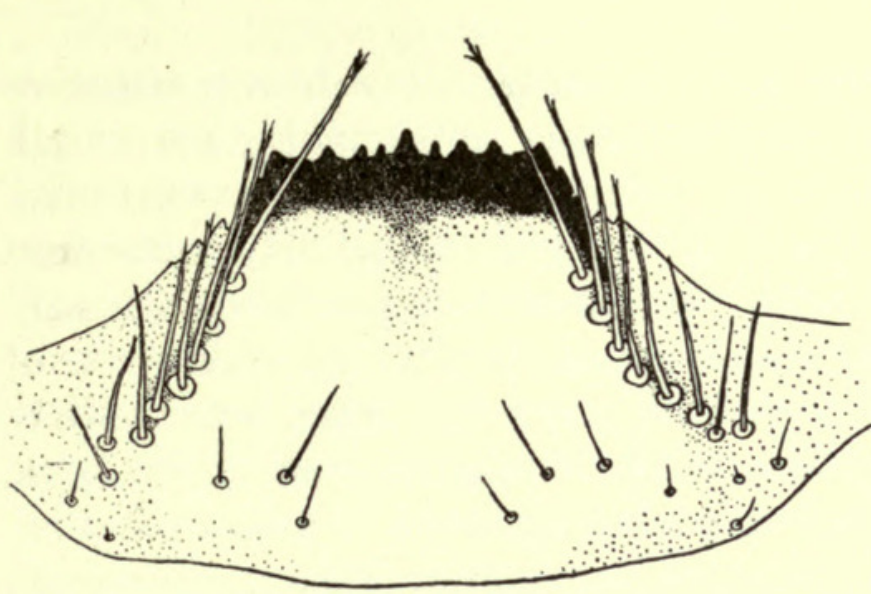

64

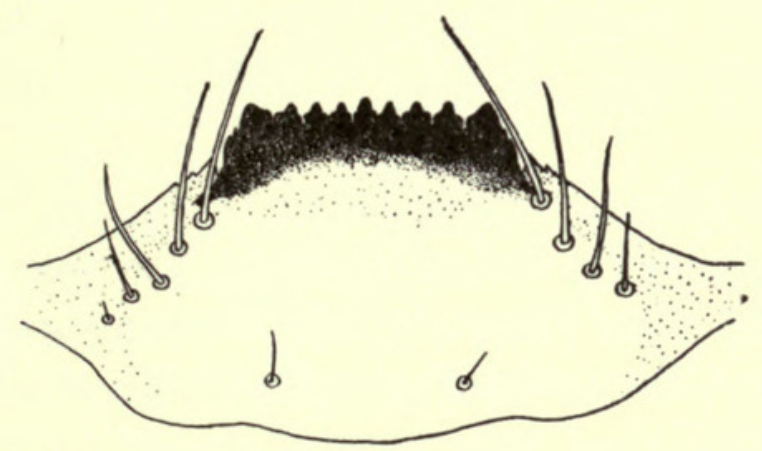

66

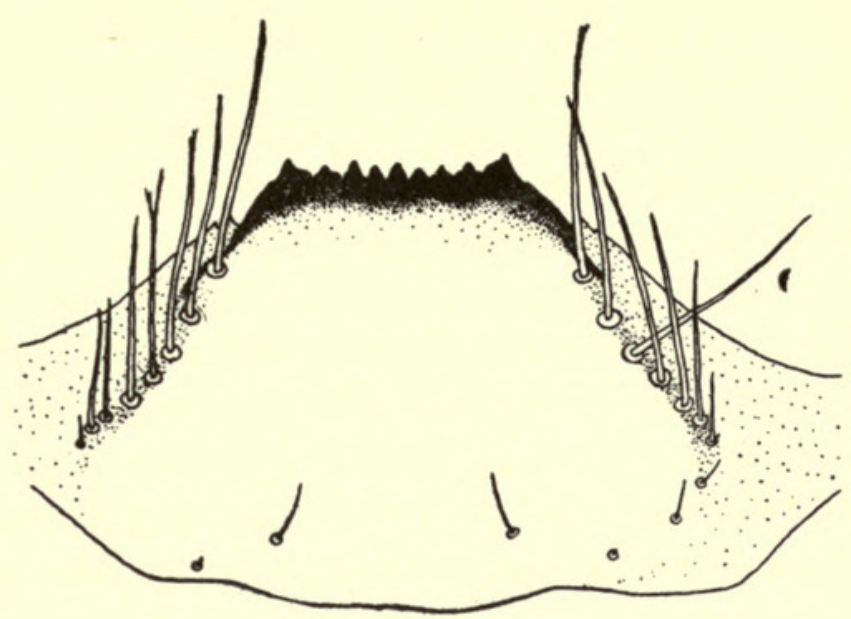

65
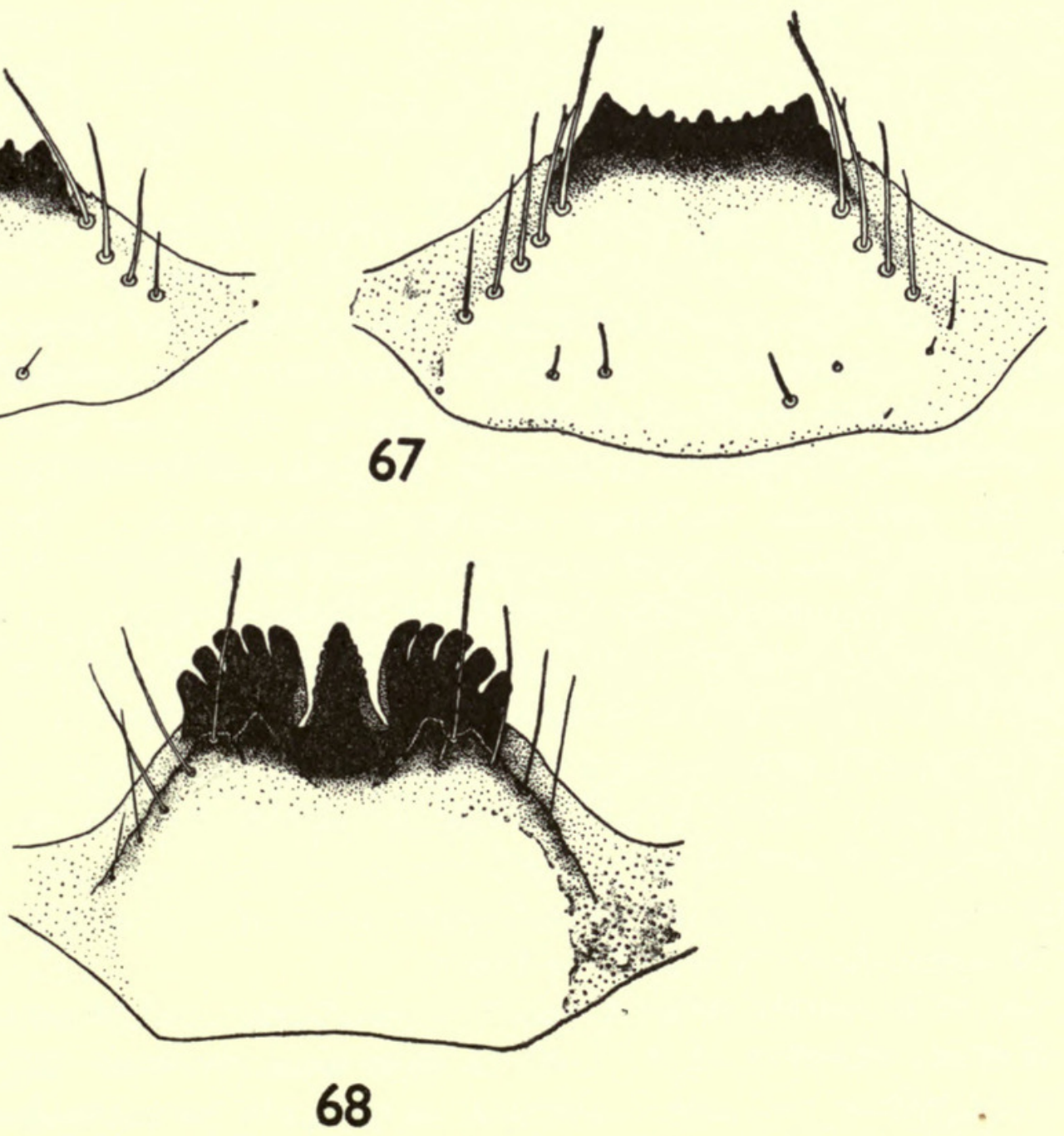

FIgS. 64-68. Hypostomium of (64) S. vorax; (65) S. colas-belcouri; (66) S. bovis ; (67) $S$. damnosum; (68) S. berneri. 


\section{Simulium impukane de Meillon}

Larva closely similar to alcocki; no reliable means of separation has been found.

Length. Mature larva, 4.75-5 mm.

Head. Head capsule pale yellowish-white with variable yellow-brown negative pattern (Text-fig. I4), sometimes almost unpigmented. Postgenal cleft small, subquadrate or very slightly rounded (Text-fig. 3I), somewhat similar to aureosimile ; postgenal bridge long, distinctly longer than the hypostomium. Hypostomium (Text-fig. 5I) with usual row of 9 apical teeth, median and corner teeth strongly prominent and more developed than in most alcocki-group species, the middle one of the intermediate teeth small and strongly sunken between the other intermediate teeth ; 6-9 strongly developed lateral serrations with the hindmost serration lying well posterior to the first hypostomial seta ; hypostomial setae 4-5 in each row, most often 4, lying subparallel to lateral margin of hypostomium; distance between apex of corner tooth and first hypostomial seta subequal to that between corner teeth. Antenna (Text-fig. 72) long, almost unpigmented, first segment about 7 times as long as broad, segment length ratios $7: 6:$ ro. Mandible of typical form, posterior serration present, small (Text-fig. I0o), second comb tooth much smaller than first and shorter than third. Maxillary palp long, $3 \cdot 2$ times as long as breadth at base. Cephalic fan with $38-4$ I rays.

Thorax. Yellowish-white with pale brown banding; cuticle bare. Proleg circlet with about 22 rows of $5-6$ hooks ; lateral plate unpigmented, with about 8 processes. Pupal respiratory histoblast with Io thin tightly coiled filaments, first divisions near the base ; postero-dorsal edge of the " gill-spot" more strongly compressed towards the centre than in alcocki (Text-fig. I75).

Abdomen. Shaped as in Text-fig. 7; pale yellowish-white with yellow-brown or brown segmental mottling, whitish ventro-apically. Ventral papillae present, slightly pointed. Cuticle of the posterior abdominal segments dorsally with numerous strongly sclerotized fan-shaped scales (Text-fig. I38) similar to those of alcocki but sometimes rather more parallel-sided and longer. Rectal scales present. Rectal gills unusually simple in material seen, each lobe either without secondary lobules (Text-fig. I72) or with one or two small thumb-like secondary lobules on the lateral lobes (this may not always be the case and further material may show more numerous digitate secondary lobules). Anal sclerite of usual form, strongly sclerotized (Textfig. I63), posterior arms extending to about IIth row of hooks. Posterior circlet with about $64-67$ rows of $8-12$ hooks.

MATERIAL EXAMINED. From Northern Nigeria and Nyasaland.

LARVAL HABITAT AND RANGE. Larvae occur in small streams attached to dead leaves, grasses and stones, sometimes in swift shallow water, but often in slow muddy water where detritus and algae accumulate. Known from West Africa (Ghana) to South Africa, but records are few ; impukane is very easily confused with forms of alcocki, but in Nigeria at any rate seems to occur frequently on its own unassociated with other species. 
Length. Mature larva, $5 \mathrm{~mm}$.

Head. Head capsule pale yellowish-white with variable brown negative pattern sometimes very strongly pigmented (Text-fig. I6), and similar to cervicornutum, the brown pigmentation extending laterally on the cephalic apotome to the cleavage line thereby delimiting the pale head-spots clearly into antero- and postero-median and antero- and postero-lateral groups ; pale spots on sides of head usually clearly marked and the postero-ventral region of the head darkly pigmented. Postgenal cleft of unusual form, large and broader than long, anterior margin rounded but with a very slight trace of a widely obtuse angle (Text-fig. 33) ; postgenal bridge short, little more than half as long as hypostomium. Hypostomium (Text-fig. 53) with usual row of 9 apical teeth, the median and corner teeth little developed so that the anterior teeth form an almost even row as in medusaeforme-group species with subequal intermediate teeth and broad blunt corner teeth; 3-5 lateral serrations with the hindmost serration about level with or only just posterior to first hypostomial seta ; hypostomial setae 4-5 in each row (3 seen also in one specimen but probably exceptional), lying subparallel to lateral margin of hypostomium; distance between apex of corner tooth and first hypostomial seta only about two-thirds of that between corner teeth. Antenna (Text-fig. 75) relatively shorter than in most alcocki-group species and only slightly longer than stem of cephalic fan, with third segment shorter than second, first segment moderately pigmented and 5-5.5 times as long as broad, segment length ratios $6: 6: 5$. Mandible of typical form, posterior serration present, small (Text-fig. I03), second comb tooth longer than third so that the $3 \mathrm{comb}$ teeth form a gradually diminishing series, bristle-like teeth very long and strong and the first tooth of this series at least twice as long as third comb tooth. Maxillary palp about $2 \cdot 8$ times as long as breadth at base (Text-fig. I20). Cephalic fan with about $38-40$ rays.

Thorax. Yellowish-white with pale brown banding; cuticle bare. Proleg circlet with about 36 rows of $8-\mathrm{I} 2$ hooks ; lateral plate lightly pigmented, with about I8 processes. Pupal respiratory histoblast with 8 thin tightly coiled filaments arising in pairs with divisions very near the base (Text-fig. I78), shape rather obliquely elongate.

Abdomen. Probably shaped as in Text-fig. 7; yellowish-white with brown segmental mottling, milky-white ventro-apically. Ventral papillae present. Cuticle postero-dorsally with numerous small compound scales, sometimes of simple fan type, but usually with the branches further subdivided (Text-fig. I39), the scales black, strongly sclerotized. Rectal scales present. Rectal gills with numerous finger-like secondary lobules, about Io-I4 in each lobe. Anal sclerite of usual form, strongly sclerotized, posterior arm extending to about $\mathrm{I} 3^{\text {th }}-\mathrm{I} 5^{\text {th }}$ row of hooks. Posterior circlet with about $82-85$ rows of I3-I6 hooks.

Material examined. From Southern Cameroons.

LARVAL HABITAT AND RANGE. This is a swift-water species, and larvae and pupae occur mostly on trailing grasses in turbulent, rocky-bedded streams; the larva of kenyae has more hooks per row and more rows of hooks in both the posterior 

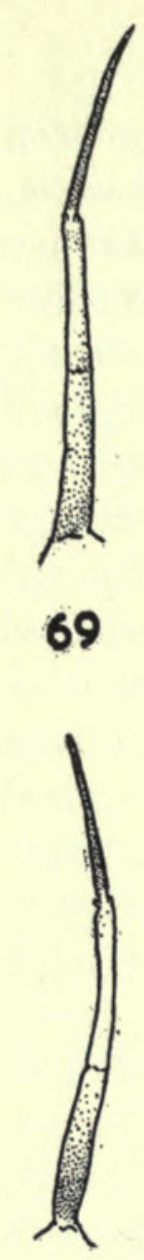

76

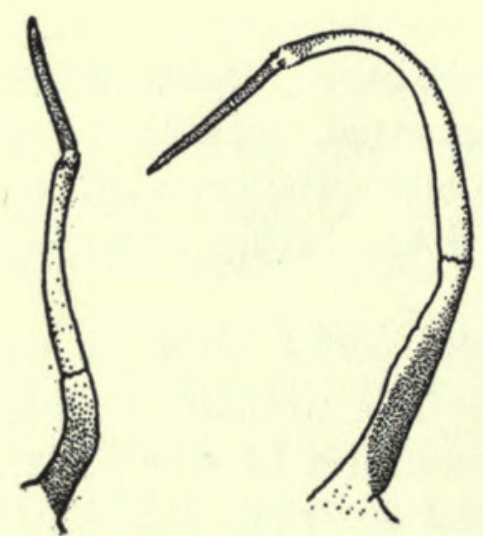

83

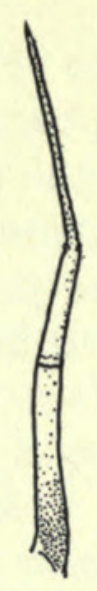

70

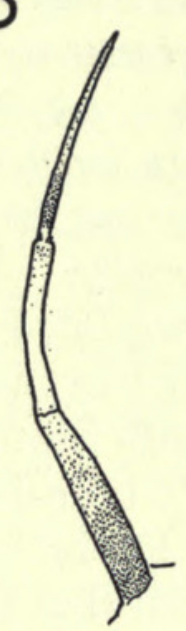

77
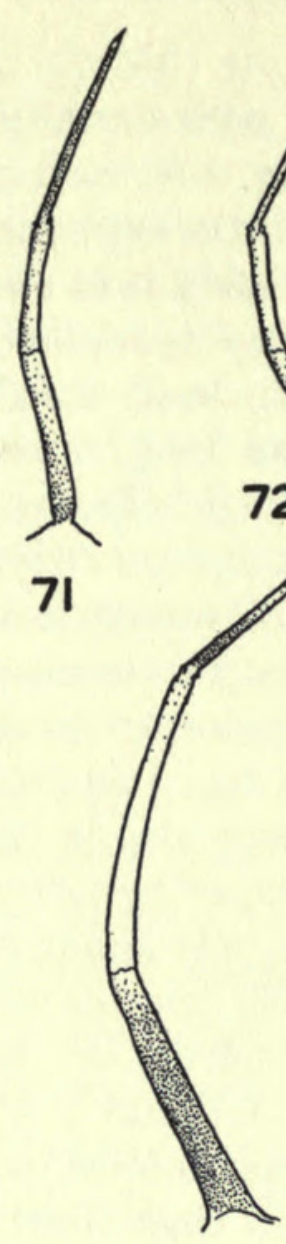

78
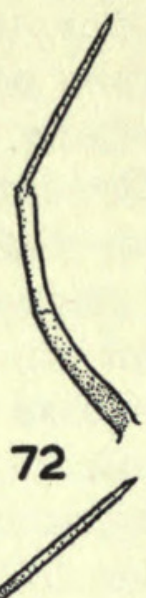
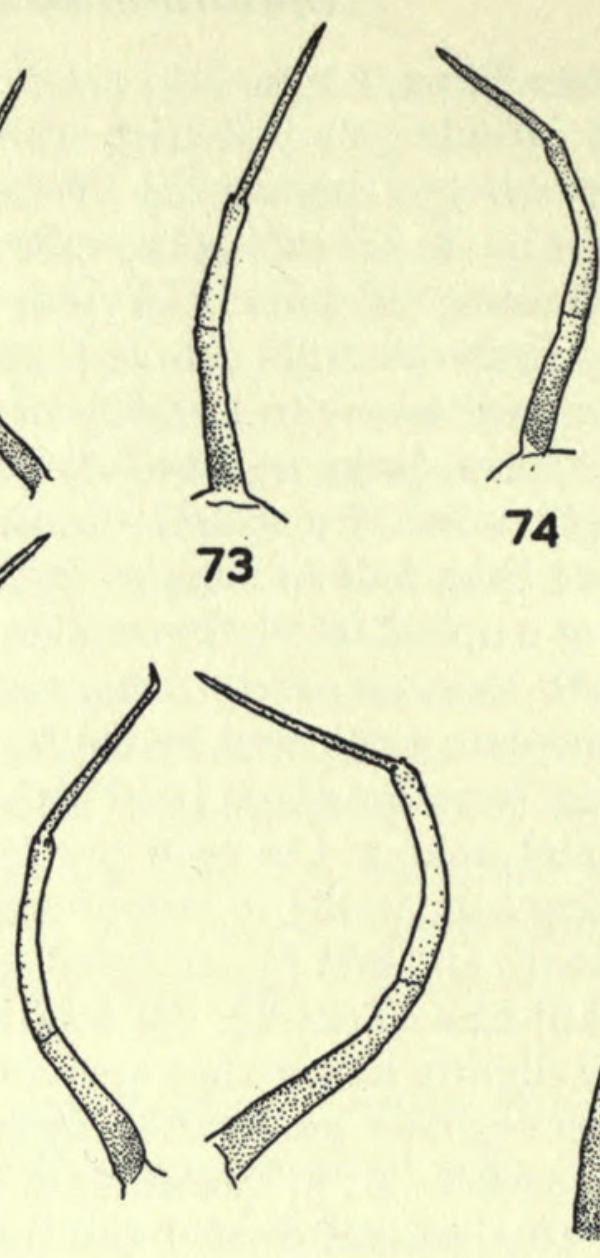

79

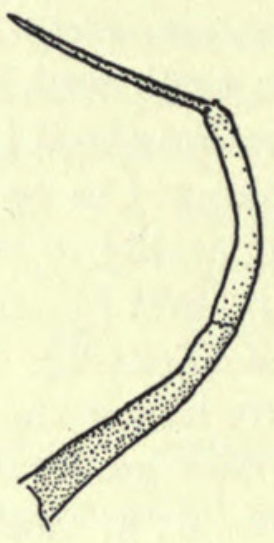

80

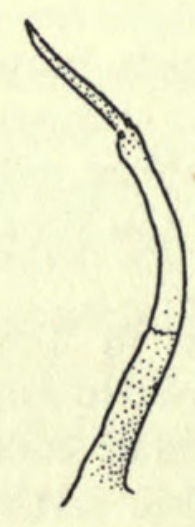

86

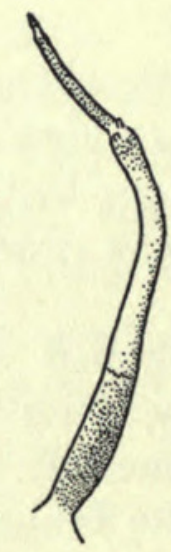

87

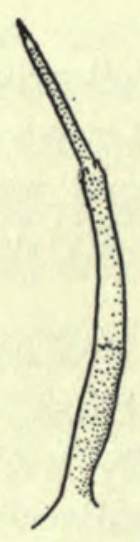

88

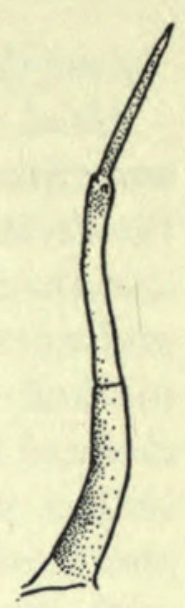

75

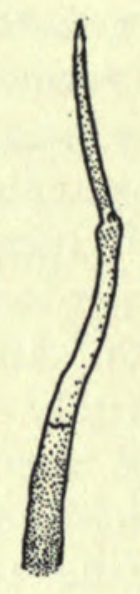

81

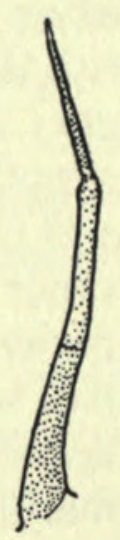

82

FIGS. 69-89. Antenna of (69) S. alcocki; (70) S. johannae; (7I) S. schoutedeni ; (72) S. impukane; (73) S. mamahoni; (74) S. cervicornutum; (75) S. kenyae; (76) S. unicornutum ; (77) S. ruficorne; (78) S. aureosimile ; (79) S. adersi ; (80) S. hirsutum ; (8I) S. berneri; (82) S. griseicolle; (83) S. loutetense ; (84) S. dentulosum; (85) S. vorax : (86) S. medusaeforme hargreavesi; (87) S. colas-belcouri; (88) S. bovis ; (89) S. damnosum. 
and the proleg circlets and the secondary lobules of the gills are more numerous than in other species of the alcocki-group, adaptations to its preferred habitat in fast-moving water. West and Equatorial Africa from Liberia to Sudan and Uganda, but not known south of Ruanda Urundi.

\section{Simulium mcmahoni de Meillon}

Larva similar to unicormutum and schoutedeni with erect black scales on dorsum of posterior abdominal segments.

Length. Mature larva, 4-4.5 mm.

Head. Head capsule pale yellow with variably developed negative pattern (Text-fig. I5), the dark pigmentation often extending towards the cleavage line on the cephalic apotome as in cervicornutum and clearly delimiting the pale posteromedian and postero-lateral head-spots; postero-ventral areas of head capsule usually extensively darkened. Postgenal cleft large and shaped as in Text-fig. 32, less parallel-sided than in unicornutum and less pointed apically; postgenal bridge a little shorter than hypostomium. Hypostomium (Text-fig. 52) with usual row of 9 apical teeth, median and corner teeth moderately prominent and intermediate teeth well developed and subequal in size ; 4-6 lateral serrations with the hindmost serration lying about level with the first hypostomial seta; hypostomial setae 3-4 in each row, lying parallel to lateral margin of hypostomium; distance between apex of corner tooth and first hypostomial seta subequal to that between corner teeth. Antenna (Text-fig. 73) long, first segment lightly pigmented and about $6 \cdot 5-7$ times as long as broad, segment length ratios $5: 3 \cdot 8: 5 \cdot 6$. Mandible of typical form, posterior serration present, small (Text-fig. I06), second comb tooth much smaller than first and slightly shorter than third. Maxillary palp about 2.75 times as long as breadth at base (Text-fig. II9). Cephalic fan with 33-4I rays.

Thorax. Pale yellowish-grey with pale brown banding; cuticle dorsally with minute colourless hairs. Proleg circlet with about 20 rows of $6-8$ hooks; lateral plate with about I2 processes. Pupal respiratory histoblast with 8 thin tightly coiled filaments borne on a long stalk (Text-fig. I77), rather similar to schoutedeni.

Abdomen. Shaped as in Text-fig. 7, but some specimens with dorso-lateral swellings on intermediate segments ; yellowish-grey with brown segmental mottling, pale yellowish ventro-apically. Ventral papillae present, small. Cuticle dorsally and dorso-laterally on posterior segments with numerous erect black scales, the scales (Text-fig. I4I) deeply incised apically into about I2 finger-like processes, the processes reaching nearer to the base of the scale than in schoutedeni; cuticle of anterior segments dorsally with minute colourless hairs as on the thorax. Last abdominal segment laterally without small black sclerite in material seen. Rectal scales present. Rectal gills with median lobe simple or with one thumb-like secondary lobule, lateral lobes with 2-3 secondary lobules (Text-fig. I70) in material seen, but gills might be more complex in other specimens. Anal sclerite of usual form, strongly sclerotized, posterior arm extending to about Ioth-I2th row of hooks. Posterior circlet with about 66 rows of 9-I2 hooks.

Material examined. From Nyasaland. No West African material has been seen. 
LARVAL habitat AND RANGe. Pupae of this species occur mainly in slow-moving water in streams attached principally to trailing grasses, and it may be inferred that this is the usual larval habitat. Widely distributed from Sudan to Transvaal and Bechuanaland, but also extending into West Africa. I have collected momahoni at a few localities in Northern Nigeria in the pupal stage, but did not obtain larvae.

\section{Simulium cervicornutum Pomeroy}

Type form. Closely similar to unicornutum.

Length. Mature larva, $4.5 \mathrm{~mm}$.

Head. Head capsule with very distinct negative pattern (Text-fig. I7), a lyreshaped brown pigmented area on the cephalic apotome surrounding the pale headspots, and reaching the cleavage line (cf. unicornutum) medio-laterally; sides of the head capsule infuscated behind and above eye-spots, but with usual clear eyebrow stripe; ground colour creamy-white, pigmentation usually strongly marked but occasionally indistinct. Postgenal cleft large and rounded (Text-fig. 34), lateral margins slightly curved and apical margin evenly rounded without the distinct angle of unicornutum; postgenal bridge shorter than hypostomium. Hypostomium (Text-fig. 54) with usual row of 9 apical teeth, median and corner teeth moderately prominent (less so than in unicornutum) and intermediate teeth of equal size forming an even row ; 5-6 lateral serrations, the hindmost serrations usually blunt and lying well posterior to first hypostomial seta ; hypostomial setae 3-4 in each row, lying parallel to lateral margin of hypostomium; distance between apex of corner tooth and first hypostomial seta distinctly shorter than that between corner teeth. Antenna (Text-fig. 74) short, only slightly longer than stem of cephalic fan, unpigmented, first segment $4 \cdot 5-5$ times as long as broad, segment length ratios $3: 3 \cdot 7: 3$. Mandible of typical form, posterior serration present, small (Text-fig. I09), second comb tooth much smaller than first and as long as third. Maxillary palp about 2.75 times as long as breadth at base (Text-fig. I2I). Cephalic fan with about 36 rays.

Thorax. Milky or greyish-white with dark grey or greyish-brown marking; cuticle dorsally and dorso-laterally with numerous minute colourless hairs as in momahoni and unicornutum. Proleg circlet with about 25 rows of $4-5$ hooks; lateral plate unpigmented, with about 9 processes. Pupal respiratory histoblast with 9 stout wrinkled branches, of which 5 are visible without dissection (Text-fig. I79) and comprise two straight branches anteriorly and three S-shaped branches posteriorly.

Abdomen. Shaped as in Text-fig. 7; pale grey or greyish-white with black or brown segmental mottling, milky-white ventro-apically. Ventral papillae present, small and obtuse or slightly rounded apically. Cuticle of posterior segments dorsally and dorso-laterally with numerous large scattered black scales, the scales strongly serrate apically (Text-fig. I42) ; cuticle on dorsum of anterior segments with a few minute pale hairs as on the thorax. Last abdominal segment just anterior to posterior circlet laterally with a small black sclerite as in unicornutum (Text-fig. 155), the sclerite sometimes divided into two or three parts and occasionally inconspicuous but traces at least always present. Rectal scales present. Rectal gills with 7-Io secondary lobules on each lobe, lobules usually fewer on the median lobe than on 
the lateral lobes. Anal sclerite of usual form, strongly sclerotized but usually with an unsclerotized break in the median line (Text-fig. I62), posterior arm extending to Ioth-I3th row of hooks. Posterior circlet with about 6o-67 rows of I0-I4 hooks.

Material examined. From Northern Nigeria, Liberia, Sierra Leone, Uganda.

LARVAL HABITAT AND RANGE. Larvae of this species tolerate very varied conditions, and are found in very large rivers as well as in very small streamlets, both in slowly-moving and swift turbulent water. In small slow streams larvae are most commonly found on dead leaves or recently-fallen leaves, often in company with the larvae of alcocki and unicornutum; in the rapids of large rivers the larvae occur mostly on blades of trailing grass or on sticks and corn-stalks lodged among rocks, and in these situations may be found among larvae of damnosum and bovis. Common and widely distributed from Sierra Leone to Southern Africa in both forested and savannah areas.

\section{Simulium unicornutum Pomeroy}

Type form. Closely similar to cervicornutum, but distinguishable by the form of the postgenal cleft.

Length. Mature larva, $4 \cdot 5-4 \cdot 75 \mathrm{~mm}$.

Head. Head capsule pale yellowish or creamy-white with negative pattern (Text-fig. I8), the dark pigmentation round the pale antero- and postero-median spots forming an $\mathrm{H}$-shaped or slightly lyre-shaped mark on the cephalic apotome, the infuscation usually less extensive laterally than in cervicornutum so that the lateral head-spots are not clearly demarcated; degree of pigmentation variable but often intensively marked, the ventro-lateral aspects of the head capsule usually strongly infuscated dark brown. Postgenal cleft large and mitre-shaped (Text-fig. 35), distinctly angulate apically and more parallel-sided than in cervicornutum; postgenal bridge much shorter than hypostomium. Hypostomium (Text-fig. 55) with usual row of 9 apical teeth, median and corner teeth strongly prominent, intermediate teeth well developed and subequal in size ; 6-7 lateral serrations with the hindmost serration lying posterior to first hypostomial seta; hypostomial setae 3-4 in each row, lying parallel to lateral margin of hypostomium; distance between apex of corner tooth and first hypostomial seta slightly less than or subequal to that between corner teeth. Antenna (Text-fig. 76) short, almost unpigmented, first segment about 6 times as long as broad, segment length ratios I2: I3: I3. Mandible of typical form, posterior serration present, small (Text-fig. 92), second comb tooth much smaller than first and shorter than third. Maxillary palp about 3 times as long as breadth at base (Text-fig. I22). Cephalic fan with 37-4I rays.

Thorax. Pale grey or yellowish-grey with dark or brownish-grey banding; cuticle dorsally and dorso-laterally with minute colourless hairs. Proleg circlet with about $2 \mathrm{I}-24$ rows of $5-7$ hooks ; lateral plate very lightly pigmented, with about 9 processes. Pupal respiratory histoblast formed by two very large strongly wrinkled lobes, the anterior lobe simple and the posterior lobe recurved upon itself (Text-fig. I80).

Abdomen. Shaped as in Text-fig. 7; pale grey or yellowish-white with boldly 


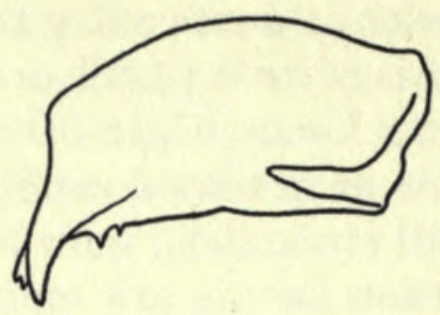

a

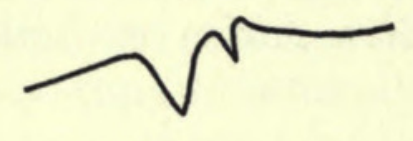

91

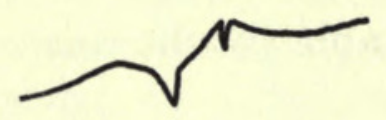

94

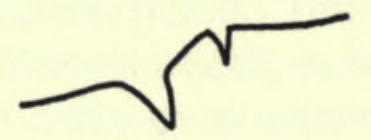

97

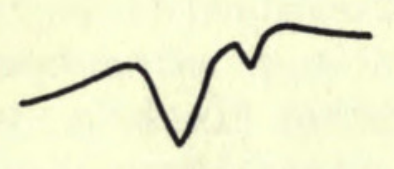

100

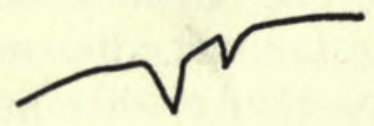

103

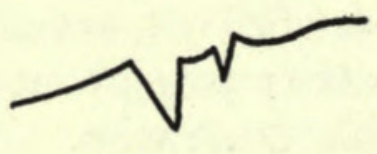

106

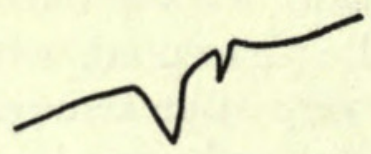

109

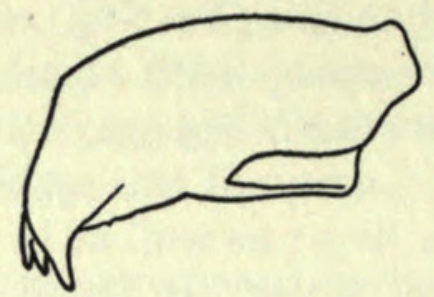

b

90

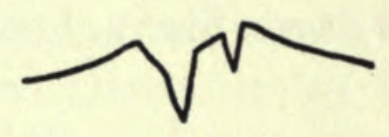

92

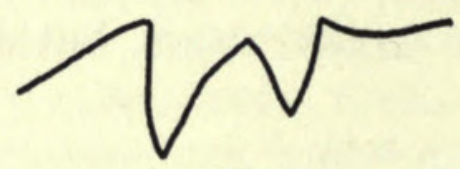

95

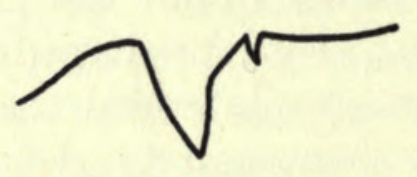

98
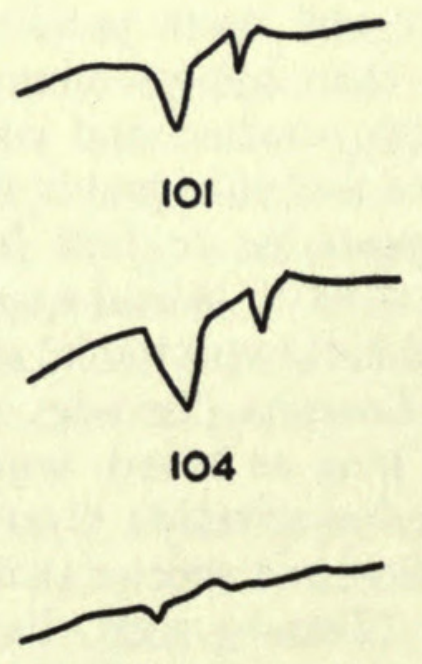

107

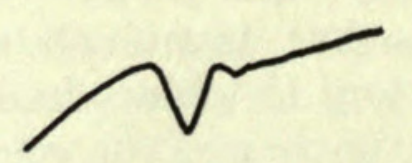

110

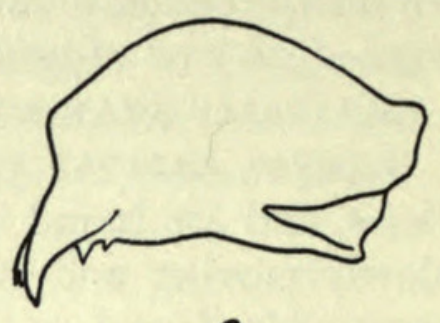

C

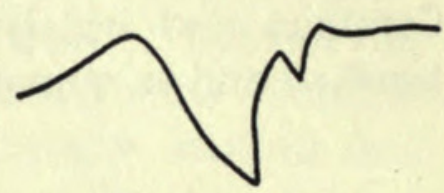

93

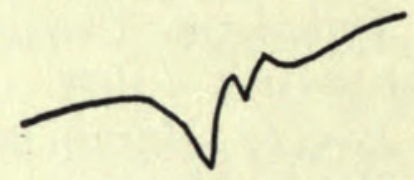

96

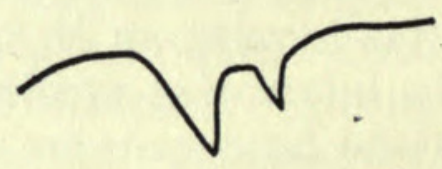

99
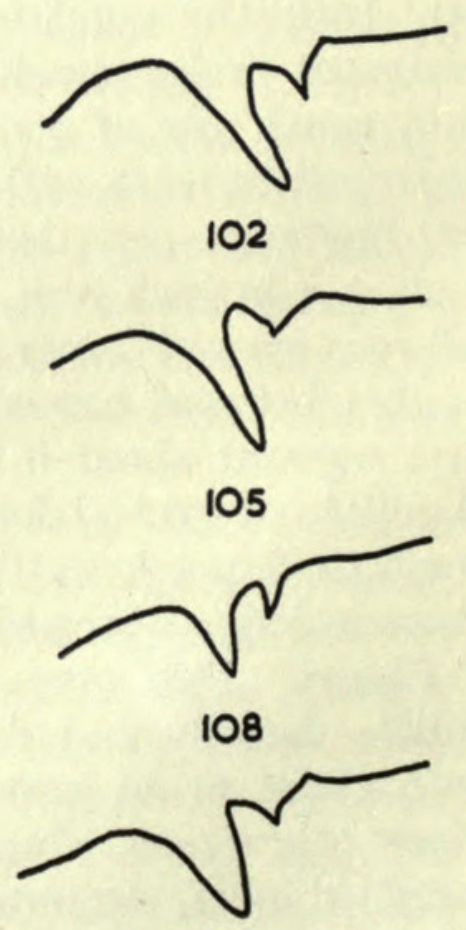

III 
marked black, dark brownish-grey or grey segmental mottling, milky-white ventroapically. Ventral papillae present, slightly rounded apically. Cuticle of posterior segments dorsally and dorso-laterally with numerous large scattered scales, the scales black, strongly sclerotized, and deeply serrate apically (Text-fig. I43); cuticle of anterior and posterior segments with numerous minute colourless hairs, those on the posterior segments among the scales. Last abdominal segment just anterior to posterior circlet laterally with a small black sclerite (Text-fig. I55), the sclerotization sometimes developed in two or three slightly separated parts. Rectal scales present. Rectal gills with finger-like secondary lobules, 8-I2 in each lateral lobe and 6-Io in median lobe. Anal sclerite of usual form, strongly sclerotized but usually unsclerotized in fine median line (Text-fig. I6I), posterior arm extending to 9th-IIth row of hooks. Posterior circlet with about 63 rows of 9-I3 hooks.

Material EXAmined. From Northern Nigeria, Sierra Leone, Uganda, Nyasaland.

LARVAL HABITAT AND RANGE. Like cervicornutum this species will tolerate both swift and slowly-flowing rivers and streams, but has a very strong preference for slowly-moving, often heavily-shaded, streams where the larvae are found on dead leaves, pebbles, etc. in company with those of alcocki, cervicornutum, johannae, schoutedeni and other slow-stream species. In small swift rocky streams it sometimes occurs with medusaeforme form hargreavesi, and occasional larvae may be found amongst those of damnosum in larger turbulent rivers. Common and widely distributed over more or less the whole Ethiopian Region.

\section{Simulium unicornutum form palmeri Pomeroy}

A larva collected with pupae of this form (from Southern Cameroons) and presumably of palmeri is indistinguishable from the type form. The pupal respiratory histoblast is not however developed, but it may be assumed that the lobes of the gill-spot show slight constrictions at intervals as in the respiratory organ of the pupa.

\section{[Simulium unicornutum form blacklocki Edwards}

This pupal form is only known from the type locality in Sierra Leone, and the larva is unknown. If it is genuinely a form of unicornutum the larva will probably show almost identical characteristics to the type form except in the formation of the "gill-spot". The habitat is likely to be slow streams.]

FIGs. 90-III. (90) Shape of mandible of $(a)$ the majority of species ; (b) S. berneri with base of apical tooth very broad ; (c) S. dentulosum with outer margin strongly arched. (9I-III) mandibular serrations of (9I) S. alcocki; (92) S. unicornutum; (93) S. dentulosum; (94) S. johannae; (95) S. ruficorne; (96) S. loutetense; (97) S. schoutedeni; (98) S. aureosimile; (99) S. medusaeforme hargreavesi; (гоo) S. impukane; (го I) S. hirsutum; (I03) S. vorax; (I02) S. kenyae; (104) S. adersi; (I05) S. colas-belcouri; (I06) S. mcmahoni; (I07) S. berneri; (108) S. bovis ; (I09) S. cervicornutum ; (I I0) S. griseicolle; (III) S. damnosum. 


\section{Simulium ruficorne Macquart}

The ruficorne-group is distinguished by having ventral papillae and a positive head pattern. S. ruficorne is distinguished from aureosimile by the absence of anterolateral head-spots.

Length. Mature larva, 6-6.5 mm.

Head. Head capsule with boldly marked positive pattern of dark brown spots on creamy-yellow ground colour, the spots themselves surrounded by narrow yellowbrown infuscation (Text-fig. 20). Cephalic apotome with antero- and posteromedian, and postero-lateral head-spots, but antero-lateral spots absent or with only the very faintest traces visible; head capsule laterally with dark spots as in Text-fig. 20, and dark infuscation round the eye-spots; usual pale eyebrow stripe present. Postgenal cleft very small (Text-fig. 36), slightly broader anteriorly than posteriorly and with apical margin slightly rounded, a little less subquadrate than in aureosimile; postgenal bridge a little longer than hypostomium. Hypostomium (Text-fig. 56) with usual row of 9 apical teeth, median and corner teeth very strongly developed, and median one of intermediate teeth very small and much shorter than other intermediate teeth ; 5-8 lateral serrations (usually 6 or 7 ), serrations strongly developed, with hindmost serration lying well posterior to first hypostomial seta ; hypostomial setae 3-5 in each row, lying parallel to lateral margin of hypostomium, hindmost seta sometimes widely separated from other setae; distance between apex of corner tooth and first hypostomial seta distinctly less than that between corner teeth. Antenna (Text-fig. 77) long, lightly pigmented, first segment about 6 times as long as broad, segment length ratios Io : 8.7: II. Mandible of typical form, serrations (Text-fig. 95) unusual, the posterior serration large and broad at the base, not much smaller than anterior serration, second comb tooth about equal in length to third and much smaller than first. Maxillary palp unusually long, about $3 \cdot 5-3 \cdot 6$ times as long as breadth at base (Text-fig. I23). Cephalic fan with $35-42$ rays (56 rays seen in mature larva from desert oasis, Sinai).

Thorax. Milky or creamy-white with pale grey-brown marking; cuticle bare. Proleg circlet with about $23-27$ rows of 5-7 hooks ; lateral plate unpigmented, with about I6 processes. Pupal respiratory histoblast with 4 large wrinkled tubular filaments, curled round so that their apices are directed upwards (Text-fig. I8I).

Abdomen. Shaped as in Text-figs. 7 and II ; pale yellowish-white with traces of pale brown segmental mottling (never seen with very dark banding), milky-white ventro-apically. Ventral papillae present (Text-fig. I56), large and usually strongly pointed conical in shape. Cuticle apparently completely bare, without scales or spines, but with minute colourless hairs dorsally on the posterior segments particularly around the anal sclerite (Text-fig. I44). Rectal scales present. Rectal gills variable, often simpler than in most species, each lobe sometimes without secondary lobules; small thumb-like secondary lobules sometimes present, 2-4 on each lobe; some specimens with 6-7 finger-like secondary lobules on each lobe. Anal sclerite of usual form, strongly sclerotized, anterior arms sometimes rather short and broad, posterior arm extending to Ioth or IIth row of hooks. Posterior circlet with about 63 rows of $9-13$ hooks. 
Material examined. From Northern Nigeria, Uganda, Egypt.

LARVAL HABITAT AND RANGE. Larvae live on trailing grasses, leaves, pebbles, or rocky beds in very slowly-moving water, usually in small streams, occasionally in larger rivers. Immature stages may often be found in situations where almost no flow exists, and even at times in stagnant water (for example in the marshy fadamas of the drier parts of Northern Nigeria) ; this habitat often contains much algal growth, and larvae are often covered with organic matter. Larvae usually occur in masses of the one species, and are rarely associated with other species since these cannot tolerate the conditions favoured by ruficorne. Common throughout Africa, including Algeria, Egypt, Morocco, and islands of the Malagasy sub-region, extending into the desert areas on the fringes of the Sahara.

\section{Simulium aureosimile Pomeroy}

Similar to ruficorne but readily distinguished by the presence of well-marked antero-lateral head-spots.

Length. Mature Larva, 5·75-6.5 mm.

Head. Creamy-yellow with very distinct positive pattern of brown head-spots, with areas of yellow-brown infuscation around the spots (Text-fig. I9) ; cephalic apotome with all groups of head-spots well developed including antero-lateral spots (cf. ruficorne) ; sides of head capsule with dark spots and infuscation round eye-spots as in Text-fig. I9, eyebrow stripe present but narrow and not very distinct ; pigmentation less variable than in most species and head-spots always distinct. Postgenal cleft small and subquadrate (Text-fig. 37), more truncate and less rounded apically than in ruficorne; postgenal bridge long, about $\mathrm{I} \cdot 5$ times as long as hypostomium. Hypostomium (Text-fig. 59) with usual row of 9 apical teeth, median and corner teeth short and blunt (cf. ruficorne), corner teeth very broad basally, intermediate teeth subequal in size or middle one very slightly smaller than other intermediate teeth ; 6-9 lateral serrations (usually 7-8), the serrations small and blunt, not strongly developed as in ruficorne, with hindmost serration lying posterior to first hypostomial seta ; hypostomial setae 5-7 in each row, the hindmost seta well separated from the other setae as in some specimens of ruficorne, setae lying parallel to lateral margin of hypostomium; distance between apex of corner tooth and first hypostomial seta distinctly less than that between corner teeth. Antenna (Text-fig. 78) very long, very lightly pigmented, first segment about 7.5 times as long as broad, segment length ratios $7 \cdot 6: 9: 6 \cdot 6$. Mandible of typical form, posterior serration present, very small (Text-fig. 98), second comb tooth as long as or very slightly longer than third, much smaller than first. Maxillary palp unusually long, about 3.8 times as long as breadth at base (Text-fig. I24). Cephalic fan with 5I-60 rays (cf. ruficorne), usually 53-56.

Thorax. Greyish-white with only very faint darker marking; cuticle bare. Proleg circlet with about 30 rows of 6-Io hooks; lateral plate lightly pigmented, with about I3-I6 processes. Pupal respiratory histoblast with 4 long wrinkled tubular filaments, longer and more coiled than in ruficorne, with the apices directed caudad (Text-fig. I82).

Abdomen. Shaped as in Text-fig. 7 ; pale grey or greyish-white, with only faintly 


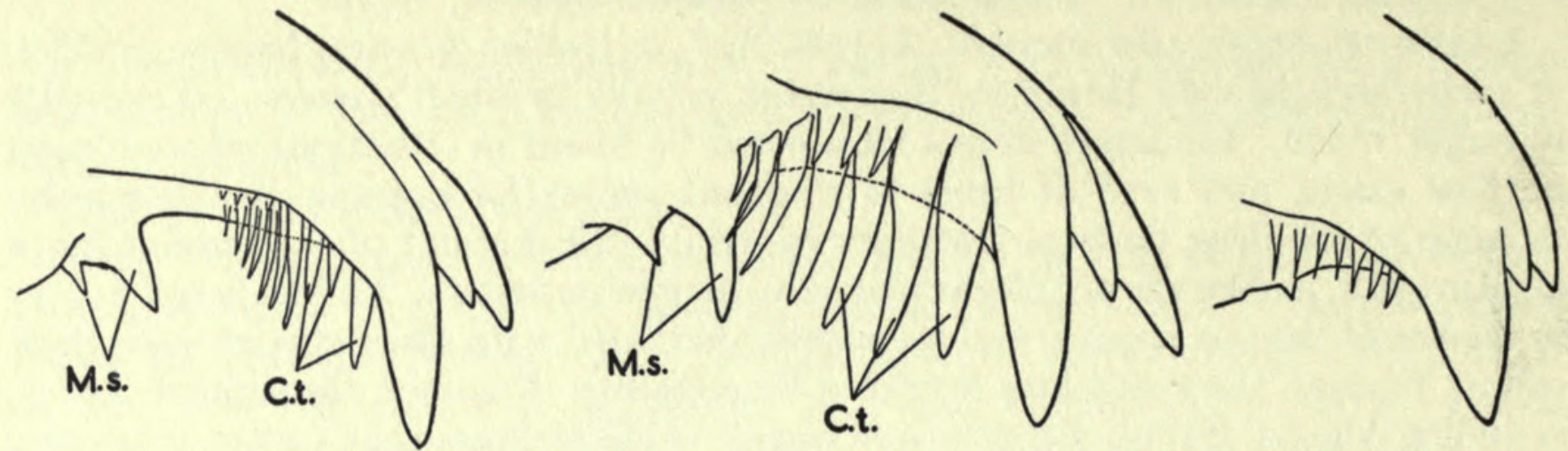

112

113

114
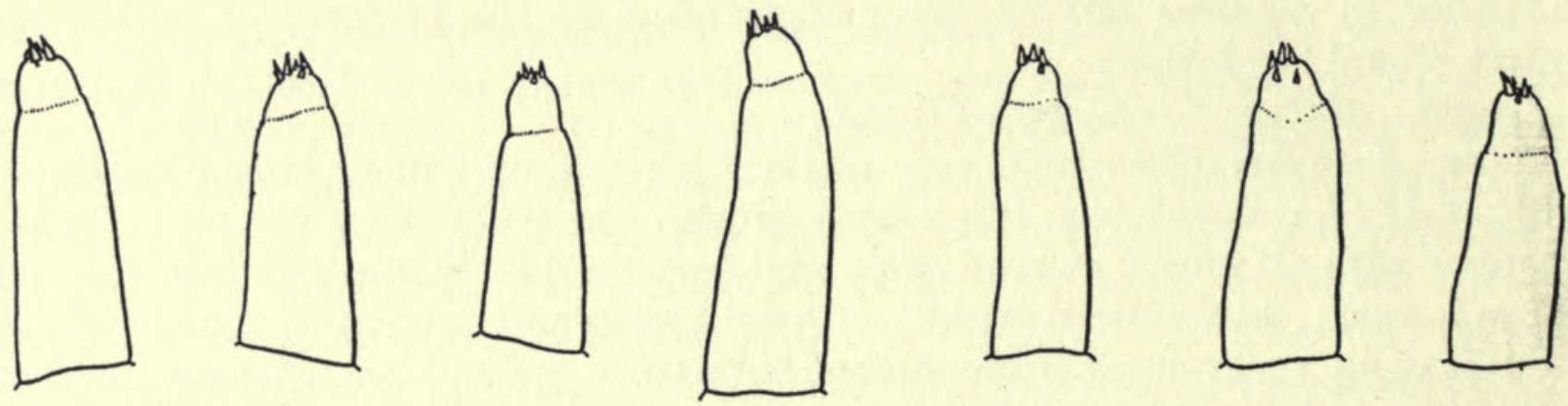

115
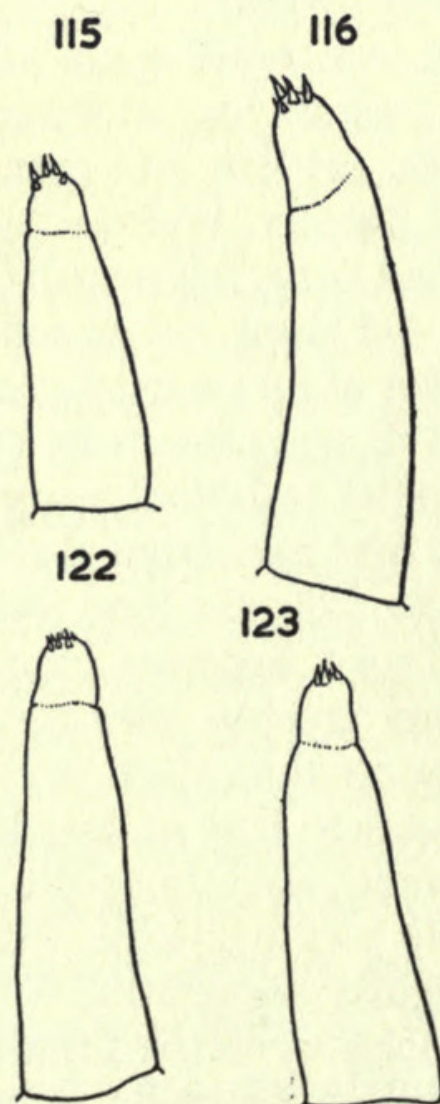

123

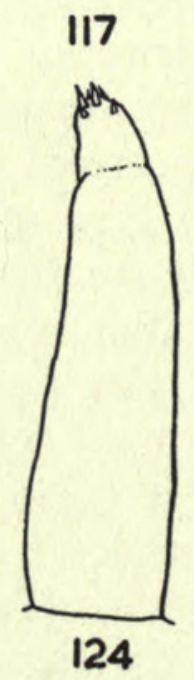

118

119

120

I2I
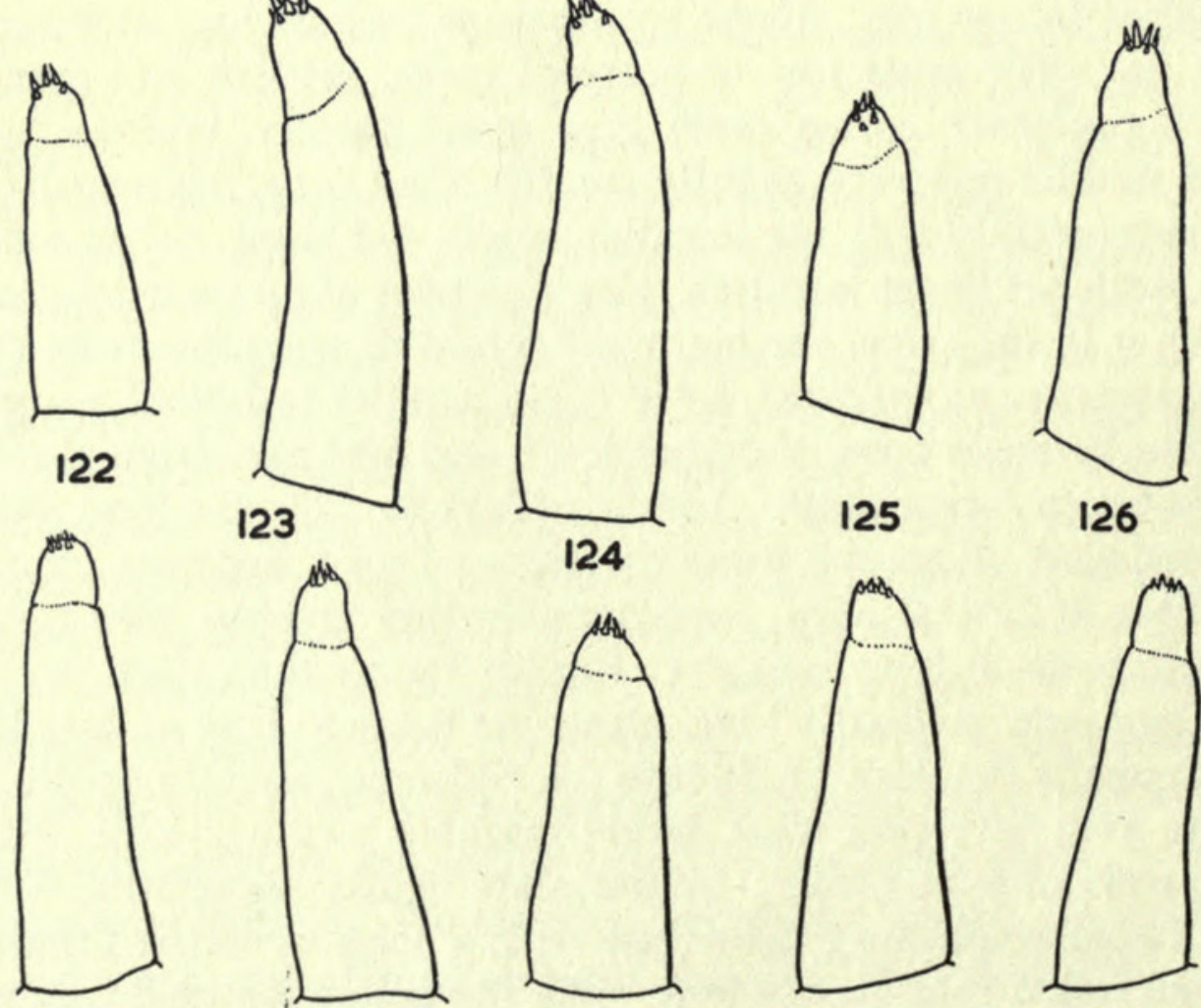

125

126
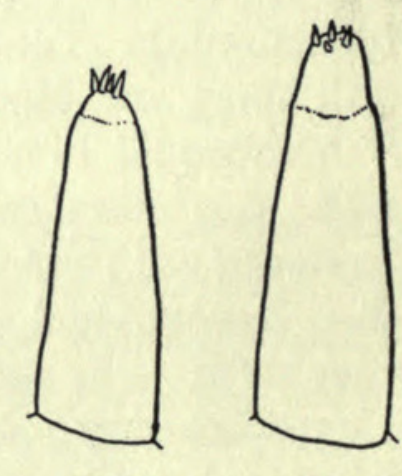

127

128
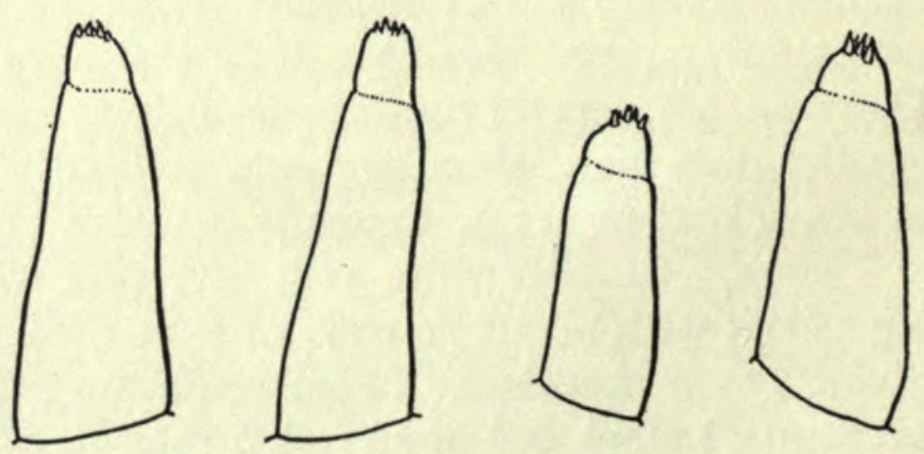

129

130

|3|

132

133

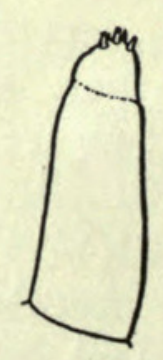

134 
indicated darker segmental mottling so that the whole body appears pale grey, milky-white ventro-apically; ventral nerve-cord grey, very distinct. Ventral papillae present, large and rather pointed. Cuticle apparently completely bare, without scales or spines, but with a few minute colourless hairs postero-dorsally particularly near the anal sclerite (as in ruficorne, Text-fig. I44). Last abdominal segment laterally just anterior to posterior circlet often (but not in all specimens) with very small dark sclerotizations, three or four in number lying one above the other (as in some specimens of damnosum), the sclerotizations not combined into such a definitive sclerite as in unicornutum. Rectal scales present. Rectal gills with numerous finger-like secondary lobules, 8-Io in median lobe and I0-I2 in each lateral lobe. Anal sclerite of usual form, strongly sclerotized, posterior arm extending to I2th-I4th row of hooks. Posterior circlet with about 72 rows of I0-I3 hooks.

Material EXAmined. From Northern Nigeria (personally collected at Kaduna and Zaria). The above description is based on this material. Freeman \& de Meillon (I953) have synonymized brachium Gibbins and simplex Gibbins with aureosimile Pom.: I have examined Gibbins' larvae (spirit material of brachium and 7 slides of simplex) and they show certain differences from the Nigerian material. The size is larger, length of mature larvae $7-8 \mathrm{~mm}$., colour apparently darker grey (possibly discoloured), the cephalic fans have only 3I-40 rays in mature larvae, and the anal gills are less complex, with $4-6$ short secondary lobules per lobe ; the gills in one specimen have however Io lobules, but the gills are of course frequently very variable. Other characters, including the head markings, hypostomium, elongate maxillary palp, respiratory histoblast, etc. are identical with those of the Nigerian aureosimile. The differences mentioned probably lie within the natural variability of aureosimile and I think Gibbins' Uganda material and the Nigerian material may safely be regarded as conspecific.

LARVAL HABITAT AND RANGE. Larvae are found principally in swiftly-flowing, broken water, in small rivers and streams particularly where the water flows over boulders ; larvae often occur in very large masses attached to grasses and stones. At Zaria, Northern Nigeria, larvae were found on the boulders laid down in a river as a vehicle-ford ; in these artificially turbulent conditions aureosimile immature stages occurred in company with those of medusaeforme and damnosum. Known from many parts of Tropical Africa from Guinea to Nyasaland, but in South Africa its place is taken by the closely related nigritarsis Coquillet.

Figs. II2-I35. (II2-II4) Apex of mandible of (II2) species of Division A (comb teeth small and second comb tooth usually shorter than first and third comb teeth) ; (II3) most species of Division B (comb teeth large in an even row), drawn from S. vorax ; (I I4) $S$. berneri (comb teeth and serrations very reduced). (II5-I35) Maxillary palp of (II5) S. alcocki; (II6) S. johannae; (II7) S. schoutedeni ; (II8) S. impukane ; (II9) S. momahoni ; (120) S. kenyae; (I2I) S. cervicornutum; (I22) S. unicornutum; (I23) S.ruficorne ; (124) S. aureosimile; (125) S. hirsutum; (126) S. adersi ; (127) S. berneri; (128) S. griseicolle; (129) S. dentulosum; (г3о) S. loutetense; (г31) S. medusaeforme hargreavesi; (132) S. vorax; (133) S. colas-belcouri ; (134) S. bovis ; (135) S. damnosum. $M . s,=$ mandibular serrations ; C.t. $=$ comb teeth. 


\section{Simulium hirsutum Pomeroy}

Type form. Closely similar to adersi, and difficult to distinguish reliably; in the limited material seen the hypostomial teeth are weaker, the maxillary palp shorter and the antenna longer than in adersi, and the head capsule is devoid of even faint pigmentation. These differences may not be constant.

Length. Mature larva, 5-5.5 mm.

Head. Head capsule pale yellow or creamy-yellow, without pigmentation in material seen but a weak negative pattern similar to that in adersi probably occurs in some specimens. Postgenal cleft large and rounded, similar to adersi (Text-fig. $38)$, very slightly angulate apically; postgenal bridge a little shorter than hypostomium. Hypostomium (Text-fig. 58) with usual row of 9 apical teeth, median and corner teeth little developed, less prominent than in adersi, intermediate teeth subequal in size forming a more or less even row ; 5-6 small lateral serrations, with hindmost serration lying on level with or a little anterior to first hypostomial seta ; hypostomial setae 4 in each row, lying parallel to lateral margin of hypostomium; distance between apex of corner tooth and first hypostomial seta subequal to or a little less than that between corner teeth. Antenna (Text-fig. 80) long, very lightly pigmented, first segment about $7 \cdot 5$ times as long as broad, segment length ratios I2.3 : II : II. Mandible of typical form, posterior serration present, small (Text-fig. IOI), second comb tooth much smaller than first and subequal in size to third. Maxillary palp short, about 2.8 times as long as breadth at base (Text-fig. I25). Cephalic fan with about $30-34$ rays.

Thorax. Pale yellowish-white with only faint traces of darker marking; cuticle bare. Proleg circlet with (?) about 30 rows of 6-Io hooks; lateral plate almost unpigmented, with about I5 processes. Pupal respiratory histoblast with 8 long thin tightly coiled filaments arising in three pairs, two filaments dividing again more apically ; shape of "gill-spot" (Text-fig. I83) less regularly oval than in adersi.

Abdomen. Shaped as in Text-fig. 7; pale yellowish-white with little trace of darker segmental mottling, milky-white ventro-apically (Gibbins (I936) gives general colour pale grey). Ventral papillae present. Cuticle of posterior segments dorsally with small scattered simple setae (Text-fig. I45). Rectal scales present. Rectal gills seen only in single specimen in which the median lobe is simple and each lateral lobe bears one small thumb-like secondary lobule (the specimen figured by Gibbins (I936)), but gills are probably somewhat variable as in most species. Anal sclerite of usual form, strongly sclerotized but not in the median line, posterior arm extending to about I2th or I3th row of hooks. Posterior circlet with about 76-80 rows of 8-I5 hooks (Gibbins gives about I04 rows but there are fewer than this in his slide material in B.M. collection).

Material examined. Only two larvae in poor condition together with some fragments from Uganda have been available for study, and no West African material has been seen. These larvae were Gibbins' material, one in spirit and the other with the fragments on slides ; remounts have been made where necessary, but it should be noted that the above description has been drawn up from limited and imperfect material, and that slight discrepancies may appear when larvae from West Africa are known. 
LARVAL HABITAT AND RANGE. Immature stages are found on trailing grasses and stones, principally in broken swiftly-flowing water in streams. Gibbins (I936) records the larvae living under cascades in association with cervicornutum. In Nigeria I have found the pupae amongst those of kenyae in turbulent rocky streams. Widely distributed in the Ethiopian Region from Sierra Leone to Natal.

\section{Simulium adersi Pomeroy}

Length. Mature larva, 4.5-5 mm. $(5 \cdot 5-6 \mathrm{~mm}$. in larvae from Nsadzi Island, Lake Victoria ; Gibbins' material described in Gibbins (I934)).

Head. Head capsule creamy-yellow, pale yellow or fulvous with negative pattern, the cephalic apotome with a yellow-brown $\mathrm{H}$-shaped or lyre-shaped pigmented area (Text-fig. 2I), pale postero-median head-spots usually distinct but other headspots not clearly defined; lateral areas of the head unpigmented, or with the usual 3-shaped pigmented area behind the eye-spots (Text-fig. 2I). Postgenal cleft large and subcircular or very slightly cordate (Text-fig. 38), not perfectly rounded apically but with trace of widely obtuse angle; postgenal bridge distinctly shorter than hypostomium. Hypostomium (Text-fig. 57) with usual row of 9 apical teeth, median and corner teeth strongly prominent, intermediate teeth well developed subequal in size or with median one slightly smaller than the others ; 5-8 lateral serrations (usually 7), the serrations often strong and the strongly sclerotized anterior serration sometimes very strongly developed and directed slightly outwards, hindmost serration lying posterior to or level with first hypostomial seta; hypostomial setae 3-5 (usually 4) in each row, lying parallel to lateral margin of hypostomium ; distance between apex of corner tooth and first hypostomial seta slightly less than that between corner teeth. Antenna (Text-fig. 79) of moderate length (only slightly longer than stem of cephalic fan), very lightly pigmented, first segment about 6 times as long as broad, segment length ratios $8:$ Io : 10.3. Mandible of typical form, posterior serration present, small (Text-fig. I04), second comb tooth much smaller than first, about equal in size to third, first comb tooth very enlarged in some specimens seen. Maxillary palp long, about $3 \cdot \mathrm{I}$ times as long as breadth at base (Text-fig. I26). Cephalic fan with 38-47 rays, usually about 44 (Gibbins (I934) gives 28-32, but examination of his Nsadzi, Lake Victoria, material shows that mature larvae have $38-4 \mathrm{I}$ rays).

Thorax. Greyish or pale yellowish-white with pale greyish-brown marking; cuticle bare. Proleg circlet with about 25 rows of 4-7 hooks; lateral plate unpigmented, with about I5 processes. Pupal respiratory histoblast with II long thin tightly coiled filaments, outline of the organ sub-oval (Text-fig. I84).

Abdomen. Shaped as in Text-fig. 7; greyish or yellowish-white with darker brownish segmental mottling, sometimes faint, milky-white ventro-apically. Ventral papillae present, small (Text-fig. I57) and sometimes difficult to see (papillae are absent in Gibbins' material from Nsadzi Island). Cuticle of posterior segments dorsally with very numerous small simple setae, the setae slightly broadened at the centre, black and strongly sclerotized basally but clear apically (Text-fig. I46). Rectal scales present. Rectal gills with several finger-like secondary lobules in each lobe, but only seen fully extruded in one specimen in which the median lobe 
136
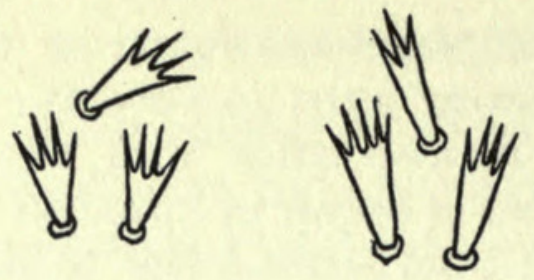

SIMULIIDAE

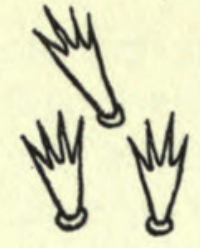

137

138

139

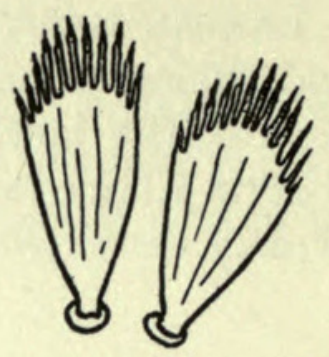

140
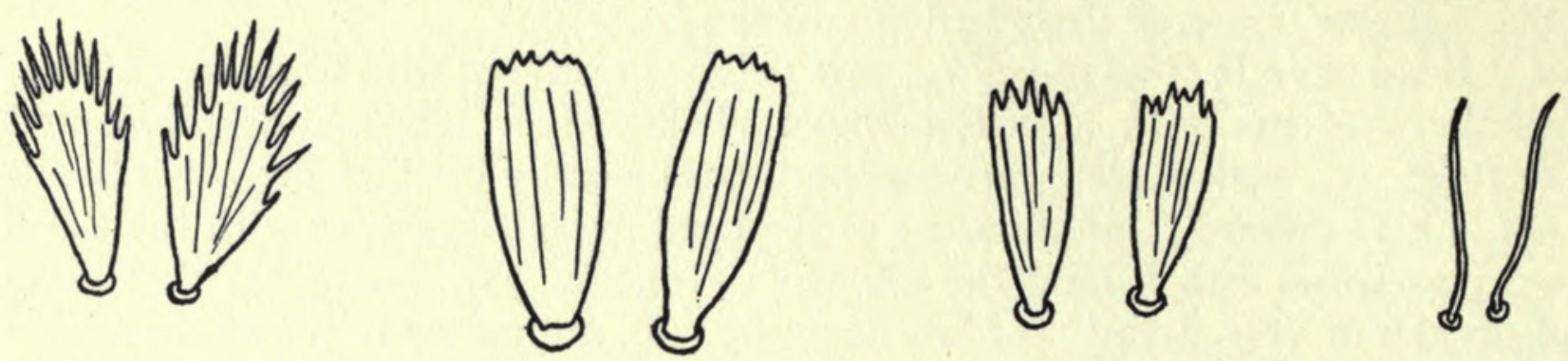

141

142

143

144

1

145

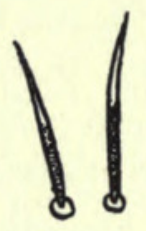

146

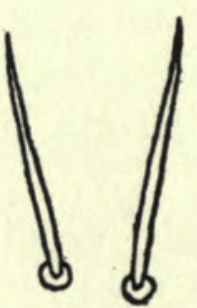

151

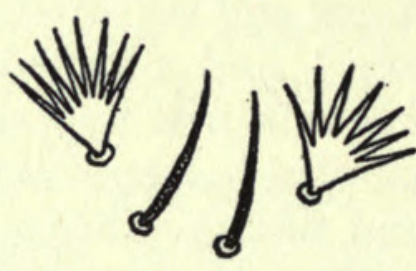

147

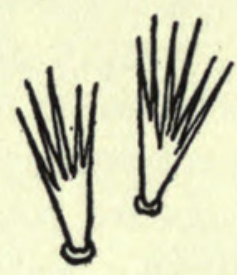

148

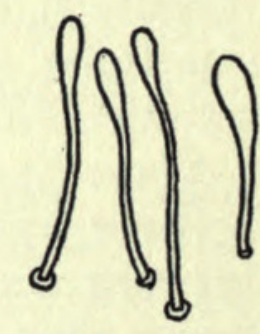

149

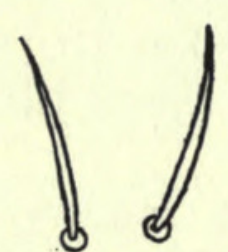

150

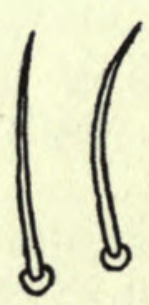

152
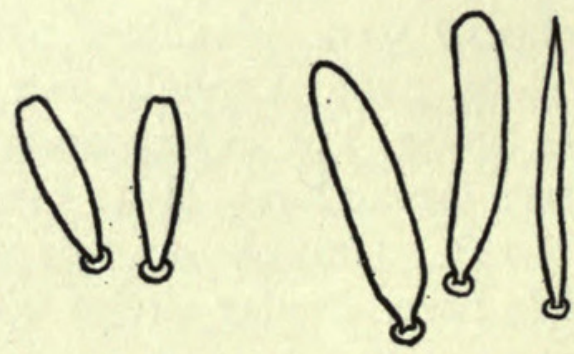

154

FIGS. I36-I54. Setae or scales of abdominal cuticle of (136) S. alcocki; (137) S. johannae; (I38) S. impukane; (I39) S. kenyae; (I40) S. schoutedeni; (I4I) S. momahoni; (I42) S. cervicornutum; (I43) S. unicornutum; (I44) S. ruficorne, few setae of kind shown present only around anal sclerite, as also in aureosimile; (I45) S. hirsutum; (I46) S. adersi; (I47) S. griseicolle; (I48) S. griseicolle, scales on area of anal sclerite; (I49) S. berneri, short broad seta illustrated on right is the form seen on dorsum of thorax; (I50) S. medusaeforme ; (I5I) S. vorax ; (I52) S. colas-belcouri, (I53) S. bovis ; (I54) $S$. damnosum, narrow pointed scale is the form seen on proleg. 
has 7 lobules and each lateral lobe 8 lobules. Anal sclerite of usual form (Text-fig. I64), strongly sclerotized, anterior arms sometimes a little shorter and posterior arms a little broader than usual, posterior arm extending to about IIth-I3th row of hooks. Posterior circlet with about $69-75$ rows of 9-I5 hooks (Gibbins (I934) gives about I20 rows of I9-25 hooks in his description of the larva from Nsadzi Island).

Material Examined. From Northern Nigeria, Sudan and Nyasaland; the description above is based on the Nigerian material. I have also examined Gibbins' slides and spirit material of adersi collected by him from the rocky shore of Nsadzi Island, Lake Victoria (see his I934 paper, p. 6I) and the larvae from this locality differ in several important respects from those of other areas. The larvae from Nsadzi are very large, the head capsule is very heavily pigmented, the hypostomial teeth are rather blunt, ventral papillae are absent, and the posterior circlet has a very large number of rows of hooks: the form of the postgenal cleft, the II-filamented pupal respiratory histoblast, the simple abdominal setae, and other characters however are the same as those of adersi larvae from elsewhere. The larvae from Nsadzi are undoubtedly correctly associated with the pupae and adults from the same area (material in B.M. collection), and the structure of the pupa and male genitalia appears to be identical with adersi from other parts of Africa ; however the absence of ventral papillae and large size give a very different impression from adersi larvae as known from elsewhere, and it is possible that a pair of sibling species exists. The high number of hooklet rows in the posterior circlet is perhaps a local adaptation to the unusual environment on Nsadzi Island where the larvae are subjected to wave action on an exposed rocky headland.

LARVAL HABITAT AND RANGE. Larvae tolerate very widely differing conditions and occur in large rivers as well as very small streams, both in slow water and in swift rapids, attached to grasses, leaves, sticks, corn-stalks, rocks and pebbles; in large rivers, especially in semi-arid areas such as the far north of Nigeria, adersi often occurs in large numbers unassociated with other species or occasionally in company with damnosum ; in smaller streams it is also frequently found without other species but may occur with medusaeforme. At Man o' War Bay near Victoria in the Cameroons immature stages have been found on herbage attached to the piles of a wharf in brackish water where a small stream discharges into the sea. Widely distributed over most of the Ethiopian Region.

\section{Simulium berneri Freeman}

A remarkable species easily distinguished from all other known Ethiopian species by the form of the hypostomium (Text-fig. 68).

Length. Approximately $6 \mathrm{~mm}$.

Head. Head capsule unusually long with traces of transverse wrinkling on the dorsum, eye-spots very small; without definite pattern, rather evenly pigmented yellow-brown with slightly more intense pigmentation medially on cephalic apotome. Postgenal cleft absent (Text-fig. 39), the ventral surface of the head capsule completely sclerotized or with only faint traces of a postgenal cleft, the postgenal bridge 
therefore very long and reaching the hind margin of the head. Hypostomium (Text-fig. 68) of extraordinary form, very heavily sclerotized apically with a large deeply sunk median tooth and 5 subequal blunt outwardly-curving teeth on either side ; lateral margins of median tooth slightly serrate ; lateral margins of hypostomium behind apical teeth smooth, non-serrate; hypostomial setae very long and fine, 4-5 in each row, lying subparallel to lateral margin of hypostomium. Antenna (Text-fig. 8I) short, lightly pigmented, first segment about 5 times as long as broad, segment length ratios approximately $5: 6.4: 6$ (specimens seen are not completely matured and proportions in fully mature larvae may be slightly different). Mandible of unusual form (Text-fig. $90 b$ ) with the basal area of the large apical tooth very broad and the comb teeth very reduced (Text-fig. II4) ; serrations also very reduced, a small anterior serration present but posterior serration absent or possibly represented by a slight irregularity in the edge of the mandible (Text-fig. I07). Maxillary palp about 2.8 times as long as breadth at base (Text-fig. I27). Cephalic fan with 50 and 52 rays in almost mature specimen seen, rays narrower than in most species.

Thorax. Pale grey or greyish-yellow, without darker marking; cuticle including that of proleg closely covered with pale elongate slightly clubbed hairs (Text-fig. I49), those on the dorsum shorter and more strongly spatulate than the other hairs. Proleg circlet with numerous hooks (invaginated and not possible to count in material seen). Pupal respiratory histoblast not seen, presumably with 38 very thin sinuous filaments, probably tightly coiled and arising near the base.

Abdomen. With the segmentation unusually clearly marked and the terminal segments distinctly demarcated from anterior segments; pale grey or greyishyellow, evenly coloured without darker segmental mottling. Ventral papillae absent. Entire cuticle densely covered with almost colourless long thin slightly clubbed hairs, sinuous and apparently very flexible, the alveoli very small but clearly present so that the hairs are modified macrotrichia. Rectal scales not seen, apparently absent. Rectal gills with several secondary lobules, one specimen seen with 8 finger-like secondary lobules in the median lobe, and 6 and 7 lobules on the lateral lobes. Anal sclerite unusual, arms very long and narrow only strongly sclerotized along the centre of each arm (Text-fig. I66), anterior arms rather strongly directed forwards, and in lateral view curved and slightly hook-like, posterior arm extending to about 26th-28th row of hooks; position of anal sclerite distinctly postero-dorsal, not dorsal, so that it lies terminally on the abdomen with the posterior circlet occupying a ventro-apical position instead of the usual strictly apical position. Posterior circlet with about 96 rows of I4-2I hooks.

Material examined. Paratype larvae from Ghana.

LARVAL HABITAT AND RANGE. This is a striking and remarkable species in which the larvae and pupae live attached to mayfly nymphs of the genus Elassoneuria; several of the larval characters closely resemble those of $S$. copleyi Gibbins and $S$. lumbwanus de Meillon in which the larvae are also found on mayfly nymphs. The head-capsule is elongate with traces of transverse wrinkling on the dorsum, the eye-spots are very reduced, the body segmentation is very distinct, and the posterior circlet occupies an oblique position ventro-posteriorly with the unusual anal sclerite in a terminal position. Some of these characteristics are no doubt 


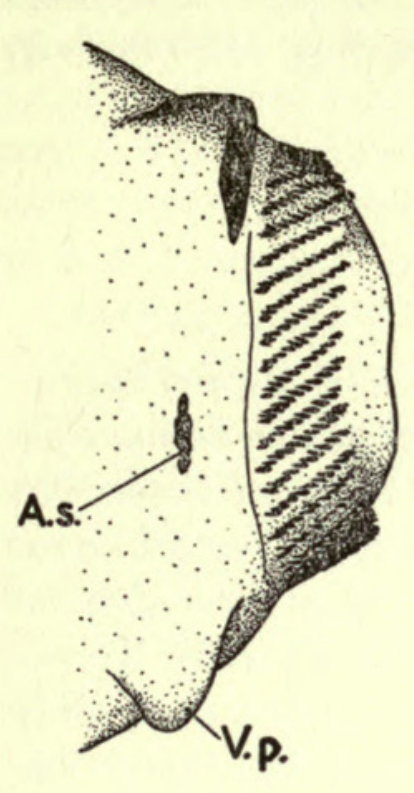

155

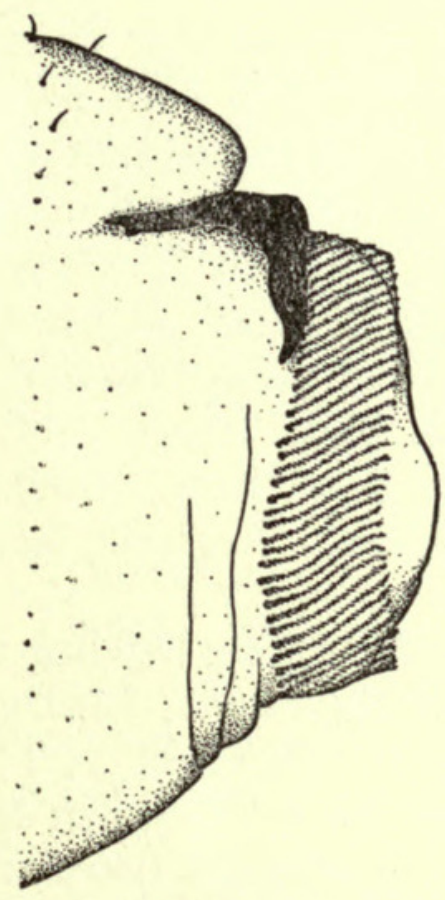

158

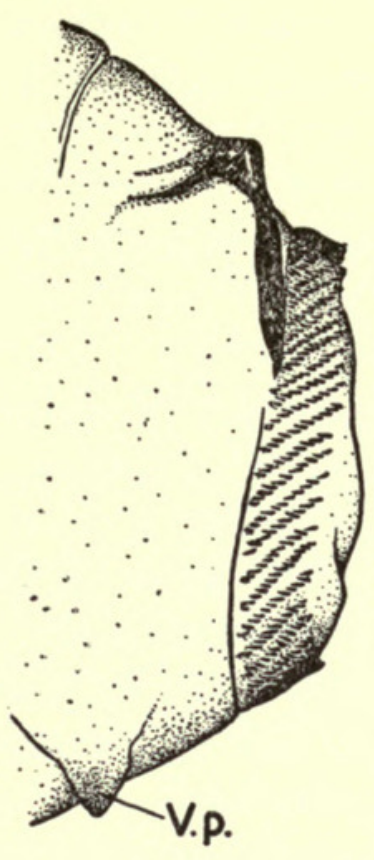

156

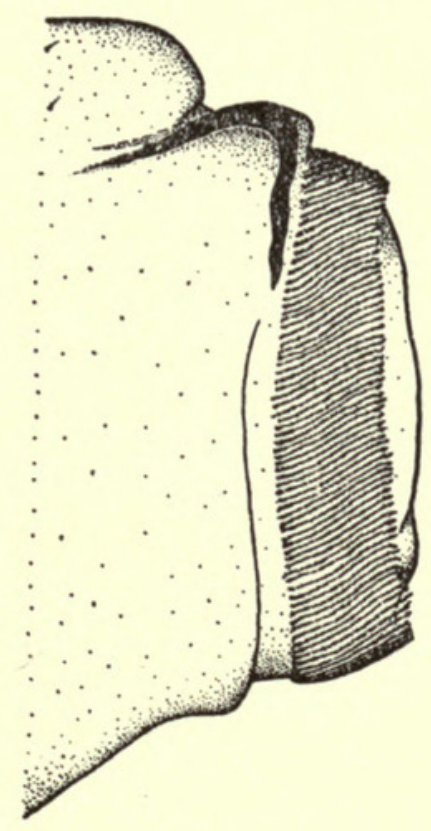

159

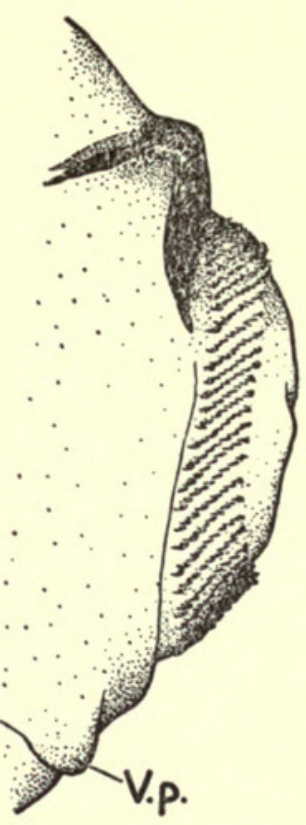

157

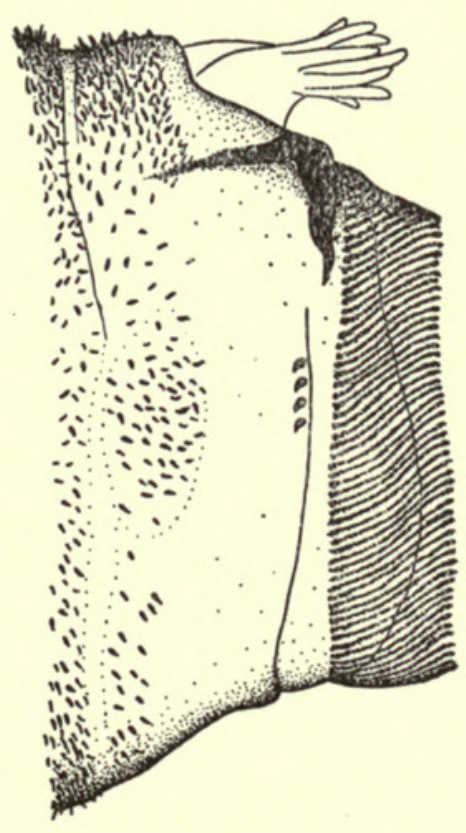

160

FIGS. I55-I60. Lateral view of terminal abdominal structures : I55-I 57, Division A species with ventral papillae and few rows of circlet hooks (I55) S. unicornutum; (I56) S. ruficorne; (I 57) S. adersi, ventral papilla small. I58-160, Division B species without ventral papillae and with very numerous rows of circlet hooks (158) S. medusaeforme; (I59) S. vorax; (I6o) S. damnosum. A.c. = accessory sclerite ; V.p. $=$ ventral papilla. 
adaptations to the specialized environment provided by the association with the mayfly nymphs, and are also found in the East African species (neavei-complex) which occur on crabs. At present $S$. berneri is known only from Ghana and Cameroons Republic, but it almost certainly exists in Nigeria also, and possibly elsewhere in West Africa.

Type form.

\section{Simulium griseicolle Becker}

Length. Mature larva, 4-4.25 mm.

Head. Head capsule pale, milky-white to creamy-yellow, without pigmentation. Postgenal cleft very large and subcircular (Text-fig. 40), similar in shape to damnosum; postgenal bridge short, distinctly shorter than hypostomium; in some specimens the edges of the postgenal cleft are difficult to distinguish from the white membranous area filling the cleft, so that in spirit material the cleft may appear at first sight as though it is very reduced or absent and careful examination may be required. Hypostomium (Text-fig. 60) with usual row of 9 apical teeth, median and corner teeth strongly developed and rather prominent, intermediate teeth well developed and subequal in size; anterior part of hypostomium back to second lateral serration rather strongly set off from rest of hypostomium ; 5-6 lateral serrations, hindmost serration weak, and anterior two serrations strongly developed and set off more clearly from the others than usual; hindmost serration lying just posterior to or level with first hypostomial seta; hypostomial setae 3-4 (usually 3) in each row, setae fine, lying subparallel to or slightly diverging posteriorly from lateral margin of hypostomium; distance between apex of corner tooth and first hypostomial seta subequal to or a little less than that between corner teeth. Antenna (Text-fig. 82) short, unpigmented, first segment about $5 \cdot 5-6$ times as long as broad, segment length ratios $5: 5 \cdot 6: 5$. Mandible of typical form, only a single serration (Text-fig. IIO), the posterior serration absent or represented only by a slight irregularity, second comb tooth almost as large as first and about equal in length to third. Maxillary palp about 3 times as long as breadth at base (Text-fig. I28). Cephalic fan with $26-34$ rays.

Thorax. Milky or yellowish-white with very pale yellowish-brown darker banding ; cuticle dorsally and dorso-laterally closely covered with abundant setae, mostly simple, but with an admixture of a few compound fan-shaped setae (Text-fig. I47); cuticle ventrally and on proleg bare. Proleg normal (as pointed out by Freeman \& de Meillon (I953), Gibbins (I935) was mistaken in stating that the proleg is peculiar with the circlet borne on a protuberance), circlet with approximately I7-20 rows of 3-6 hooks ; lateral plate unpigmented, with about I2 processes. Pupal respiratory histoblast with 3 flattened strongly wrinkled lobes, the median lobe lying inside the others with only the apex visible on external examination of the " gill-spot " (Textfig. I85).

Abdomen. Shaped as in Text-fig. 7; milky or yellowish-white with darker yellowish-grey or very pale brownish segmental mottling, white ventro-apically. Ventral papillae absent. Cuticle closely covered, principally on the dorsum, with short simple setae and compound fan-shaped setae (Text-fig. I47), the fan-like 
scales sometimes very numerous on posterior segments, but sometimes restricted to last segment; anterior segments usually without or with only a few fan setae but with abundant simple setae; fan setae present on cuticle of apical surface enclosed by posterior circlet. Rectal scales present, but weakly sclerotized and difficult to see. Rectal gills with several finger-like secondary lobules, 4-8 in median lobe and 5-8 in each lateral lobe. Anal sclerite of usual form, strongly sclerotized, anterior arms short and broad basally and median area rather broad, posterior arm extending to about Ioth row of hooks. Posterior circlet with about 66 rows of 9-I4 hooks.

Material EXAMined. From Northern Nigeria and Sudan.

LARVAL HABITAT AND RANGE. Larvae are found, often in large numbers, on sticks, dead grasses, sedge, corn-stalks, fish-traps and even on hard mud in smooth or only slightly broken but swift water. S. griseicolle favours very large rivers, such as the Nile and Niger, but breeding occurs also in smaller rivers, and in Northern Nigeria I have collected larvae in company with those of bovis and adersi in these smaller rivers and in company with damnosum in the Niger. The typical form ranges from Egypt and Sudan westwards to Northern Nigeria and south to the Congo and Uganda.

\section{Simulium griseicolle form tridens Freeman \& de Meillon}

Larvae of this form are almost identical with the type form, but the fan-like scales are fewer in the material seen and restricted to the last abdominal segment ; some very large fan-like well sclerotized scales near anal sclerite (Text-fig. I48); in the pupal respiratory histoblast the innermost (median) of the 3 lobes is not externally visible (Text-fig. I86).

Material examined. From Northern Nigeria.

LARVAL HABITAT AND RANGE. Larvae occur in similar situations to those of the type form. Form tridens appears to be mainly West African (Nigeria and Ghana) but is known also from Nyasaland.

\section{Simulium dentulosum Roubaud}

Type form.

Length. Mature larva, 9-10.5 mm.

Head. Head capsule evenly suffused yellowish-brown with only small clear pale areas around eye-spots, narrow eye-brow stripes, and antero-laterally on cephalic apotome, but with a very distinct positive pattern in addition to general pigmentation (Text-fig. 22) ; pattern of cephalic apotome comprises very distinct brown antero-median and antero-lateral head-spots, less distinct postero-lateral and posteromedian spots, the latter groups surrounded by dark suffusions on median and postero-lateral areas of cephalic apotome ; sides of head capsule with less distinct spots, but row of three small spots below and behind eye-spots and two large dark areas against the post-occiput usually distinguishable from general pigmentation. Lateral arms of cleavage line strongly convergent anteriorly so that cephalic apotome is a little more triangular in form than usual. Postgenal cleft very small, in some specimens almost absent, broader than long and truncate anteriorly (Text-fig. 4I), or sometimes subtriangular and pointed apically (as figured by Grenier \& Ovazza 
(I956)) ; postgenal bridge very long, almost twice as long as hypostomium. Hypostomium (Text-fig. 6I) with usual row of 9 apical teeth, median tooth slightly prominent, corner teeth broad and blunt, middle one of intermediate teeth slightly smaller than other intermediate teeth; 8-II lateral serrations, the first 2 or 3 strongly sclerotized and lying behind corner teeth in usual way, other serrations small and blunt, formed only by slight incisions into antero-lateral margin of hypostomium, hindmost serration lying about level with or a little posterior to first hypostomial seta ; hypostomial setae very numerous, but variable, I2-I8 in each row, hindmost setae usually lying irregularly ; setal rows diverging posteriorly from lateral margins of hypostomium, lateral areas of hypostomium outside the setae unusually broad ; distance between apex of corner tooth and first hypostomial seta about two-thirds of that between corner teeth. Antenna (Text-fig. 84) long, first and third segments strongly pigmented dark brown, apex of second segment lightly pigmented, first segment about 6-6.5 times as long as broad but distinctly tapering apically, second segment long, segment length ratios $7 \cdot 6:$ ro $: 5$. Mandible unusually broad with the outer margin strongly arched (Text-fig. 9oc), posterior serration present, small, anterior serration broad basally as in most species (Text-fig. 93), not elongate as in vorax, comb teeth forming a fairly even row, the second comb tooth only slightly smaller than first. Maxillary palp long, about $3 \cdot 3-3.4$ times as long as breadth at base (Text-fig. I29). Cephalic fan with $54-70$ rays.

Thorax. Fairly evenly dark grey or grey-black in not fully mature larvae, but mature larvae milky-white dorsally and laterally behind pupal respiratory histoblast ; cuticle bare. Proleg circlet with about $40-50$ rows of $8-\mathrm{I}_{3}$ hooks; lateral plate pigmented yellow-brown, with about $24-26$ processes. Pupal respiratory histoblast (Text-fig. I87) with I4 tubular filaments, the filaments with black pointed tips mostly directed caudad.

Abdomen. Shaped as in vorax (Text-fig. Io), the segments gradually increasing in size to widest point and then contracting rather sharply to the posterior circlet ; first 2 segments generally dark grey or blackish, other segments dark grey or greyblack above but milky-white ventrally and ventro-laterally; ventral nerve-cord distinct, dark grey. Ventral papillae absent. Cuticle apparently bare, without scales or setae, but with minute pale hairs (? microtrichia) dorsally, particularly on terminal segments and near anal sclerite. Faint traces of lateral sclerotization present just anterior to posterior circlet. Rectal scales present, very numerous. Rectal gills with 7-II finger-like secondary lobules in each lobe, usually about 8 and median lobe usually with same number as lateral lobes; some mature specimens with only 5-6 lobules in each lobe, in which case one lobule is much larger than the others. Anal sclerite (Text-fig. I67) of usual form, strongly sclerotized, anterior arms with broad flange-like sclerotized areas posteriorly especially near the base, posterior arm extending to about $37^{\text {th }}$-40th row of hooks, and a small median sclerotized extension present posteriorly. Posterior circlet with about 220 rows of 24-39 hooks, most rows with 26-33 hooks (Gibbins (I934) gives 50-60 hooks per row but I have not seen this many even in Gibbins' own material).

Material examined. From Nyasaland, Uganda and Ruanda Urundi. No West African material has been seen, and $S$. dentulosum is at present only known from 


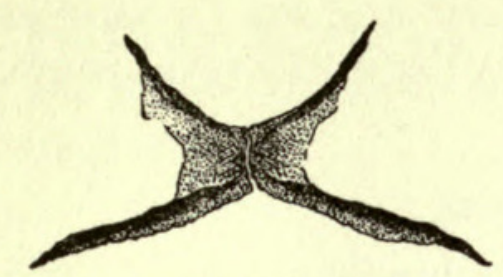

161

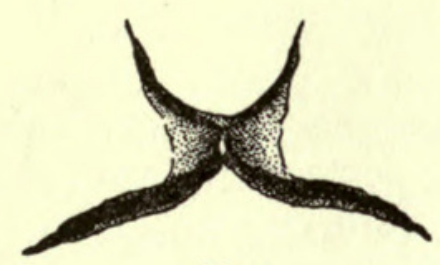

164

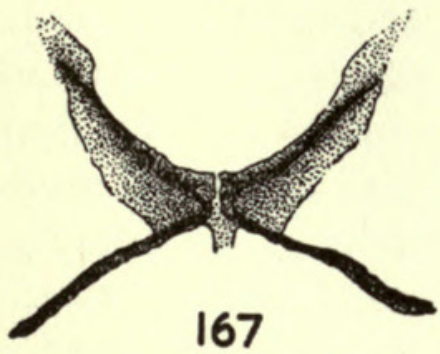

167

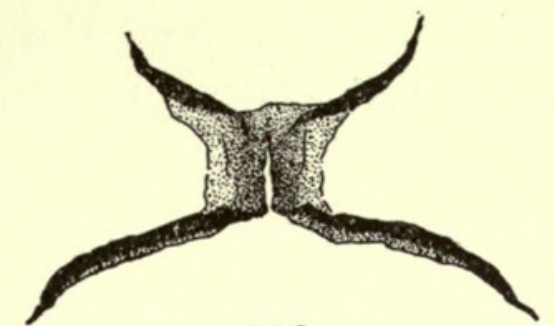

162

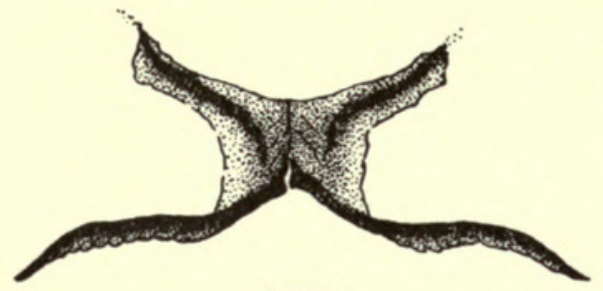

165

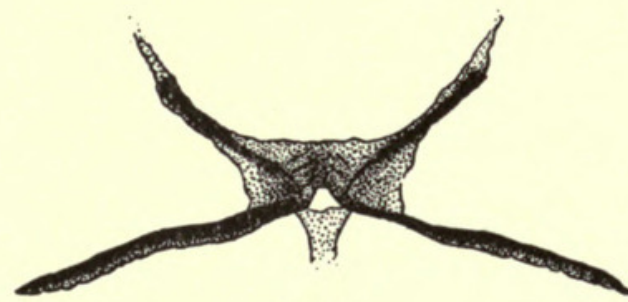

168

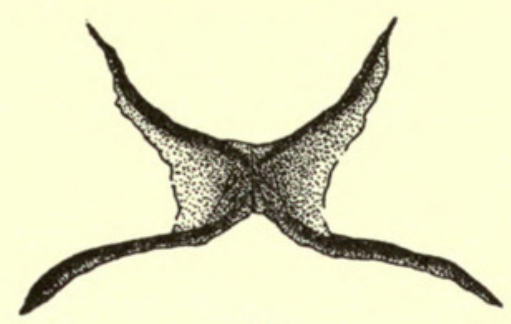

163

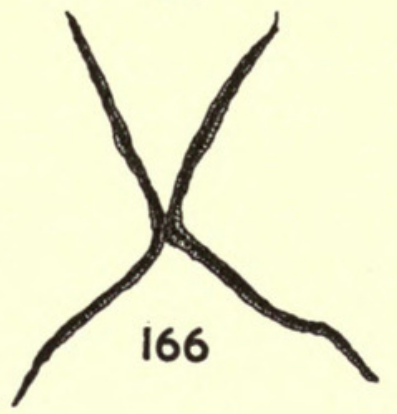

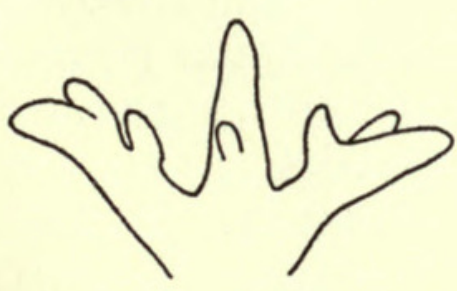

170

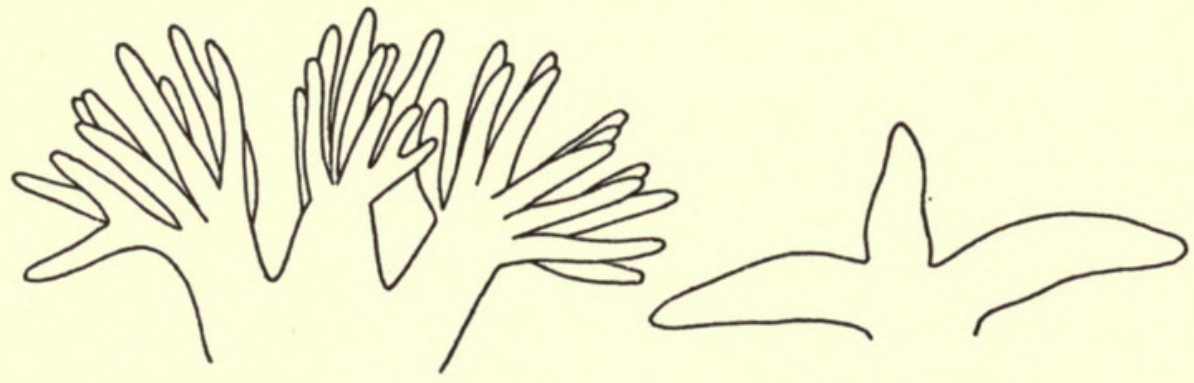

171

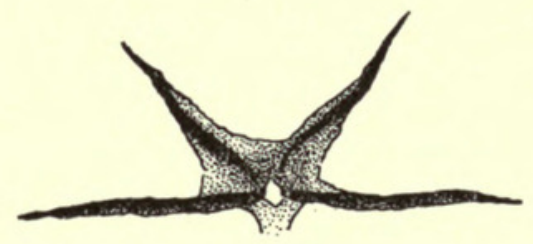

169

Figs. I6I-I72. (I6I-I69) Anal sclerite of (I6I) S. unicornutum ; (I62) S. cervicornutum ; (I63) S. impukane; (164) S. adersi; (165) S. ruficorne; (166) S. berneri; (I67) S. dentulosum; (I68) S. vorax; (I69) S. damnosum. (I70-I72) Rectal gills of (I70) larva with only a few thumb-like secondary lobules drawn from S. momahoni ; (I7I) larva with numerous long finger-like secondary lobules, drawn from S. damnosum; (I72) larva with simple trifid gill without secondary lobules, drawn from $S$. impukane.

two localities in West Africa (Bangan, Southern Cameroons, type locality of S. gilvipes Pomeroy, and Upper Volta). Gibbins' Uganda material has been examined and it may be mentioned here that his figure (Gibbins, I934) of dentulosum mandible is incorrect: as already pointed out by Freeman \& de Meillon (I953) Gibbins' drawings seem to have been made from whole mounts of larvae and consequently a distorted impression is given of some structures.

LARVAL HABITAT AND RANGE. Larvae live on grasses, sticks, stones, and rocks on the beds of streams, in very swiftly-flowing turbulent water, often in mountain 
torrents and cascades. S. dentulosum occurs from Upper Volta and the Cameroons to Abyssinia, Uganda and Kenya, and southwards as far as Cape Province, South Africa.

\section{Simulium loutetense Grenier \& Ovazza}

Only three larvae have been seen, all slide material, and it is not possible to give coloration but dark segmental mottling is evident and the head capsule is lightly pigmented, rather as in medusaeforme.

Length. Mature larva, $5.5 \mathrm{~mm}$.

Head. Head capsule probably light creamy-yellow in ground colour; with positive head pattern comprising distinct antero-median, postero-median and antero-lateral spots, without postero-lateral spots although cephalic apotome is moderately strongly pigmented in postero-lateral corners and behind posteromedian head-spots (Text-fig. 23) ; sides of head capsule with dark spots behind and below eye-spots and with pigmented suffusions posteriorly against post-occiput, postero-ventrally, and antero-dorsally above and in front of eye-brow stripe. Postgenal cleft large and mitre-shaped (Text-fig. 42), somewhat similar to that of medusaeforme; postgenal bridge short, a little shorter than hypostomium. Hypostomium (Text-fig. 62) with usual row of 9 apical teeth, median tooth moderately strongly developed, corner teeth blunt and broad basally, intermediate teeth subequal in size ; 4-7 small blunt lateral serrations, the serrations sometimes little more than rounded irregularities in margin of hypostomium, with hindmost serration lying a little anterior to first hypostomial seta; hypostomial setae 6-7 in each row, slightly diverging posteriorly from lateral margin of hypostomium ; distance between apex of corner tooth and first hypostomial seta about two-thirds of that between corner teeth. Antenna (Text-fig. 83) long, first and third segments lightly pigmented, first segment about 5 times as long as broad, segment length ratios II : I5.5: II. Mandible of typical form, posterior serration present, small (Text-fig. 96), the 3 comb teeth forming an evenly decreasing row. Maxillary palp long, about $3 \cdot 2$ times as long as breadth at base (Text-fig. I30). Cephalic fan with about 40 rays.

Thorax. Cuticle dorsally with minute colourless hairs. Proleg circlet with about 45 rows of 7-I2 hooks; lateral plate strongly pigmented, with about 22 processes. Pupal respiratory histoblast with 6 thin tightly coiled filaments arising in pairs (Text-fig. I88).

Abdomen. Shaped as in Text-fig. 6; coloration probably similar to dentulosum. Ventral papillae absent. Cuticle dorsally with minute pale hairs, long and prominent around anal sclerite, but without scales or spines. Rectal scales present. Rectal gills not seen extruded, probably with several secondary lobules to each lobe. Anal sclerite of usual form, strongly sclerotized, posterior arm extending to I7th or I8th row of hooks. Posterior circlet with 70-80 rows of I3-I6 hooks.

MATERIAL EXAMINED. Three larvae only seen (slide material) from Southern Cameroons and Sierra Leone.

LARVAL HABITAT AND RANGE. Immature stages occur on grasses and stones in swiftly-flowing turbulent water, mainly in streams; pupae have been collected in company with those of colas-belcouri. S. loutetense appears to be rare with a 
scattered distribution and is known from the Congo Republics, Sudan, Northern Rhodesia, Cameroons, Ghana and Sierra Leone ; it is not known to me from East Africa.

\section{Simulium medusaeforme form hargreavesi Gibbins}

Length. Mature larva, 5·75-7 mm., usually about $6 \mathrm{~mm}$.

Head. Head capsule creamy-white or pale yellow in ground colour with very variable yellow-brown or brown pigmentation and postive head pattern (Text-fig. 24) ; antero-median, antero-lateral, postero-median, and postero-lateral head-spots all present, but spots surrounded with dark infuscation so that the spots themselves are sometimes indistinct, postero-lateral spots sometimes almost absent; median and postero-median areas of cephalic apotome sometimes very strongly pigmented dark brown so that head-spots are almost invisible in the general infuscation; antero-lateral spots usually lying close to infuscated area between median groups of spots so that together they present a $\dagger$-like mark; sides of head with row of three dark spots below and behind eye-spots and with usual dark pigmented areas posteriorly and postero-ventrally, eye-brow stripe distinct, strongly pigmented above and in front of eye-brow stripe. Postgenal cleft large, shaped as in Text-fig. 43 ; postgenal bridge short, distinctly shorter than hypostomium. Hypostomium (Text-fig. 63) with usual row of 9 apical teeth, the teeth broad and blunt, intermediate teeth subequal and median tooth slightly prominent ; corner teeth very broad and hardly projecting beyond intermediate teeth ; 4-6 (usually 5) lateral serrations, strongly acuminate, with hindmost serration lying a little anterior to first hypostomial seta ; hypostomial setae 4-6 (usually 4) in each row, strongly diverging posteriorly from lateral edge of hypostomium; distance between apex of corner tooth and first hypostomial seta two-thirds or a little less than two-thirds of that between corner teeth. Antenna (Text-fig. 86) short, very little longer than stem of cephalic fan, very lightly pigmented, first segment about 4.5 times as long as broad, segment length ratios $5: 6 \cdot 8: 4$. Mandible of typical form, posterior serration present and moderately large (Text-fig. 99), comb teeth forming an even row of gradually decreasing size. Maxillary palp short, about 2.7 times as long as breadth at base (Text-fig. I3I). Cephalic fan with 38-45 rays.

Thorax. Milky-white with dark grey marking; cuticle bare. Proleg circlet with about 35 rows of 9-I2 hooks; lateral plate very lightly pigmented, with about I4 processes. Pupal respiratory histoblast with 6 stout wrinkled tubular filaments, the middle two arising from a common base, and numerous thin secondary filaments (Text-fig. Igo).

Abdomen. Shaped as in Text-fig. 8 ; anterior segments dark grey, other segments dark grey dorsally and milky-white ventrally; some specimens with abdomen rather evenly coloured pale grey, others brownish-grey or sometimes almost black ; ventral nerve-cord dark grey, distinct and contrasting sharply with white ventral surface. Ventral papillae absent. Cuticle dorsally on posterior segments with numerous simple setae (Text-fig. I50), the setae well sclerotized and often strongly curved. Rectal scales present, very numerous. Rectal gills with 5-8 finger-like 
secondary lobules in median lobe and 5-9 lobules in each lateral lobe, usually 6-8 in lateral lobes; in specimens with only 5 lobules one is usually larger than the others. Anal sclerite of usual form, strongly sclerotized, similar to vorax (Text-fig. I68) with slightly sclerotized median posterior projection, posterior arm extending to about 26th-30th row of hooks. Posterior circlet with about I40 rows of $18-30$ hooks. (Gibbins (I934) in his description of elgonense Gibbins-synonym of hargreavesi - gives 40-45 hooks per row but I have not seen nearly as many as this in Gibbins' slide material, or more than 30 hooks per row in any of the material examined.)

Material examined. From Northern Nigeria, Sudan, S. Rhodesia and Uganda (including Gibbins' slides of hargreavesi and elgonense).

LARVAL HABITAT AND RANGE. Larvae are found in both large rivers and small streams, often in enormous numbers, attached to trailing grasses, dead leaves, sticks, stones and the solid rock surfaces forming the beds of watercourses particularly where there are cascades and turbulent foamy water; although swift broken water seems to be preferred the larvae are also found in slow streams. Frequently larvae and pupae of hargreavesi occur in almost pure masses of the one form in such numbers as to blacken the surfaces of rock to which they are attached. In small placid streams larvae may be found with those of unicornutum, and in swift rocky streams in company with vorax and colas-belcouri. In the rapids of larger rivers they may occur with damnosum and even aureosimile (as in the Galma River, Zaria, Northern Nigeria). Widely distributed from Sierra Leone to Natal.

\section{Simulium medusaeforme Pomeroy, Type form}

Larvae of the type form appear to be almost identical with form hargreavesi except in the structure of the pupal respiratory histoblast, which has only 5 stout branches with the middle one not forked as in hargreavesi (Text-fig. I9I).

MAterial examined. From Uganda (Gibbins' slide material of ugandae Gibbins, synonym of medusaeforme type form).

LARVAL HABITAT AND RANGE. As in form hargreavesi.

\section{Simulium vorax Pomeroy}

Type form. Larvae closely similar to those of colas-belcouri.

Length. Mature larva, $7 \cdot 75^{-9} \mathrm{~mm}$.

Head. Head capsule strongly and rather evenly pigmented yellowish-brown to dark brown, usually pale only around eye-spots, on eye-brow stripes, and anteriorly on cephalic apotome (Text-fig. 25) ; degree of pigmentation somewhat variable ; pattern of positive type but dark head-spots only very faintly distinguishable from surrounding pigmentation, although a series of small transversely elongate anteromedian spots is usually evident (according to Gibbins (I939) the front without pigmented areas) ; lateral head-spots usually distinct from surrounding infuscation, occasionally head capsule below eye-spots only lightly pigmented and spots then only slightly darkened. Postgenal cleft subcordate in shape, of medium size (Text-fig. $44)$; postgenal bridge with a lightly pigmented longitudinal median area contrasting with dark pigmentation on either side (Text-fig. 44), a little shorter than hypostomium. 
Hypostomium (Text-fig. 64) with usual row of 9 apical teeth, median tooth slightly prominent and other teeth broad and blunt, corner teeth very broad and only as long as or even a little shorter than intermediate teeth which are equal in size ; 4-6 lateral serrations, the serrations very weak, with hindmost serration lying a little anterior to first hypostomial seta; hypostomial setae 7-Io in each row, strongly diverging posteriorly from lateral margin of hypostomium; distance between apex of corner tooth and first hypostomial seta only half of that between corner teeth. Antenna (Text-fig. 85) short, only slightly longer than stem of cephalic fan, distinctly pigmented, first segment short only about $3 \cdot 75^{-4}$ times as long as broad, segment length ratios $3 \cdot 7: 6: 3 \cdot 5$. Mandible of typical form, small posterior serration present and anterior serration narrow and very elongate (Text-fig. I02), comb teeth very large and second comb tooth about equal in size to or even slightly longer than first and third comb teeth, the teeth only slightly shorter than large apical tooth (Text-fig. II3). Maxillary palp about 2.75 times as long as breadth at base. Cephalic fan with 50-60 rays, usually about 54-56 (Gibbins (I939) gives 40-50, but his material of lepidum de Meillon shows at least 50 rays).

Thorax. General colour grey except for milky-white histoblasts and general white area behind pupal respiratory histoblast in mature larvae; cuticle bare. Proleg circlet with about 45-50 rows of 9-I5 hooks, most rows with about I2 hooks ; lateral plate strongly pigmented yellowish-brown, with about I4 processes, the processes strong and not subdivided into smaller secondary processes in specimens seen. Pupal respiratory histoblast with 5 stout wrinkled primary branches (Text-fig. I92) and several thin secondary filaments not visible externally.

Abdomen. Gradually expanding posteriorly in lateral view to the widest, rather bulbous, point and then abruptly contracting to posterior circlet (Text-fig. Io) ; general colour pale to dark grey, milky-white ventro-apically, ventral nerve-cord grey. Ventral papillae absent. Cuticle dorsally on posterior segments with numerous scattered simple setae (Text-fig. I5I). Some specimens with a row of small flattened scale-like accessory sclerotizations laterally on last abdominal segment in front of posterior circlet, the sclerotizations sometimes pale but in other larvae distinctly darkened. Rectal scales present, very numerous. Rectal gills with very variable number of secondary lobules, I3-I8 very long narrow lobules in each lobe in Nigerian material seen, but only 6-7 lobules per lobe in Uganda material (Grenier, Hamon \& Rickenbach (I955) give a total of $40-50$ lobules in specimens from Upper Volta). Anal sclerite of usual form, arms very strongly sclerotized, with a median posterior prolongation and usually a triangular unsclerotized hollow between the base of this projection and the body of the sclerite (Text-fig. I68), posterior arm extending to about 4 oth $-45^{\text {th }}$ row of hooks. Posterior circlet with about 220 rows of $28-38$ hooks.

Material eXamined. From Northern Nigeria and Uganda (Gibbins' slide material described as lepidum de Meillon by Gibbins (I939)).

LARVAL HABITAT AND RANGE. Larvae of vorax occur in very swift, turbulent foamy water in rocky streams and small rivers, often in tumbling mountain streams with waterfalls or cascades ; larvae in such situations are usually abundant, attached to rock-surfaces under the water, stones, dead leaves, branches and other detritus lodged in the rapids. The immature stages are often mixed with those of medusae- 


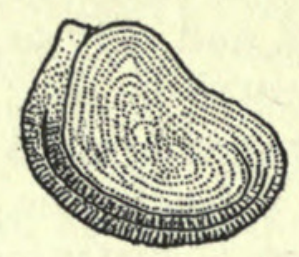

173

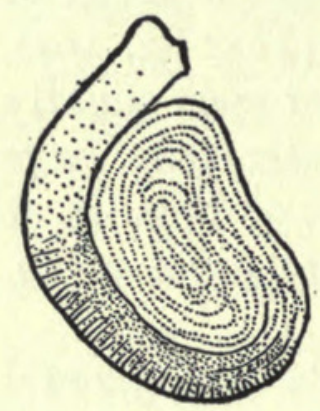

177

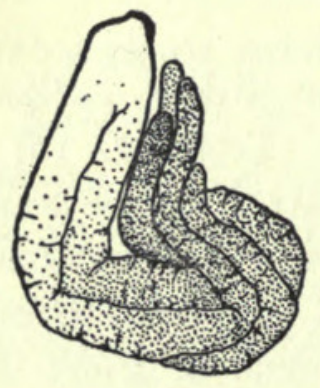

181

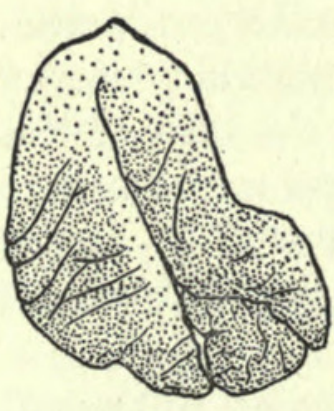

185

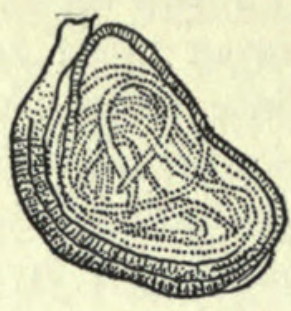

174

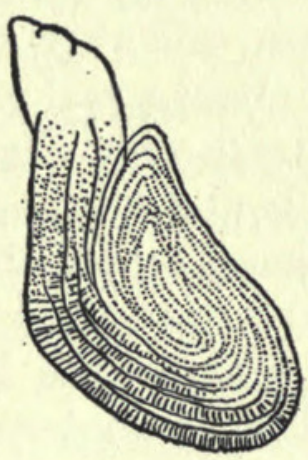

178

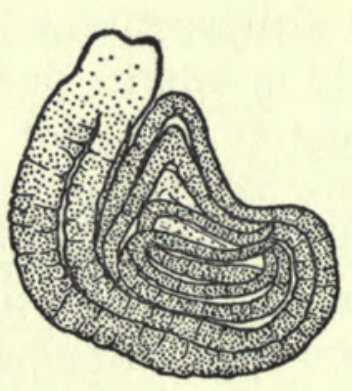

182

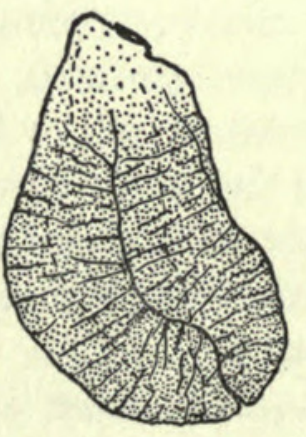

186

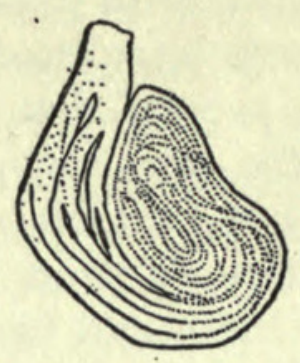

175

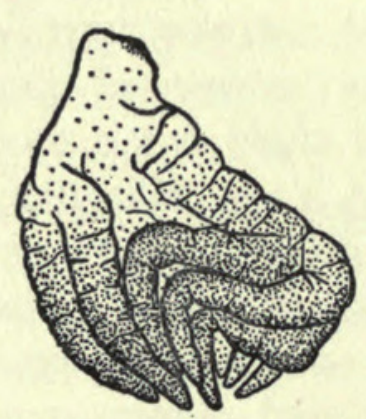

179

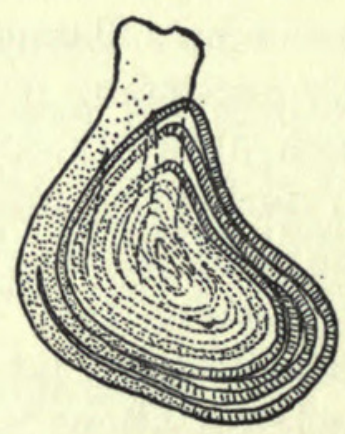

183

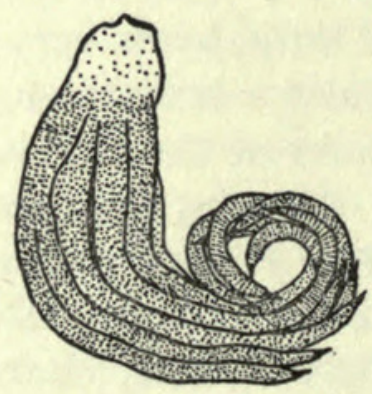

187

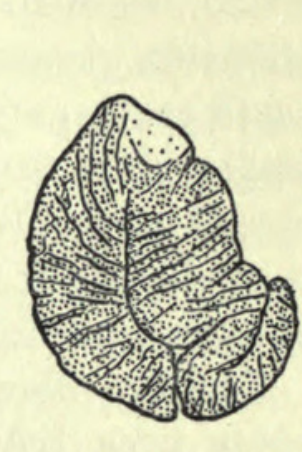

180

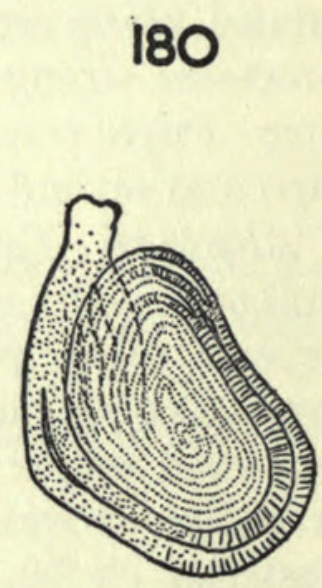

184

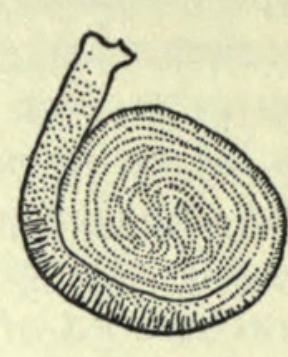

176

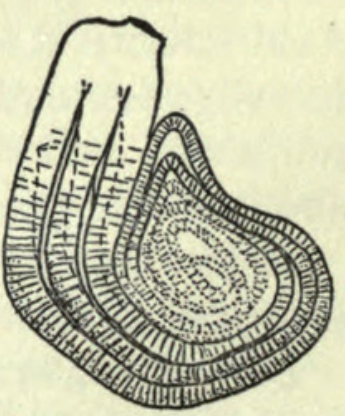

188 
forme hargreavesi and colas-belcouri which also favour places with dashing broken water. Distributed from Upper Volta eastwards to Tanganyika and south to South Africa.

\section{Simulium colas-belcouri Grenier \& Ovazza}

Very similar to vorax and difficult to distinguish reliably except in fully mature larvae with the pupal respiratory histoblast darkened; the postgenal cleft appears to be consistently more pointed apically and less rounded, the median lightly pigmented area on the postgenal bridge is less evident, and the dark head-spots of the cephalic apotome are in most cases more distinct but the pigmentation of the head capsule is variable and not consistently different from vorax. The corner teeth of hypostomium are more pointed and the median tooth shorter than in vorax in specimens seen but this may not be a constant difference.

Length. Mature larva, 8-9.25 $\mathrm{mm}$. (on average slightly larger than vorax).

Head. Head capsule heavily pigmented yellowish-brown to dark brown, pale around eye-spots, on eye-brow stripes and anteriorly and laterally on cephalic apotome (Text-fig. 26) ; positive pattern of usual groups of dark head-spots, the antero-median spots distinct but other head-spots indistinctly marked off from general pigmentation of posterior half of cephalic apotome; lateral head-spots sometimes distinct but occasionally not evident and in some specimens the head capsule is extensively pale below the eye-spots. Postgenal cleft pentagonal in shape (Text-fig. 45) and sharply angulate anteriorly, less heart-shaped than in vorax; postgenal bridge more or less evenly pigmented (without the distinct pale median longitudinal area which is present in vorax), shorter than hypostomium. Hypostommium (Text-fig. 65) with usual row of 9 apical teeth, the teeth forming a straight rather even row with the corner teeth broad and blunt, the intermediate teeth equal in size, and median tooth small and only slightly more prominent than other teeth ; 2-4 very small blunt lateral serrations, the two strongly sclerotized serrations normally lying just posterior to corner tooth sometimes absent so that the ridge between corner tooth and first hypostomial seta is smooth, hindmost serration lying anterior to first hypostomial seta ; hypostomial setae 7-8 in each row, strongly diverging posteriorly from lateral margin of hypostomium; distance between apex of corner tooth and first hypostomial seta only about three-fifths of that between corner teeth. Antenna (Text-fig. 87) short, only slightly longer than stem of cephalic fan, lightly pigmented, first segment about 4 times as long as broad, segment length ratios $7: 12 \cdot 3: 7$. Mandible of typical form, very small posterior serration present and anterior serration narrow and very elongate (Text-fig. I05) as in vorax, comb teeth very large and forming an even row as in vorax (Text-fig.

Figs. I73-I88. Pupal respiratory histoblast ("gill-spot") of mature larva of (I73) S. alcocki type form; (I74) S. johannae; (I75) S. impukane; (I76) S. schoutedeni; (I77) S. momahoni; (I78) S. kenyae; (I79) S. cervicornutum type form ; (180) S. unicornutum type form ; (I8I) S. ruficorne ; (I82) S. aureosimile ; (I83) S. hirsutum type form ; (I84) S. adersi ; (I85) S. griseicolle type form ; (I86) S. griseicolle form tridens ; (187) S. dentulosum type form; (188) S. loutetense, 
II3) (in the mandible figured by Grenier \& Ovazza (I95I) the apex of the elongate anterior serration is evidently broken off, and the serration appears truncate; I have seen specimens like this myself but it is clear that the anterior serration is naturally long and narrow as in most mandibles examined and as in vorax). Maxillary palp narrow, about 3-3.I times as long as breadth at base (Text-fig. I33). Cephalic fan with about 57 rays (Grenier \& Ovazza (I95I) give 45-50).

Thorax. Generally grey with milky-white histoblasts; cuticle bare. Proleg circlet with about 52 rows of 8-I3 hooks ; lateral plate strongly pigmented yellowishbrown, with about I2-I4 processes, the processes strong and not subdivided into weaker secondary processes. Pupal respiratory histoblast with 5 stout wrinkled branches (broader than in vorax) externally visible (Text-fig. I93) and II smaller wrinkled tubular filaments behind (total of 16 digitate filaments in respiratory organ).

Abdomen. Shaped as in vorax (Text-fig. Io) ; general colour grey with traces of darker segmental mottling, milky-white ventrally and ventro-apically, ventral nerve-cord grey. Ventral papillae absent. Cuticle dorsally on posterior segments with a few scattered simple setae (Text-fig. I52). No trace of lateral sclerotizations on last abdominal segment in material seen. Rectal scales present, very numerous. Rectal gills probably very variable, each lobe with 7-8 secondary lobules in material described by Grenier \& Ovazza (I95I), but in Nigerian material seen with gills partially extruded there is a principal lobule and 4 or 5 smaller lobules only to each lobe. Anal sclerite of usual form, strongly sclerotized, with a posterior median sclerotized prolongation as in vorax (Text-fig. I68), posterior arm extending to about 39 th or 4 oth row of hooks. Posterior circlet with about I90-200 rows of about 30-49 hooks.

Material examined. From Northern Nigeria and French Congo.

LARVAL HABITAT AND RANGE. The habitat of colas-belcouri is the same as that of vorax, in swift foamy cascades, and the two species sometimes occur together. Larvae and pupae have been found in masses covering the lips of small waterfalls and in places where the water runs steeply down smooth rock inclines. In addition to vorax the larvae may be found in company with medusaeforme hargreavesi and loutetense. S. colas-belcouri is apparently rare, and is known to me only from French Congo, Sudan, and Northern and Eastern Nigeria.

\section{Simulium bovis de Meillon}

Length. Mature larva, $4.5 \mathrm{~mm}$.

Head. Head capsule clear pale yellowish-white or creamy-white without pattern or pigmentation. Postgenal cleft very large and bulbous (Text-fig. 46), with a trace of a widely obtuse angle apically; postgenal bridge very short, much shorter than hypostomium. Hypostomium (Text-fig. 66) very broad with usual row of 9 apical teeth, the teeth blunt and broad basally and forming an almost even straight row, corner teeth only about as long as intermediate teeth, and median tooth only very slightly more prominent than other teeth; flattened lobe-like area behind each apical tooth unusually distinct ; 3-5 very small, blunt, indistinct lateral serrations, with hindmost serration lying a little anterior to first hypostomial seta ; hypostomial 
setae 4 in each row (occasionally very small fifth seta present), diverging posteriorly from lateral margin of hypostomium ; distance between apex of corner tooth and first hypostomial seta about half of that between corner teeth. Antenna (Text-fig. 88 ) short, only slightly longer than stem of cephalic fan, very lightly pigmented, first segment about $4-4 \cdot 5$ times as long as broad, segment length ratios $6: 6 \cdot 8: 5 \cdot 7$. Maxillary palp short, about 2.7 times as long as breadth at base (Text-fig. I34). Cephalic fan with $34-45$ rays.

Thorax. Generally milky-white, very pale; cuticle bare. Proleg circlet with about 35-40 rows of 8-Io hooks ; lateral plate very lightly pigmented, with about II-I2 processes, the processes strong and not subdivided. Pupal respiratory histoblast as in Text-fig. I89, with 3 primary branches ( 2 arising from a common base) and numerous thin secondary filaments.

Abdomen. Shaped as in Text-fig. 6; general colour very pale, milky-white, without trace of darker segmental mottling in material seen. Ventral papillae absent. Cuticle dorsally on median and posterior segments with numerous flattened spatulate scales (Text-fig. I53), the scales strongly tapering basally. Rectal scales present. Rectal gills with variable number of long secondary lobules, 8-I2 in each lateral lobe and 5-10 in the median lobe in material seen (Freeman \& de Meillon (I953) state that each lobe is without secondary lobules but this is the case, as usual, only in small immature larvae). Anal sclerite of usual form, strongly sclerotized, without the median posterior sclerotization seen in other species of the medusaeformegroup, posterior arm extending to I6th-20th row of hooks. Posterior circlet with about IIO-I25 rows of I9-28 hooks.

Material EXAmined. From Northern Nigeria and Transvaal.

LARVAL HABITAT AND RANGE. Larvae of bovis are found mainly on trailing grasses in swift-flowing broken water, often in rapids, of large rivers. Immature stages only rarely occur in small watercourses, although in large rivers they are found in circumstances where the flow may be very reduced in the dry season. Larvae sometimes occur in company with those of damnosum, cervicornutum, or griseicolle. Widely distributed over the Ethiopian Region from Ghana east to Eritrea and south to Cape Province.

\section{Simulium damnosum Theobald}

Larva distinguishable from other Ethiopian species by the dense covering of dark flattened spatulate scales and the conical dorso-lateral tubercles on the abdominal segments (Text-fig. 9).

Length. Mature larva, $5-6.5 \mathrm{~mm}$.

Head. Head capsule with variable pigmentation, usually strongly pigmented yellow-brown to dark brown, sometimes very dark brown or even blackish-brown; pale areas around eye-spots and on eye-brow stripes, and usually also anteriorly on cephalic apotome; some specimens with head capsule pale and only pigmented on medium part of cephalic apotome and laterally above level of eye-spots ; in addition to general pigmentation head capsule shows indistinct positive pattern comprising antero-lateral and postero-median groups of head-spots (Text-fig. 27), the head-spots darker than surrounding pigmentation, and traces of darker pigmen- 


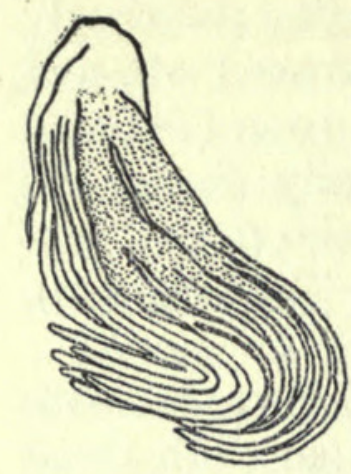

189

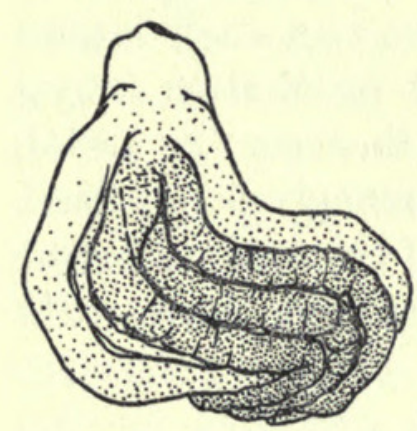

192

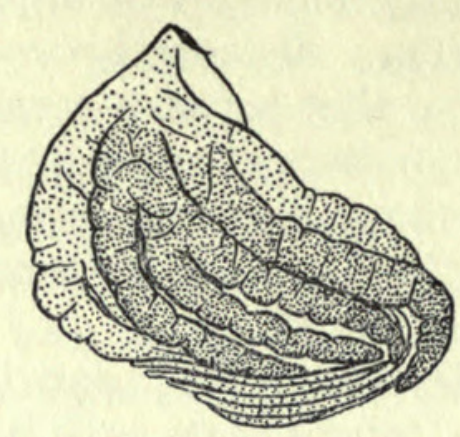

190

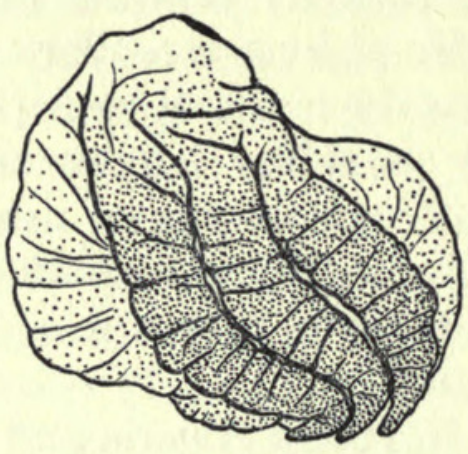

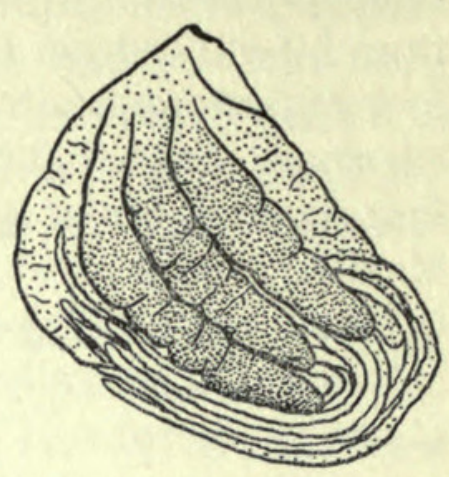

191

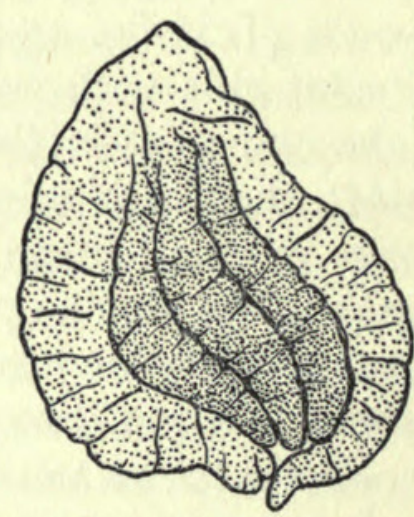

Figs. I89-194. Pupal respiratory histoblast ("gill-spot") of mature larva of (I89)

$S$. bovis; (I90) S. medusaeforme form hargreavesi; (I9I) S. medusaeforme type form;

(192) S. vorax type form; (I93) S. colas-belcouri; (I94) S. damnosum.

tation in area of postero-lateral spots ; antero-median spots absent or very indistinct ; sides of head capsule with indistinct spots (Text-fig. 27). Postgenal cleft very large, rounded cordate (Text-fig. 47), occupying almost the whole ventral aspect of head; postgenal bridge very short, less than half as long as hypostomium. Hypostomium (Text-fig. 67) with usual row of 9 apical teeth, the teeth broad and blunt and forming a slightly concave row, so that the corner teeth are the most prominent, and median tooth usually slightly shorter than corner teeth; middle tooth of intermediate teeth a little larger than inner intermediate tooth, so that the smallest apical teeth are those immediately on either side of median tooth ; 3-4 small lateral serrations, only one (instead of the usual two) strongly sclerotized serration on the ridge running back from corner tooth, with hindmost serration lying slightly anterior to first hypostomial seta ; hypostomial setae $4-6$ (usually 5 ) in each row, diverging posteriorly from lateral margin of hypostomium; distance between apex of corner tooth and 
first hypostomial seta only a little over half of that between corner teeth. Antenna (Text-fig. 89) short and just about equal in length to stem of cephalic fan, pigmented yellowish-brown, pigmentation strong on first segment, first segment about 3.5-4 times as long as broad, segment length ratios $4 \cdot 4: 7: 4 \cdot 6$. Mandible of typical form, posterior serration present, small (Text-fig. III), anterior serration slightly elongate but not produced as in vorax, comb teeth very large and strong and first 3 comb teeth equal in size forming an even row (figured by Grenier \& Ovazza (I95I)). Maxillary palp rather short and stout, about 2.5 times as long as breadth at base (Text-fig. I35). Cephalic fan with very variable number of rays, 37-46 in West African material seen, but only I9-24 in some material from Uganda (as recorded by Gibbins (I933)). Freeman \& de Meillon (I953) give " about 20 " and suggest that the number is fewer than in most species, but this is not the case in larvae from most areas. Grenier \& Ovazza (I95I) give about 40 for material from French Congo, and it appears that this is about the usual number.

Thorax. Pale yellowish, grey or sometimes greenish-grey, histoblasts usual milky-white except for dark respiratory organ of mature larva; cuticle densely covered dorsally and laterally with dark setae, the setae flattened and elongate, slightly scale-like (Text-fig. I54); cuticle of proleg laterally and ventrally with numerous setae, these setae generally narrower and more spine-like than general body setae. Proleg circlet with about 30-35 rows of 7-II hooks; lateral plate only very lightly pigmented, with about 9-Io processes, the processes strong and without secondary processes. Pupal respiratory histoblast with 5 large wrinkled branches externally visible (Text-fig. I94), and 6 other branches arising in pairs behind these (the figure of the " gill-spot " given by Gibbins (I933) is not accurate since it shows 4 filaments lying between the basal arms).

Abdomen. Shaped usually as in Text-fig. 9, with remarkable conical dorso-lateral paired tubercles on first 5 segments (and traces of a pair of similar tubercles on metathoracic segment making a series of 6 pairs), the tubercles often very strongly developed as sharp pointed cones but sometimes reduced and in some larvae more or less absent ; tubercles apparently absent in first stage larva, but present in second instar and subsequent stages. General colour pale yellowish, yellow-grey, pale grey or greenish-grey with traces of darker segmental mottling, but colour blackish to naked eye because of the dense covering of dark setae, especially on dorsal tubercles. Ventral papillae absent. Cuticle densely covered with flattened scale-like setae (Text-fig. I54), the setae variable in size and slightly variable in form, dark and strongly sclerotized; distribution of scales fairly even but few ventrally on intermediate abdominal segments and strongly concentrated dorsally on tubercles, the concentration of setae giving the tubercles a darkened appearance; setae abundant ventrally on terminal segments so that ventro-apical region of abdomen does not appear much paler than rest of abdomen as in most species. Rectal scales absent. Rectal gills with numerous but a variable number of long narrow secondary lobules in each lobe, from 9-I5 lobules seen in the median lobe and Io-I7 in lateral lobe ; total number of lobules in whole gill varying from about 29-49; median lobe often with fewer lobules than in each lateral lobe, but some specimens with the same number of lobules in each lobe, or median lobe occasionally with more lobules 
than the other lobes (gills first described by Roubaud (I907)). Anal sclerite (Text-fig. I69) of usual form, strongly sclerotized, anterior arms rather short, with a short posterior median lightly sclerotized prolongation, posterior arm reaching to about 26th-29th row of hooks. Posterior circlet with about I30-I55 rows of $18-27$ hooks, most rows with about 2I-24 hooks (Gibbins (I933) gives up to 30 hooks but I have not seen more than 27 per row in the mature larvae I have examined).

Material examined. From Northern Nigeria, Southern Cameroons, Ghana, Sierra Leone, Sudan, Uganda, Tanganyika, and Nyasaland. There appears to be little geographical variation in the larvae, although in some larvae seen from Tanganyika, Uganda and Nyasaland there are a number of much larger scales scattered among the usual small scales, whereas in West African and Sudanese larvae the scales are of more uniform small size. In some larvae from Tanganyika a small number of enormously enlarged scales are present postero-dorsally on the abdomen.

LARVAL HABITAT AND RANGE. Larvae are found on trailing grasses, sticks, palm-fronds, corn-stalks, fish-traps, and other objects dipping into or lodged in swiftly-flowing broken water, mainly in the rapids of larger rivers; larvae also occur occasionally on stones, the solid rock-bed of rivers, or even on hard mud, sometimes in placidly-flowing unbroken water. The most favoured stiuation, however, is normally on grass-stems and leaf-blades (principally on living grasses) which trail in foaming turbulent water or in places where the water flows very rapidly down rock-inclines but may not be broken. There is usually little or no breeding actually in waterfalls, but characteristic breeding places are in the rapids above and below falls. In small streams there is usually little or no breeding of damnosum, although occasional larvae and pupae may be found in suitable parts of the smaller tributaries during the wet-season in the savannah areas and throughout the year in forested areas. Larvae are frequently found in very large masses (appearing black because of the dense covering of setae) and may be in company with other fast-water species, including vorax, medusaeforme hargreavesi and bovis; in very large rivers they sometimes occur with adersi and griseicolle, and in slow water of smaller rivers with unicornutum. I have also collected damnosum occasionally with cervicornutum and aureosimile. Common and widely distributed throughout the Ethiopian Region, even into the very dry territories such as Sudan, Eritrea and South-West Africa.

\section{ACKNOWLEDGMENTS}

I am most grateful to Dr. Paul Freeman and Dr. Alan Stone for their helpful advice, to Dr. D. J. Lewis for collecting larval material, and to Mr. D. Macfarlane for the use of a phase-contrast microscope. I would also like to thank Mrs. M. E. Crosskey for making many larval collections in Nigeria.

\section{REFERENCES}

Anthon, H. (1943). Zum Kopfbau der primitivsten bisher bekannten Dipterenlarve: Olbiogaster sp. (Rhyphidae). Ein Beitrag zur Phylogenie der nematoceren Dipteren. Ent. Medd. 23 : 303-320.

Austen, E. E. (1909). Illustrations of African blood-sucking flies, other than mosquitoes and tsetse-flies. London, Brit. Mus. (Nat. Hist.). 
Chiswell, J. R. (1955). On the last instar larva of Tipula livida van der Wulp (Diptera, Tipulidae) with notes on the fronto-clypeal region of larval Tipulinae and caterpillars. Proc. R. ent. Soc. Lond. (A), $30: 127-136$.

Cook, E. F. (1944a). The morphology of the larval heads of certain Culicidae (Diptera). Microentomology, $9: 38-68$.

$(\mathrm{r} 944 \mathrm{~b})$. On the morphology of the larval head of a species of Chironomus (Diptera : Chironomidae). Ibid. 9:69-77.

Crosskey, R. W. (I956). The distribution of Simulium damnosum Theobald in Northern Nigeria. Trans. R. Soc. trop. Med. Hyg. 50:379-392.

(I957). The Simuliidae (Diptera) of Northern Nigeria. Bull. ent. Res. $48: 59-74$.

Dalmat, H. T. (I955). The black flies (Diptera, Simuliidae) of Guatemala and their role as vectors of onchocerciasis. Smithson. misc. Coll. 125 : No. I, 425 pp.

Dorier, A. (1945). Sur la capsule céphalique des larves de simulies (Dipt. Némat.). Bull. Soc. ent. France, 50 : ro8-109.

Edwards, F. W. (I920). On the British species of Simulium. II. The early stages. Bull. ent. Res. $11: 2$ I I-246.

(1934). The Simuliidae (Diptera) of Java and Sumatra. Arch. f. Hydrobiol. 13, Suppl. "Tropische Binnengewasser" 5 : 92-138.

Freeman, P. (1954). A new African species of Simulium (Diptera, Simuliidae) in phoretic association with mayfly nymphs. Ann. Mag. nat. Hist. 12 (7) : II3-II5.

\& DE Meillon, B. (1953). Simuliidae of the Ethiopian Region. London, Brit. Mus. (Nat. Hist.).

Grbbins, E. G. (1933). Studies on Ethiopian Simuliidae. Simulium damnosum, Theo. Trans. R. ent. Soc. Lond. $81: 37-51$.

(1934). Further studies on Ethiopian Simuliidae. Ibid. 82:51-97.

(1935). Simulium griseicolle Becker, from the Sudan. Ann.trop. Med. Parasit. 29 : 177-184.

(1936). Uganda Simuliidae. Trans. R. ent. Soc. Lond. 85: 21 7-242.

(I937). Simuliidae of the Buganda, Eastern and Western Provinces of Uganda. Bull. ent. Res. 28 : 289-309.

(1939). Simuliidae in Ruwenzori Expedition 1934-35, 1: II-27. London, Brit. Mus. (Nat. Hist.).

Gouin, F. J. (I959). Morphology of the larval head of some Chironomidae (Diptera, Nematocera). Smithson. misc. Coll. $137:$ I75-201.

Grenier, P. (I949). Contribution à l'étude biologique des Simuliides de France. Physiol. Comp. Oec. 1 : 165-330.

(1953). Simuliidae de France et d'Afrique du Nord. Encycl. Ent. 29 : I-I70.

\& Doucet, J. (I949a). Simulies de Madagascar. Mém. de l'Inst. Sci. Madagascar (A),

$3: 301-323$.

(1949b). Simulies de Madagascar (II). Bull. Soc. Path. exot. $42: 587-597$.

\& GRJÉbINE, A. (1958). Remarques morphologiques et biologiques concernant les

" mouka-fouhi" (Simulium neireti Roubaud, S. imerinae Roubaud) de Madagascar et

S. ambositrae nom. nov. Ibid. 51 : 98I-99r.

\& Mouchet, J. (I959). Note complémentaire sur la morphologie et la biologie de S. ovazzae Grenier \& Mouchet, I959 (Diptera, Simuliidae), espèce associée au crabe Potamonautes chaperi M.-Edw., dans l'Ouest Africain. Ibid., 52:373-385.

\& Ovazza, M. (I95I). Simulies du Moyen-Congo. Ibid. 44: 222-234.

- (1956). Contribution à l'étude des Diptères vulnérants de l'empire d'Éthiopie.

II. Simuliidae. Simulies et Onchocercose. Ibid. $49:$ r82-196.

\& Rageau, J. (I949). Simulies du Cameroun. Ibid., 42: 5I3-529.

- Hamon, J. \& Rickenbach, A. (1955). Simuliidae d'Afrique occidentale française

(Haute Volta, Dahomey, Soudan Français, Senégal, Cote d'Ivoire). Ibid. 48 : 885-891.

Harrison Church, R. J. (I957). West Africa. London, Longmans Green \& Co., 547 pp.

Headlee, T. J. (I906). Blood gills of Simulium pictipes. Amer. Nat. 40:875-885.

Hennig, W. (I950). Die lavenformen der Dipteren. Pt. 2. Berlin, $45^{8}$ pp. 
Hinton, H. E. (1958). The pupa of the fly Simulium feeds and spins its own cocoon. Ent. mon. Mag. $94:$ I4-I6.

- (1959). The function of chromatocytes in the Simuliidae, with notes on their behaviour at the pupal-adult moult. Quart. J. micr. Sci. $100: 65-7$ I.

Hora, Sunder Lal. (I927). The mechanism of the so-called " posterior sucker " of a Simulium larva. Nature, Lond. 119: 599-6oo.

Imms, A. D. (1957). A Geneval Textbook of Entomology. 9th Edn. London, Methuen \& Co. Ltd.

Johannsen, O. A. (I903). Simuliidae in, Aquatic Insects in New York State. Bull. N.Y. St. Mus. $68: 336-388$.

- (1934). Simuliidae in, Aquatic Diptera. Part I. Nemocera exclusive of Chironomidae and Ceratopogonidae. Cornell Univ. Agric. Exp. Sta. Mem. $164: 56-64$.

KInG, H. H. (I909). Report on Economic Entomology. Third. Rept. Wellcome Res. Lab. Khartoum, pp. 20I-248.

Lawson, J. W. H. (I95I). The anatomy and morphology of the early stages of Culicoides nubeculosus Meigen (Diptera: Ceratopogonidae $=$ Heleidae). Trans. $R$. ent. Soc. Lond. 102 : 5 I I -570.

Lewis, D. J. (1960). The Simulium neavei complex (Diptera, Simuliidae) at Amani in Tanganyika. Proc. R. ent. Soc. Lond., (B), 29: 7-Io.

Mackerras, M. J. \& Mackerras, I. M. (I948). Simuliidae (Diptera) from Queensland. Aust. J. Sci. Res. (B), $1: 23 \mathrm{I}-270$.

Mackerras, I. M. \& Mackerras, M. J. (I949). Revisional notes on Australasian Simuliidae (Diptera). Proc. Linn. Soc. N.S.W. $73: 372-405$.

Mackerras, M. J. \& Mackerras, I. M. (I950). Notes on Australasian Simuliidae (Diptera). II. Ibid. $75: \mathrm{I} 67-187$.

Mackerras, I. M. \& Mackerras, M. J. (I952). Notes on Australasian Simuliidae (Diptera). III. Ibid. 77 : I04-II3.

McMahon, J. P. (1957). Notes on the Simulium neavei group of Simuliidae with particular reference to S. nyasalandicum and S. woodi. Bull. ent. Res. $48: 607-6$ I 7 .

PURI, I. M. (1925). On the life-history and structure of the early stages of Simuliidae (Diptera, Nematocera). Parts I and II. Parasitology, $17: 295-369$.

Roubaud, E. (1907). Branchies rectales chez les larves de Simulium damnosum Theob. Adaptation d'une larve de Simulie à la vie dans les ruisseaux de l'Afrique équatorial. C.R. Acad. Sci. Paris, $144:$ 7I6-7I7.

— \& Grenier, P. (I943). Simulies de l'Ouest Africain (Afrique équatoriale et occidentale françaises). Bull. Soc. Path. exot. $36: 28$ I-3Ir.

Rubtzov, I. A. (I95I). Contribution to the biology and ecology of midges (Simuliidae) of Central Asia. Parasitol. Sborn. zool. Inst. Akad. Nauk. SSSR, Leningrad, 13 : 328-342. [In Russian.]

(1956). Simuliidae in, Fauna of U.S.S.R., Diptera 6, No. 6. Zool. Inst. Akad. Nauk. SSSR, Moscow (N.s.), 64 : I-86o. [In Russian.]

Smart, J. (1944). The British Simuliidae with keys to the species in the adult, pupal and larval stages. Freshw. Biol. Ass. Brit. Empire Sci. Publ. No. 9.

SNodgrass, R. E. (1947). The insect cranium and the "epicranial suture". Smithson. misc. Coll. 107, No. 7, 52 pp.

- (1959). The anatomical life of the mosquito. Ibid. 139, No. 8, 87 pp.

Sommerman, K. M. (I953). Identification of Alaskan black fly larvae (Diptera, Simuliidae). Proc. ent. Soc. Wash. $55: 25^{8-273 .}$

Stone, A. \& Jamnback, H. A. (I955). The black flies of New York State (Diptera : Simuliidae). Bull. N.Y. St. Mus. 349, I44 pp.

TerterJan, A. E. (I957). The determination of the number of instars in the larvae of blackflies (Diptera, Simuliidae). Ent. Obozr., Moscow, 36: 860-868. [In Russian.]

Tonnoir, A. L. (1925). Australasian Simuliidae. Bull. ent. Res. 15:213-255.

Vargas, L., Palacios, A. M. \& Najera, A. D. (I946). Simulidos de Mexico. Rev. Inst. Salubr. y enf. trop. 7 : 100-192.

Wanson, M. (1947). Simulies congolais élévees dans la région de Bonningville et description d'espèces nouvelles. Rev. Zool. Bot. Afr. $40:$ I95-218. 


\section{$2 \mathrm{BHL}$ Biodiversity Heritage Library}

Crosskey, Roger Ward. 1960. "A taxonomic study of the larvae of West African Simuliidae (Diptera: Nematocera) with comments on the morphology of the larval black-fly head." Bulletin of the British Museum (Natural History) Entomology 10, 1-74. https://doi.org/10.5962/bhl.part.16255.

View This Item Online: https://www.biodiversitylibrary.org/item/19383

DOI: https://doi.org/10.5962/bhl.part.16255

Permalink: https://www.biodiversitylibrary.org/partpdf/16255

\section{Holding Institution}

Natural History Museum Library, London

\section{Sponsored by}

Natural History Museum Library, London

\section{Copyright \& Reuse}

Copyright Status: In copyright. Digitized with the permission of the rights holder.

Rights Holder: The Trustees of the Natural History Museum, London

License: http://creativecommons.org/licenses/by-nc-sa/4.0/

Rights: http://biodiversitylibrary.org/permissions

This document was created from content at the Biodiversity Heritage Library, the world's largest open access digital library for biodiversity literature and archives. Visit BHL at https://www.biodiversitylibrary.org. 